\title{
TRAVEL SPEED EFFECTS OF 70 MPH SPEED LIMIT CHANGE
}

\author{
Hiba Nassereddine
}

\begin{abstract}
A thesis submitted in partial fulfillment of the requirements for the degree of:

Master of Science
\end{abstract}

From the University of Wisconsin Madison Graduate School

Department of Civil and Environmental Engineering

December 2017 


\section{EXECUTIVE SUMMARY}

Posted speed limit (PSL) on most of the Interstate highway system in Wisconsin was increased from 65 to $70 \mathrm{mph}$ during the week of June 16, 2015. Segments in the Milwaukee area as well as I-535 in Superior were excluded from this increase.

This research aimed at evaluating the impact of the change in speed on Wisconsin's Interstate system after the maximum PSL increased. The first objective was to determine the impacts of the increased maximum PSL on operating speed across the state on multiple segments identified in all counties with an Interstate highway. The second objective was to assess the safety effect of increasing the maximum PSL.

This research's primary data source was the National Performance Management Research Data Set (NPMRDS), which is provided by the Federal Highway Administration (FHWA) for use in performance monitoring and management, and the data are provided by HERE. NPMRDS provides speed data on several hundred Interstate segments in Wisconsin every five minutes. For validation, the NPMRDS speeds were compared with a second data source: Wisconsin TransPortal data. WisTransPortal Volume, Speed, and Occupancy (VSPOC) Application provides online tools to retrieve and analyze traffic detector data throughout the state of Wisconsin. General Detector Data Retrieval module was used to extract data corresponding to the investigated areas. For this research, the analysis timeframe was 2014 to 2016. One-week time periods in every month from March 2014 to May 2015 were collected for the before period. One-week time periods in every month from July 2015 to June 2016 were collected for the before period

Previous studies found that an increase in posted speed limit is associated with an increase in average operating speeds. This increase in operating speed is usually less than the posted speed limit increase. Based on previous research, the $5 \mathrm{mph}$ increase in Wisconsin was expected to increase the average operating speeds approximately 1-3 mph. The findings of this research were consistent with the literature; the mean operating speed statewide increased between 0.8 and $2.8 \mathrm{mph}$ for all vehicles in the research sample for segments with PSL change while that of segments without a PSL change (Milwaukee area) increased on average by 0.8 mph. A standard deviation of 5.25 and $5.82 \mathrm{mph}$ was found for segments with and without PSL change respectively.

Upon analyzing the data for this research, two external effects were immediately evident, the first of which was changes in operating speed that occurred in cyclic seasonal pattern. This effect was controlled for in the analysis by comparing isochronal 11-month periods before and after the change in posted speed limit. The second external effect was the effect of work zones that existed in several segments. The presence of work zones caused operating speeds to rise or fall in ways not related to the change in posted speed limit. These work zones were controlled for by identifying segments with higher magnitude shifts in speed that were not related to posted speed limit change during the timeframe of the analysis. 
Safety impact of raising the maximum PSL was investigated with a before and after study using crash frequency instead of crash rates due to missing traffic volumes for most segments. Crash data were collected from 2005 to 2017, covering 10.5 years (Jan 2005 - May 2015) prior to increasing the maximum PSL and 2.25 years (July 2015 - Sep 2017) after the increase of the maximum PSL. According to the analysis, approximately 57\% of the segments did not show any difference in the average number of monthly crashes between the before and after period, which implies that increasing the PSL did not negatively impact safety. As for the remaining $43 \%$ of segments, the analysis showed a statistically significant difference between both before and after periods. The before and after analysis does not establish a cause and effect relationship between an increase in the PSL and the increase in the average number of crashes. 


\section{Acknowledgments}

I would like to thank everyone who supported me throughout this research. Specifically, I would like to thank my advisor Dr. David Noyce for his invaluable support and advice throughout this project. I would like to thank Dr. David Noyce, Dr. Sue Ahn, and Dr. Steven Parker for being members of my thesis defense committee. I would also like to acknowledge the assistance and supervision of Peter Rafferty. A special thank you to my beloved family back home whose love and support are my motivation and the reason I stand here today. I must express my profound gratitude to my fiancé-to-be for supporting me spiritually throughout writing this thesis. Finally, a shout out to my sister Hala for providing me with unfailing support and continuous encouragement throughout my years of study. 


\section{TABLE OF CONTENT}

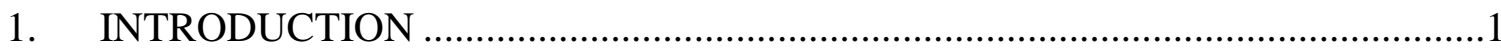

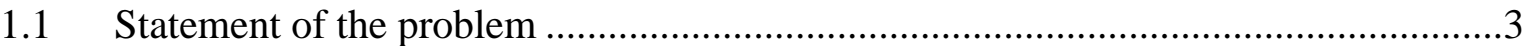

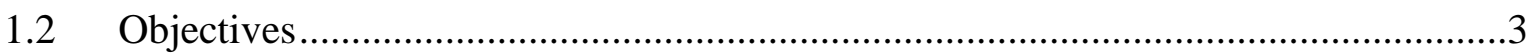

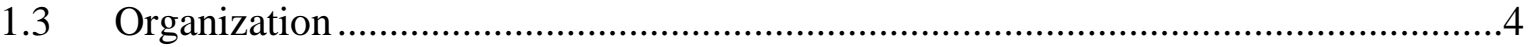

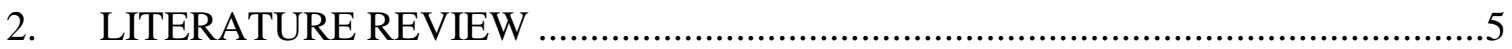

2.1 Historical Overview on the Changes in Speed Limit................................................5

2.2 Effect of Speed Limit Changes on Operating speed ...............................................6

2.3 Effect of Speed Limit Changes on Traffic Safety .......................................................

2.4 Findings from Other Midwest States ................................................................12

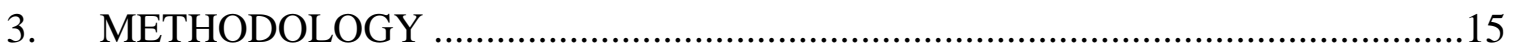

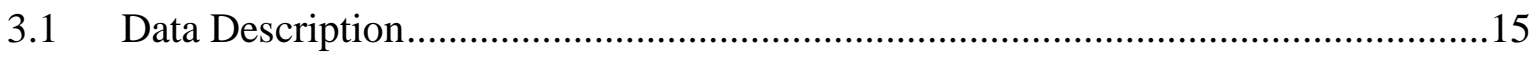

3.1.1 National Performance Management Research Data Set (NPMRDS) ................16

3.1.2 Volume, Speed, and Occupancy (VSPOC) Application Data ...........................20

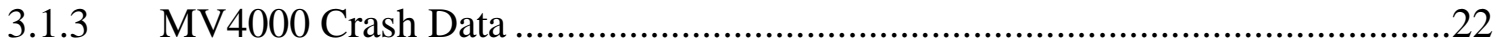

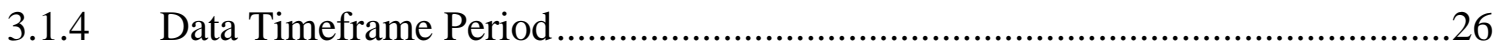

$3.2 \quad$ Statistical Tests..............................................................................................28

3.2.1 Statistical Approaches to Measuring Error ....................................................28

3.2.2 NPMRDS Speed Analysis ……………………...........................................30

3.2.3 Non-Parametric Test: Mann-Whitney U Test....................................................32

3.2.4 Statistical Hypothesis Test: F-test...................................................................

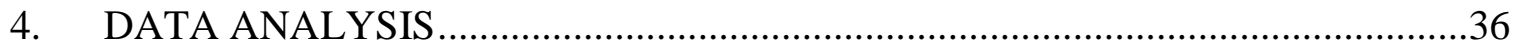

4.1 Impact of Posted Speed Limit Increase on Traveling Speed ……………................36 


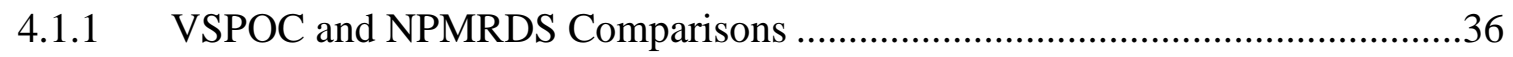

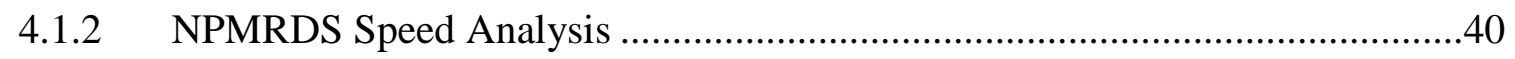

4.1.3 Non-Parametric Test: Mann-Whitney U Test (MWW test) ...........................45

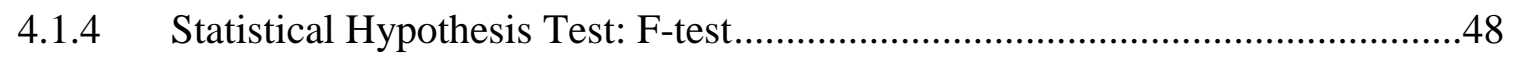

4.2 Impact of Posted Speed Limit Increase on Safety..........................................49

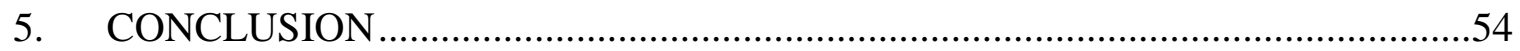

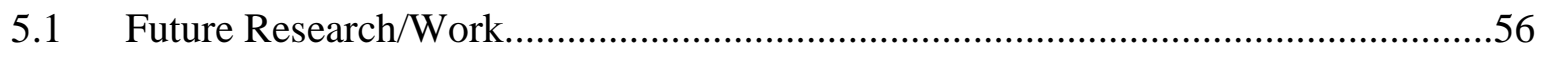

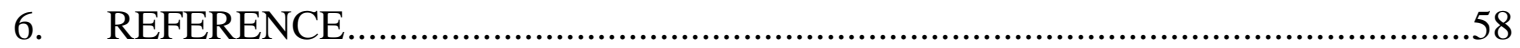

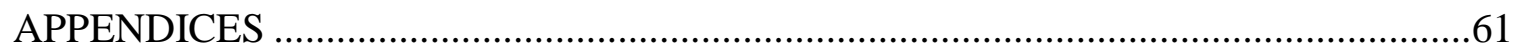

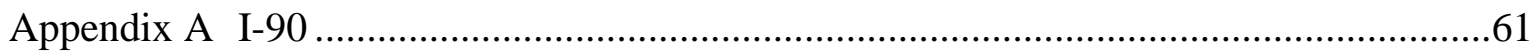

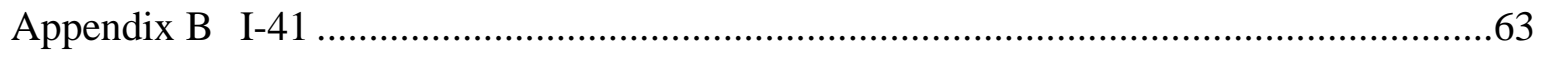

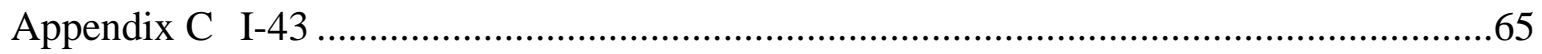

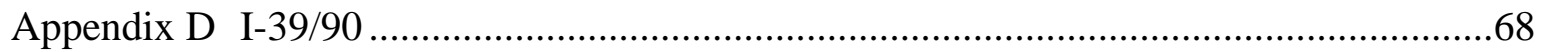

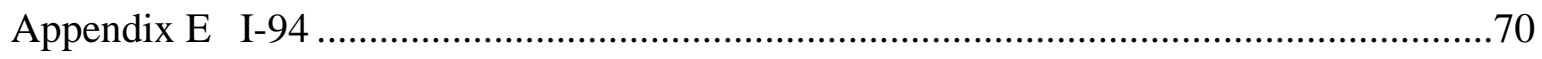

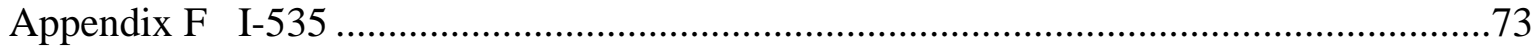

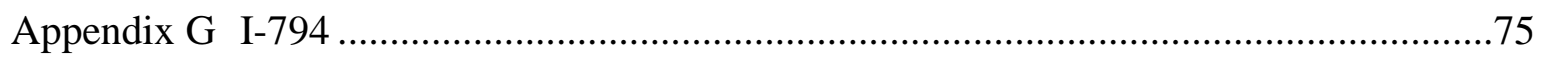

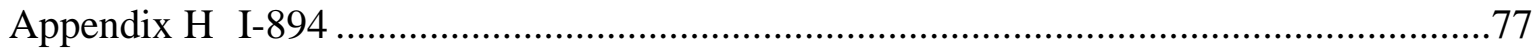




\section{LIST OF FIGURES}

Figure 1: Maximum Posted Speed Limit by State [11] .........................................................6

Figure 2: Map of Interstates (shown as green) with Speed Limit Increase .............................16

Figure 3: Wisconsin Interstate TMCs with Increased PSL from 65 to $70 \mathrm{mph}$.......................20

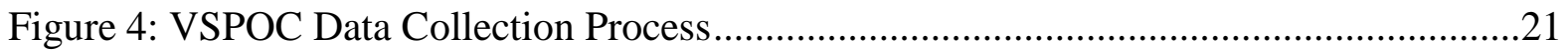

Figure 5: Example of VSPOC Detectors for the Corresponding TMC ………………..........22

Figure 6: Procedure to Retrieve Crash data ……………....................................................23

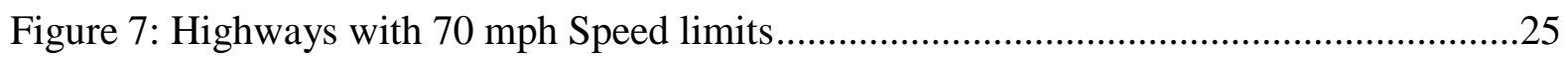

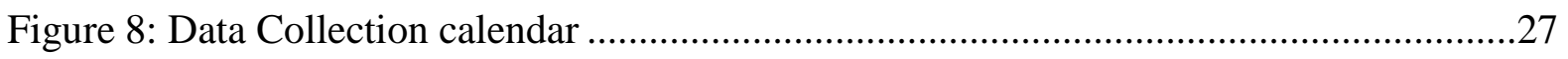

Figure 9: Good Match Between VSPOC and NPMRDS Speed ..............................................37

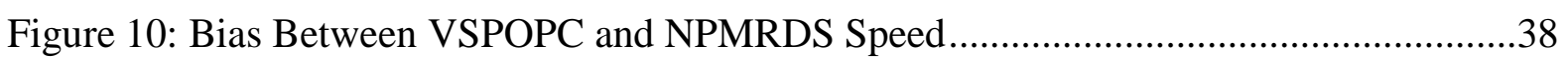

Figure 11: Moderate Match Between VSPOPC and NPMRDS Speed .....................................39

Figure 12: Before/After Speed Plot of All Segments .........................................................

Figure 13: Typical Example of Metrics for a Segment.........................................................42

Figure 14: Example of Seasonal Variation in Passenger Vehicle Speeds ................................43

Figure 15: Example Segment with Work Zone Effects ..........................................................44

Figure 16: Maximum Speed Shift for Each TMC ……….....................................................45

Figure 17: P-value (of Mann-Whitney U Test) for Each TMC's Speed Change.....................46

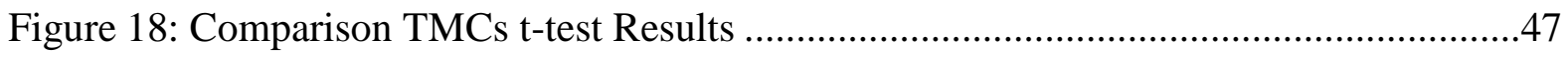

Figure 19: P-value (of t-test) for each TMC's Speed Change .................................................48

Figure 20: P-value (of F-test) for Each TMC's Speed Change ...............................................49

Figure 21: Monthly average Crashes for the Before and After Speed Limit Increase periods51 
Figure 22: Monthly average Crashes Difference Between Before and After Speed Limit

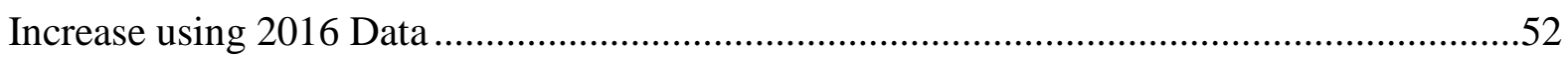

Figure 23: Monthly average Crashes Difference Between Before and After Speed Limit

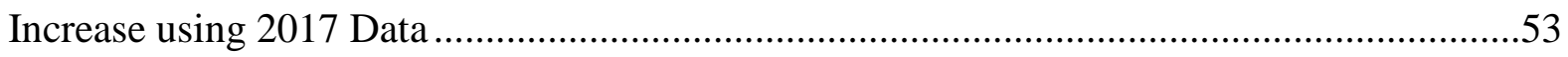

\section{LIST OF TABLES}

Table 1: Minimum List of Locations Arranged for Evaluation .........................................15

Table 2: TMC Segment Tallies by Interstate and County ..............................................18

Table 3: Segments of interest by Interstate and County ..............................................25

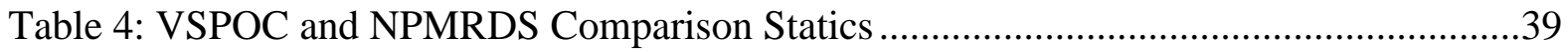

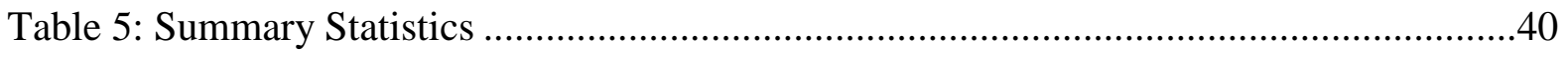

Table 6: Summary Statistics for Crash Data.................................................................50 


\section{INTRODUCTION}

An important purpose of speed limits is to improve traffic safety by reducing the risks imposed by the speed choices of drivers. This purpose is achieved in two ways. On one hand, by setting an upper bound, speed limits create a controlling threshold and hence aim to reduce both the probability and severity of crashes. On the other hand, speed limits reduce dispersion in speeds among drivers and thereby reducing potential vehicular conflicts. In addition to this primary reason, speed limits also help improve the efficiency of traffic flow by achieving an orderly flow of traffic [1].

Despite these benefits, establishing an arbitrary value for the speed limit may have a negative impact on traffic flow and safety. Hence, implementing a speed limit is effective only if set within an appropriate range. This range varies from one road to another and is determined based on several factors such as roadway functionality, roadway characteristics, sight distance, and others. As this value shifts from this range, the effectiveness declines. Therefore, in establishing speed limits for a roadway or highway segment, decision makers try to set a reasonable balance between safety (crash risks) and mobility (travel time) [2] [3].Various

aspects of speed are used depending on the application. The following terms are commonly used in speed literature and discussions:

- Design speed: a selected speed used to determine the various geometric design features of a roadway.

- Operating speed: the speed at which vehicles are observed operating during free flow conditions. Free flow speeds are those observed from vehicles whose operations are unconstrained by traffic control devices (e.g., traffic signals) or by other vehicles in the 
traffic stream. The 85th percentile of the distribution of observed speeds is the most frequently used measure of the operating speed.

- Posted speed: the maximum legal speed a vehicle can operate at for a particular location as displayed on regulatory signs.

- 85th percentile speed: the speed at or below which 85 percent of vehicles travel. [4]

When designing a new road, the characteristics of the facility guide the choice of a design speed. Speed limits are often determined by the driver operating speeds $\left(85^{\text {th }}\right.$ percentile speed - the speed at or below which $85 \%$ of all vehicles are observed to travel under freeflowing conditions past a monitored point) which in turn affect the timing of traffic signals. Achieving consistency between design speeds, actual driving speeds, and posted speed limits is also taken into consideration [1].

In 1995, the US Congress decided that setting speed limits on the roads in the United States is no longer the responsibility of the federal government. States were allowed to determine and establish their own maximum speed limits. Many states raised their speed limits at that time [3] [5]. Wisconsin State Legislature passed the 2015 Wisconsin Assembly Bill 27, effective May 21, 2015. This bill increased the maximum allowable highway speed limit from 65 mile per hour (mph) to $70 \mathrm{mph}$ on any freeway, including those that are part of the national system of interstate and defense highways and on any section of an expressway that gives priority to through traffic by using interchanges only [6] [7]. As a result, the Wisconsin Department of Transportation (WisDOT) implemented a $70 \mathrm{mph}$ speed limit on most interstate segments. This speed increase affected approximately 726 miles of interstate the week of June 16, 2015 with the exclusion of segments in the Milwaukee area. 


\subsection{Statement of the problem}

Increasing the posted maximum speed limit intensified the debate on the tradeoff between safety and mobility. This debate started in 1974 with the passage of the Emergency Highway Energy Conservation Act, which prohibited speed limits higher than $55 \mathrm{mph}$ on interstate highways in the US [8]. Following policy changes, various studies were conducted to assess the impacts of increasing the maximum speed limit on traffic crashes and fatalities [9].

While several studies showed that increases in the maximum posted speed limit negatively influence traffic safety by increasing the number and/or rate of fatalities/injuries, numerous studies indicated that higher speed limits had no effect on safety [9]. Other studies even suggested that increasing speed limits reduced traffic fatalities and improved safety [9]. Despite the various studies on the effects of speed limit changes, their impacts on traffic safety are not yet fully comprehended [10]. An interest from the state departments of transportation, media, and public remains needed in order to unfold the impacts of increasing the maximum PSL on traffic safety.

\subsection{Objectives}

The primary objective of this research is to evaluate the operations and safety on the Wisconsin Interstate Highway system after increasing the posted speed limit (PSL) from 65 to $70 \mathrm{mph}$ on 726 lane miles of roadway. The key objectives of this research are as follows: 
- Determine the impact of the increased PSL on operating speeds across the state on each identified segment.

- Provide an overview on the overall change in speeds from all segments.

- Determine the impact of raising the maximum posted speed limits on traffic safety.

\subsection{Organization}

This research is organized into five chapters, references and an appendix. The current Chapter (Chapter 1) comprises of an introduction to the research along with the hypotheses and objectives of the research. Chapter 2 represents a literature review relevant to this research. Chapter 3 describes the methodology used in the research, as well as the tests used to complete the analysis. Chapter 4 documents the results obtained and provides a detailed analysis of the acquired data. Chapter 5 summarizes the results and presents some concluding remarks. Chapter 6 includes all the references used to complete this research. Lastly, additional figures and tables that served this research are compiled in the Appendices. 


\section{LITERATURE REVIEW}

\subsection{Historical Overview on the Changes in Speed Limit}

Up until 1974, states had the authority to determine and establish their own speed limits. Limits such as $65 \mathrm{mph}$ and $75 \mathrm{mph}$ were posted on most highways. On January 1, 1974, the United States Congress implemented a National Maximum Speed Limit (NMSL) of $55 \mathrm{mph}$ to reduce fuel consumption as a response to the Arab Oil Embargo. As a result, the flow of traffic slowed down on all major highways and the total amount of travel declined. These declines were accompanied by a decrease in the number of traffic fatalities [11].

NMSL remained in effect for 13 years unaffected by the subsequent decrease in oil prices. However, in the mid-1980s, public officials from several states requested the speed limit law to be revisited and allow for higher speeds to decrease travel time. Consequently, on April 1, 1987, Congress passed the Surface Transportation and Uniform Relocation Assistance Act (STURAA) which allowed states to increase speed limits up to $65 \mathrm{mph}$ on rural Interstate highways. By the end of 1987, several states had adopted the new act [11].

On November 28, 1995, the NMSL was repealed by the National Highway System (NHS) Designation Act. This law returned the authority of setting speed limits to the states on the roadways within their boundaries. A total of 32 states used the authority granted by this law to increase posted speed limits on various roadways by the end of 1996 [11]. Wisconsin increased the maximum posted speed limit from $55 \mathrm{mph}$ to $65 \mathrm{mph}$ by the Wisconsin Act 318 in 1996 and then from $65 \mathrm{mph}$ to $70 \mathrm{mph}$ by the Wisconsin Assembly Bill 27 on several interstates in 2015 [6] [3]. Figure 1 shows the current maximum posted speed limits by state in the United States. Idaho, Montana, Nevada, South Dakota, Utah, and Wyoming have a 
maximum posted speed limits of $80 \mathrm{mph}$. Texas has various maximum posted speed limits, with the new privately-funded toll road from Austin to San Antonio featuring the nation's highest speed limit of $85 \mathrm{mph}$.

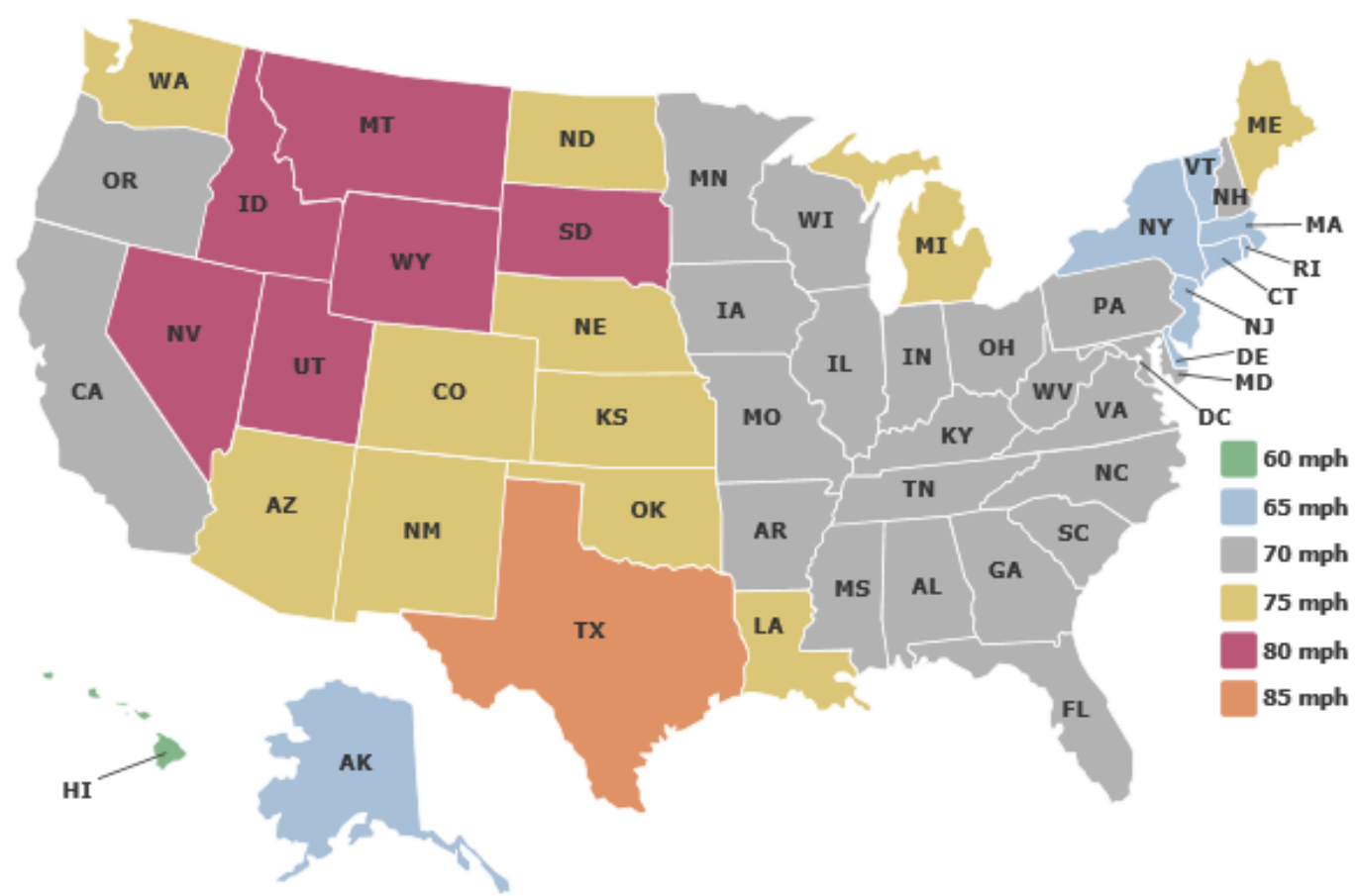

Figure 1: Maximum Posted Speed Limit by State [12]

\subsection{Effect of Speed Limit Changes on Operating speed}

Following STURAA in 1987, several studies evaluated the effect of raising the maximum posted speed limit to $65 \mathrm{mph}$ on operating speed. A study conducted by Upchurch examined the rural Interstates in Arizona in 1989, and found that the mean operating speed increased from $59.5 \mathrm{mph}$ to $65.0 \mathrm{mph}$ [13]. A similar study examined the rural and urban Interstates in Virginia. The study looked at a 6-year analysis period - 3 years each of the before and after analysis period. The average operating speed increased by $5.2 \mathrm{mph}$ and $3.1 \mathrm{mph}$ on 
rural and urban Interstates, respectively. The study also considered the $85^{\text {th }}$ percentile speed which increased by $6.3 \mathrm{mph}$ and $3.5 \mathrm{mph}$ on rural and urban Interstates, respectively [14].

A study conducted in Alabama in 1990 found that the $10 \mathrm{mph}$ increase in posted speed limit (from $55 \mathrm{mph}$ to $65 \mathrm{mph}$ ) led to an average increase of $2.4 \mathrm{mph} .85^{\text {th }}$ percentile speed increased by $2.2 \mathrm{mph}$ [15]. In 1991, a study examined the impact of increasing posted speed limits on rural Interstates in 11 states. Speed data between 1986 and 1988 were analyzed to determine the effect of increasing the speed limit from $55 \mathrm{mph}$ to $65 \mathrm{mph}$ on some speed aspects: average operating speed, speed variance, and $85^{\text {th }}$ percentile speed. The analysis showed a $4 \mathrm{mph}$ increase in the average speed, a $5 \mathrm{mph}$ increase in the $85^{\text {th }}$ percentile speed, and a 12 percent increase in speed variance. The study also found that the percentage of vehicles exceeding $70 \mathrm{mph}$ increased from 6 to 19 percent. The study also looked at the adjacent roads with a 55-mph posted speed limit. A small increase of $0.8 \mathrm{mph}$ was observed on these roads, suggesting a nominal effect from the increase in posted speed limit on other sections [16].

In 1996, WisDOT (Wisconsin Department of Transportation) looked at the implications of increasing the speed limit from $55 \mathrm{mph}$ to $65 \mathrm{mph}$. The study emphasized physical and design considerations, noting that freeways are designed for $70 \mathrm{mph}$. At that time, the $85^{\text {th }}$ percentile freeway speed was predicted to increase by $3 \mathrm{mph}$ (from $72 \mathrm{mph}$ to $75 \mathrm{mph}$ ) if the posted speed limit was increased further from $65 \mathrm{mph}$ to $70 \mathrm{mph}$ [17]. As additional data became available, a follow-up report prepared by WisDOT in 1998 showed that the average operating speeds increased by 4.5-4.6 mph on freeways when PSL increased from 55 to 65 $\operatorname{mph}[18]$. 
In 1998, McCarthy evaluated the impact of raising the speed limits from $55 \mathrm{mph}$ to $65 \mathrm{mph}$ on highways. On non-limited access roads, average speed and speed variance had small changes with respect to the increased speed. On higher-speed limited access roads, the average and the $85^{\text {th }}$ percentile speeds increased by about $4 \mathrm{mph}$, while the speed variance increased by less than $1 \mathrm{mph}[19]$.

In 2002, a study by the Washington State Department of Transportation (WSDOT) used 10 years of speed data. The 5 years period before the PSL change (1982-1987) had an average rural Interstate speed of $58.5 \mathrm{mph}$. This average increased to $64.0 \mathrm{mph}$ in the next 5 years (1987-1992) following the posted speed limit increase. The $85^{\text {th }}$ percentile speeds were also investigated in the study, and the analysis showed that they increased from $64.0 \mathrm{mph}$ to $70.6 \mathrm{mph}$ over the same period. The speed limit increase did not affect the speed variance as it increased steadily over the investigated period. Another study in Washington State in 2006 showed that an increase of $10 \mathrm{mph}$ in the posted speed limit (from $65 \mathrm{mph}$ to $75 \mathrm{mph}$ ) led to a $3.4 \mathrm{mph}$ increase in average vehicle speed [20].

A recent study in Texas evaluated the impact of increasing the posted speed limit from 70 to $75 \mathrm{mph}$. The study collected 2 months before (staring November 2012) and 2 months after (starting March 2013) speed data. The average speed increased from $69.9 \mathrm{mph}$ to 71.6 $\mathrm{mph}$, the $85^{\text {th }}$ percentile speed increased from $74.5 \mathrm{mph}$ to $76.6 \mathrm{mph}$. The standard deviation increased from 4.9 to $5.3 \mathrm{mph}$. The percentage of people exceeding the posted speed limit increased from 12.1 to 26.1 percent [21]. 
In 2013, the effect of increasing the posted speed limit in Utah from 75 to $80 \mathrm{mph}$ was investigated on rural Interstates. Speed data were collected for three consecutive years (2008, 2009, and 2010). The study showed that the average speed for passenger cars and trucks decreased between 2008 and 2009 by 2.4 and 7.3 percent, respectively. As for the period between 2008 and 2010, the average speed for passenger cars increased by 0.2 percent, while that of trucks decreased by 3.7 percent. Passenger cars and trucks on adjacent segments - where posted speed limits did not increase - were traveling 1.9 and 1.6 percent faster than expected [22].

In general, the previous studies indicated a consistent effect of raising the posted speed limit. Studies showed that in general, the average driving speeds increased by less than the amount by which the posted speed limit increased. Every $1 \mathrm{mph}$ change in PSL corresponded to a $\sim 0.4 \mathrm{mph}( \pm 0.2 \mathrm{mph})$ change in average speeds for all vehicles in uncongested conditions, which is due to drivers selecting their operating speed based on their perception of a safe speed which is based on weather, geometric characteristics of the highway, and traffic conditions rather than the posted speed limit [23].

\subsection{Effect of Speed Limit Changes on Traffic Safety}

Following STURAA in 1987, several studies evaluated the effect of raising speed limits to $65 \mathrm{mph}$ on crash frequency and severity. One of the earliest studies conducted by the Arizona DOT in 1989 looked at highway traffic crashes resulting in injury or a fatality for the period between January 1982 and December 1988. The study used the interrupted time-series method to evaluate the change in injury and fatality crash rates after the posted speed limit increased from $55 \mathrm{mph}$ to $65 \mathrm{mph}$ in May 1987. Highways that did not experience a change in the posted 
speed limit were included in the study as a control group. The results showed a 36 percent monthly increase in crash related fatality and injuries, and an increase of 1,100 injuries and fatalities in a year and a half after the speed limit increase [24].

A study in New Mexico compared fatal crashes on rural Interstates before (1982 - 1987) and after (April 1987 - April 1988) the posted speed limit increase from 55 to $65 \mathrm{mph}$. Crash trends for the before period were used to estimate the expected fatal crash rate using linear regression, and the expected values were then compared with the rate of the collected fatal crashes of the after period. Although the rate of the collected fatal crashes decreased over the study period, the percentage of fatal crashes on rural highways as a percentage of all other road types increased by as much as 3.9 percent when compared to the average proportion of fatal crashes in the 5 previous years. Single-vehicle crashes were accountable for the majority of fatal crashes on rural highways after the speed limit increase. The study concluded that higher speed limits justified the result because of consistent demographic characteristics, alcohol involvement, and seat belt use in the period of the study [25].

Friedman et al. looked at annual crash counts for all 50 states that increased the speed limit on their rural Interstates between 1995 and 2005. They also looked at annual crash counts for states that raised the speed limit on their urban Interstates, and urban and rural non-Interstate highways during the same period. This study used Poisson mixed-effects regression to evaluate the effect of speed limit increase on safety, and it showed that increasing the speed limit resulted in an increase by 3.2 percent of fatalities on all road types. Injuries increased by 11.9 percent on rural interstates and by 5.6 percent on urban Interstates [26]. 
In a recent study, Farmer examined the effects of increasing speed limits on safety in the United States for the period from 1993 through 2013. Using a Poison regression model, traffic fatality rates for 41 states were modeled as a function of time, annual state unemployment rate, percentage of the driving population aged 25 or younger, percentage of the driving population aged 65 and older, state seat belt usage, per capita alcohol consumption, and the maximum posted speed limit on any roadway segment in the state. This model predicted that each $5 \mathrm{mph}$ increase in the posted speed limit leads to an increase in interstate highways fatality rate by 8 percent [27].

Lave and Elias evaluated the influences of increasing speed limit to $65 \mathrm{mph}$ for several states. In this study, the authors argued that previous studies only looked at local effects which are specific to the segment under study rather than considering the global effects. Changing speed limits has consequences for other road segments in the state. For example, there might be a shift of traffic from rural roads to the higher speed rural interstates, which would make rural roads safer. The study looked at fatality rates instead of fatality frequency as a better estimate for before and after speed limit change periods. It was found that the statewide fatality rates decreased by 3.4 percent [28]. Oher researchers believe that statewide data is a too-wide measure, and that drivers might rarely choose rural freeways because of the geography of the state [1].

Overall, studies have shown that increasing the posted speed limit on rural Interstates and highways with similar design features resulted in increased injury and fatal crashes. The validity of results throughout the studies is likely the result of the use of different analysis 
methods, data collection sources, sample size, and other confounding factors such as weather, alcohol impairment, use of seat belt, and presence of law enforcement [23].

\subsection{Findings from Other Midwest States}

\section{Michigan}

On August 1, 1996, the speed limit on segments of Michigan freeways were increased from 65 to $70 \mathrm{mph}$. Michigan Department of Transportation (MDOT), in conjunction with the Department of Civil and Environmental Engineering at Michigan State University, conducted a study to examine the effects of this increase. The analysis compared test segments where the speed limit was increased to $70 \mathrm{mph}$ with the control segments where speed limits remained the same. The collected data showed that increasing the speed limit on some segments had an increase in the $50^{\text {th }}$ (the speed at which half of the observed vehicles are below and half of the observed vehicles are above) and $85^{\text {th }}$ percentile of $1.0 \mathrm{mph}$ and $0.5 \mathrm{mph}$ respectively [29].

\section{Indiana}

On July 1, 2005, the Interstate speed limit was raised to $70 \mathrm{mph}$. Purdue University conducted a study to analyze the effects of this increase, but did not report on operating speed changes. The study used multinomial models to investigate the impact of increasing the posted speed limit on accident severity. The results indicated that the increase in the posted speed limit had no statistically significant effect on accident injury severity [8].

\section{Iowa}

On July 1, 2005, the speed limit was increased to $70 \mathrm{mph}$ on most rural Interstates. Iowa State University, in conjunction with the Iowa Department of Transportation, evaluated 
the effects of the speed increase. The study showed that the $85^{\text {th }}$ percentile speeds increased by $2 \mathrm{mph}$ but the number of drivers exceeding the speed limit by $10 \mathrm{mph}$ decreased from $20 \%$ to about $8 \%$. Crash data were investigated from 1991 to 2007 . The study showed an increase in crash severity categories. Increases were less pronounced in some severity levels when compared to long term trends [30].

\section{Illinois}

On January 1, 2014, the Interstate speed limit was increased from 65 to $70 \mathrm{mph}$ on approximately $87 \%$ of Interstate highways and $98 \%$ of rural Interstates under Illinois Department of Transportation's jurisdiction. There have not yet been studies regarding the effect of this speed limit increase [31].

\section{Minnesota}

In 1997, the speed limit was increased from 65 to $70 \mathrm{mph}$ on rural Interstates. In 2005 , the Minnesota Department of Transportation conducted a study to evaluate the impacts of PSL increase. University of Minnesota compared operating speed data obtained during the Minnesota Speed Management Program (MSMP) with historical data. Speed data showed a 42.9\% decrease in the number of drivers traveling at least $10 \mathrm{mph}$ above the speed limit. Crash data were analyzed and the results showed a reduction in the number of fatal crashes after the implementation of MSMP [32].

\section{Ohio}

On July 1, 2013, the Interstate speed limit was increased from 65 to $70 \mathrm{mph}$. Ohio Department of Transportation (ODOT) conducted a study to investigate the effects of the speed 
limit increase. It was found that on Interstate segments where speed limit increased, the $85^{\text {th }}$ percentile speed increased by $1 \mathrm{mph}$. Before the increase, the $85^{\text {th }}$ percentile speed was slightly above $65 \mathrm{mph}$, and after the increase it remained below $70 \mathrm{mph}$ [33]. 


\section{METHODOLOGY}

\subsection{Data Description}

Travel time and operating speed data were extracted on interstate segments, in each direction.

Table 1 shows the counties and interstates where the speed data is collected, and Figure 2 shows the interstates which this research will focus on (highlighted in green).

Table 1: Minimum List of Locations Arranged for Evaluation

\begin{tabular}{|c|c|c|c|c|c|}
\hline Interstate & I-94 & I-90 & I-39 & I-41 & I-43 \\
\hline \multirow{14}{*}{ County } & St. Croix & La Cross & Marathon & Brown & Brown \\
\hline & Dunn & Monroe & Portage & Outagamie & Manitowoc \\
\hline & Eau Claire & & Waushara & Winnebago & Sheboygan \\
\hline & Jackson & & Marquette & Fond du Lac & Ozaukee \\
\hline & Monroe & & Columbia & Dodge & Waukesha \\
\hline & Juneau & & Dane & Washington & Walworth \\
\hline & Sauk & & Rock & Waukesha & Rock \\
\hline & Columbia & & & & \\
\hline & Dane & & & & \\
\hline & Jefferson & & & & \\
\hline & Waukesha & & & & \\
\hline & Milwaukee & & & & \\
\hline & Racine & & & & \\
\hline & Kenosha & & & & \\
\hline
\end{tabular}




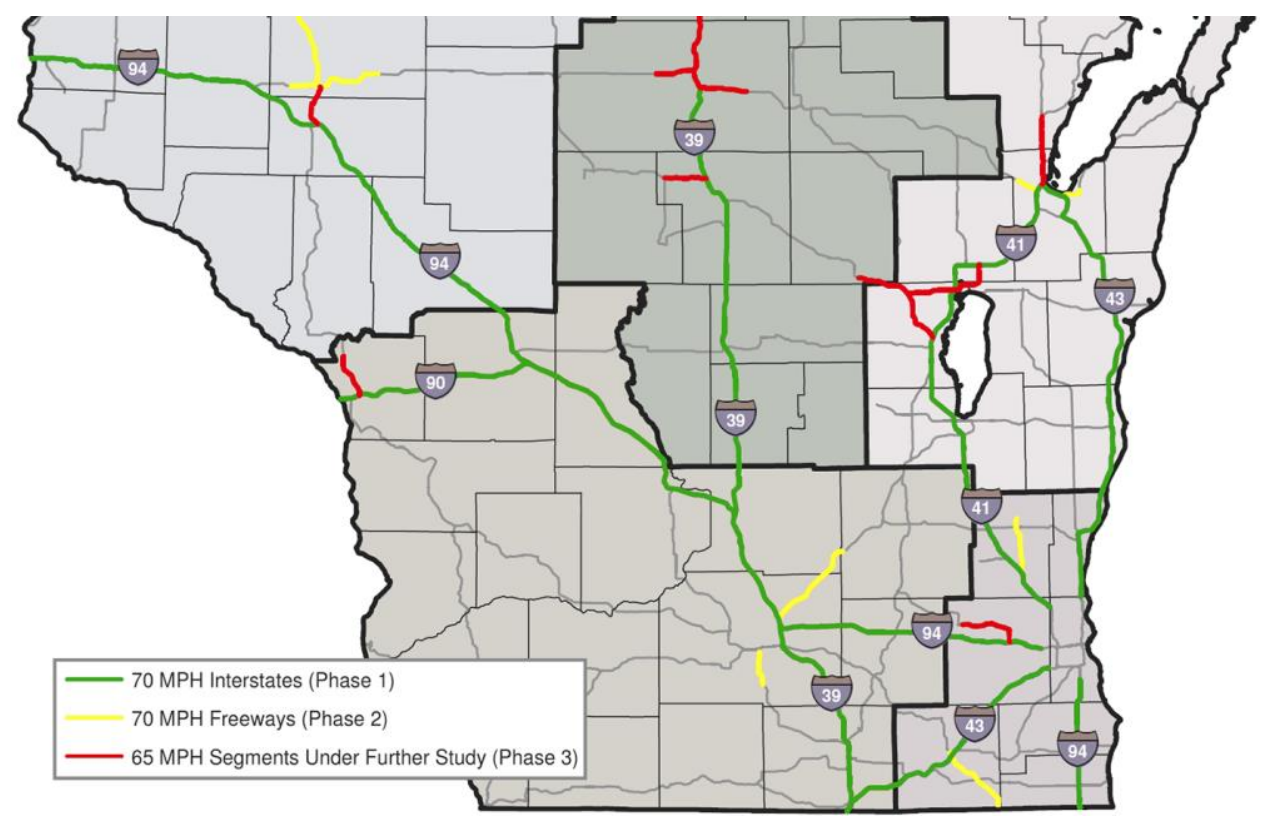

Figure 2: Map of Interstates (shown as green) with Speed Limit Increase

\subsubsection{National Performance Management Research Data Set (NPMRDS)}

Federal Highway Administration (FHWA) provides the NPMRDS for use in performance monitoring and management and is available to State Departments of Transportation and Metropolitan Planning Organizations (MPOs). The data are provided by HERE (formerly NAVTEQ and Nokia), and consist of the following [34]:

- Average travel times;

- Five-minute bins, referred to as epochs;

- National Highway System (NHS) coverage, including all interstates and US highways;

- By traffic message channel (TMC) links;

- $\quad$ By passenger, freight (5+ axle, class 7-8 per ATRI), and combined;

- With GIS shapefiles; 
- From October 2011 to present, updated monthly; and

- On a state by state basis, with a usage agreement required.

NPMRDS has been available since 2013. In early 2014, there was a significant jump in data quality. Therefore, for this research, data prior to March 2014 were not considered. This analysis used the following NPMRDS versions: 2014Q1 (Mar - Oct '14), 2014Q3 (Nov '14 Jun '15), 2015Q3 (Jul - Oct '15), and 2015Q4 (Nov '15 - Jul '16). FWHA refers to NPMRDS as a suitable sound data source and requires their use for performance measures as per the Moving Ahead for Progress in the 21st Century (MAP-21) Act [34].

For Wisconsin Interstates, 674 segments (TMCs) were available. Before carrying forward with the analysis, quality and consistency checks for each TMC were done.

- For a TMC to be used, it must exist in all four NPMRDS versions from March 2014 to June 2016. There were 58 TMCs missing from one or more version, leaving 616 segments for further consideration.

- Because NPMRDS segment lengths sometimes change from one NPMRDS version to another - which affect travel time data - all segments were checked for such changes in all four versions. If the standard deviation of the distance was greater than 0.01 mile, that segment was omitted from the analysis, which led to the removal of 21 TMCs, leaving 595 segments for further consideration.

- A typical segment length for Wisconsin Interstates ranges between 0.9 and 3.5 miles. Very short segments have fewer observations and show relatively greater variance. Segments of lengths less than 0.1 mile were removed. There were 16 such TMCs, leaving 579 segments for analysis. 
The identified 579 TMCs include samples within all counties identified in Table 1, along with additional selections from other Interstates and counties. Of these 579 segments, 455 segments had an increase in the PSL, while the remaining 124 did not. The speed limit for the 124 segments - primarily in Milwaukee County - is posted at 50 or $55 \mathrm{mph}$, and these segments are used for comparison and serve as control segments. Table 2 shows TMC segments classified by Interstate and county.

Table 2: TMC Segment Tallies by Interstate and County

I-39 (includes I-39/90; excludes concurrent section with I-94)

\begin{tabular}{|l|c|c|c|c|c|}
\hline County & NB & SB & EB & WB & Total \\
\hline Columbia & 5 & 5 & & & 10 \\
\hline Dane & 5 & 6 & & & 11 \\
\hline Marathon & 5 & 6 & & & 11 \\
\hline Marquette & 4 & 4 & & & 8 \\
\hline Portage & 11 & 10 & & & 21 \\
\hline Rock & 7 & 7 & & & 14 \\
\hline Waushara & 3 & 4 & & & 7 \\
\hline Total & 40 & 42 & & & 82 \\
\hline
\end{tabular}

I-41 (previously US 41)

\begin{tabular}{|l|c|c|c|c|c|}
\hline County & NB & SB & EB & WB & Total \\
\hline Brown & 4 & 6 & & & 10 \\
\hline Dodge & 3 & 4 & & & 7 \\
\hline Fond du Lac & 7 & 8 & & & 15 \\
\hline Milwaukee & 10 & 10 & & & 20 \\
\hline Outagamie & 10 & 10 & & & 20 \\
\hline Washington & 9 & 9 & & & 18 \\
\hline Waukesha & 3 & 3 & & & 6 \\
\hline Winnebago & 12 & 11 & & & 23 \\
\hline Total & 59 & 61 & & & 119 \\
\hline
\end{tabular}

I-43 (includes I-43/894)

\begin{tabular}{|l|c|c|c|c|c|}
\hline County & NB & SB & EB & WB & Total \\
\hline Brown & 7 & 7 & & & 14 \\
\hline Manitowoc & 7 & 8 & & & 15 \\
\hline Milwaukee & 15 & 15 & 6 & 6 & 42 \\
\hline Ozaukee & 9 & 9 & & & 18 \\
\hline Rock & 3 & 3 & & & 7 \\
\hline Sheboygan & 8 & 7 & & & 15 \\
\hline Walworth & 8 & 9 & & & 17 \\
\hline Waukesha & 5 & 5 & & & 10 \\
\hline Total & 62 & 63 & 6 & 6 & 137 \\
\hline
\end{tabular}


Table 2 continued: TMC Segment Tallies by Interstate and County

$$
\mathrm{I}-90
$$

\begin{tabular}{|l|l|l|c|c|c|}
\hline County & NB & SB & EB & WB & Total \\
\hline La Crosse & & & 6 & 7 & 13 \\
\hline Monroe & & & 4 & 4 & 8 \\
\hline Total & & & 10 & 11 & 21 \\
\hline
\end{tabular}

I-94 (includes I-39/90/94 and I-43/94)

\begin{tabular}{|l|c|c|c|c|c|}
\hline County & NB & SB & EB & WB & Total \\
\hline Columbia & 3 & 4 & 1 & 2 & 10 \\
\hline Dane & 6 & 5 & 4 & 3 & 18 \\
\hline Dunn & & & 2 & 1 & 3 \\
\hline Eau Claire & & & 4 & 5 & 9 \\
\hline Jackson & & & 5 & 4 & 9 \\
\hline Jefferson & & & 5 & 6 & 11 \\
\hline Juneau & & & 5 & 5 & 10 \\
\hline Kenosha & 5 & 4 & & & 9 \\
\hline Milwaukee & 13 & 14 & 11 & 9 & 47 \\
\hline Monroe & & & 7 & 7 & 14 \\
\hline Racine & 6 & 6 & & & 12 \\
\hline Sauk & & & 4 & 4 & 8 \\
\hline St Croix & & & 9 & 7 & 16 \\
\hline Waukesha & & & 13 & 13 & 26 \\
\hline Total & 33 & 33 & 70 & 66 & 202 \\
\hline
\end{tabular}

Other 3-Digit Interstates

\begin{tabular}{|l|c|c|c|c|c|}
\hline County & NB & SB & EB & WB & Total \\
\hline I-535 Douglas & 1 & 1 & & & 2 \\
\hline I-794 Milwaukee & & & 2 & 4 & 6 \\
\hline I-894 Milwaukee & 5 & 5 & & & 10 \\
\hline Total & 6 & 6 & 2 & 4 & 18 \\
\hline
\end{tabular}

The 455 segments which had the increased PSL on five Interstate highways (I-39, I-41, I-43, I-90, and I-94) are shown in Figure 3. These TMCs are used to evaluate the effects of changes in the speed limit on operating speed and its variations. 


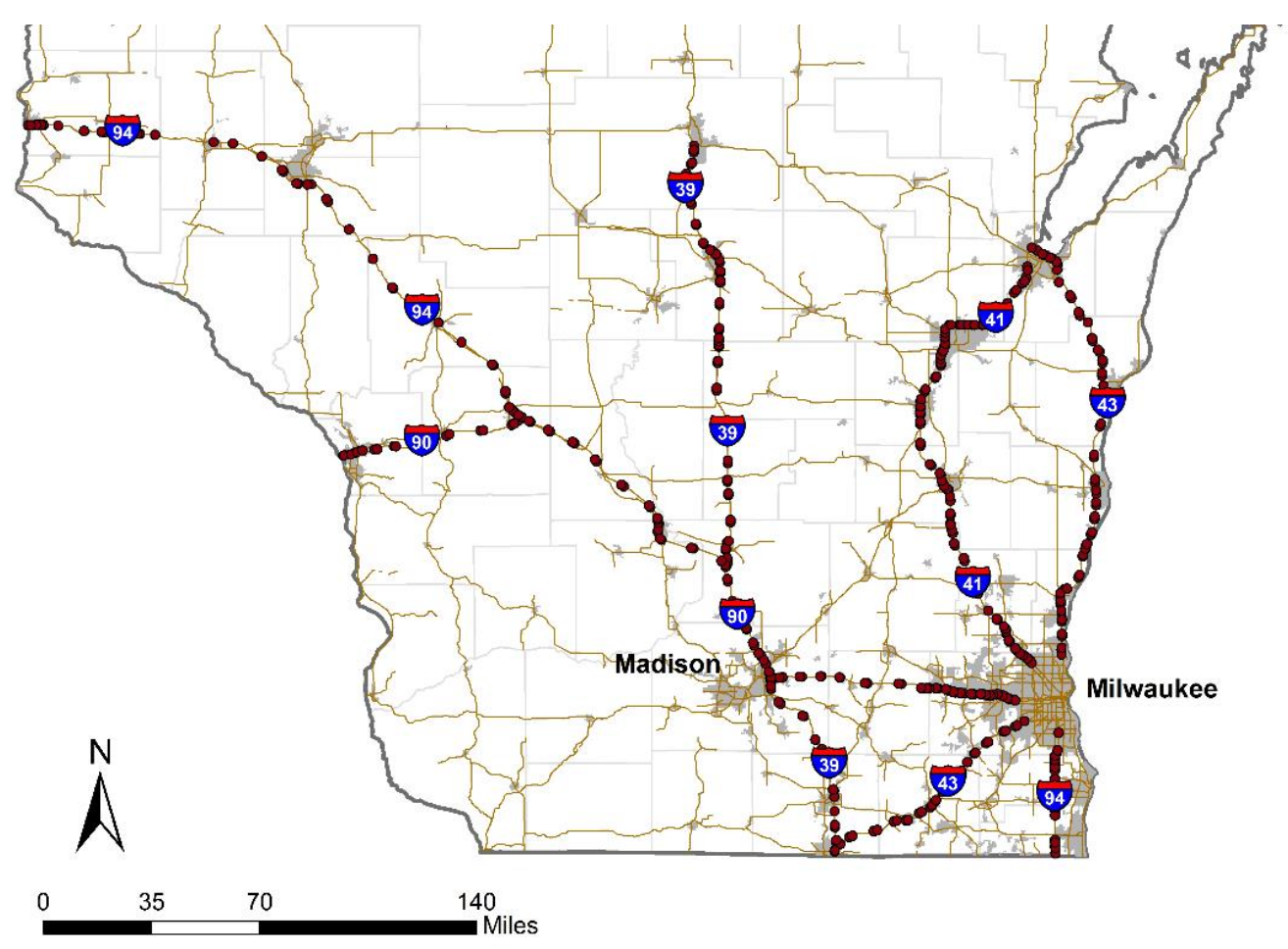

Figure 3: Wisconsin Interstate TMCs with Increased PSL from 65 to $70 \mathrm{mph}$

\subsubsection{Volume, Speed, and Occupancy (VSPOC) Application Data}

For validation, the NPMRDS speeds are compared with selected agency-collected loop and microwave detector data. The WisTransPortal Volume, Speed, and Occupancy (VSPOC) Application ${ }^{1}$ provides online tools to retrieve and analyze traffic detector data throughout the state of Wisconsin. General Detector Data Retrieval module was used to pull data corresponding to the investigated areas. After selecting the location (region, corridor, and location), the Detector IDs that fell within the limits of the TMC road segment were selected for investigation. Only Detector IDs located along the main road were selected; those associated with on/off ramps were omitted since drivers slow down to make these maneuvers,

\footnotetext{
${ }^{1}$ http://transportal.cee.wisc.edu/applications/vspoc.html
} 
yielding to data which is not reflective of mainline travel. In addition, Detector IDs within one mile of ramps were also avoided since drivers would still be adjusting speed.

From the 579 TMC segments there are 294 that have available detectors in VSPOC. Data were retrieved for 43 segments of these 294. These segments included I-39, I-39/I-90, I43/I-94 and I-43/I-894 and will be used to compare VSPOC and NPMRDS data. Once the Detector IDs for the roadway segment were identified, five-minute detector data for speed were collected by averaging over the selected detectors. Figure 4 provides a graphical overview of this data collection process.
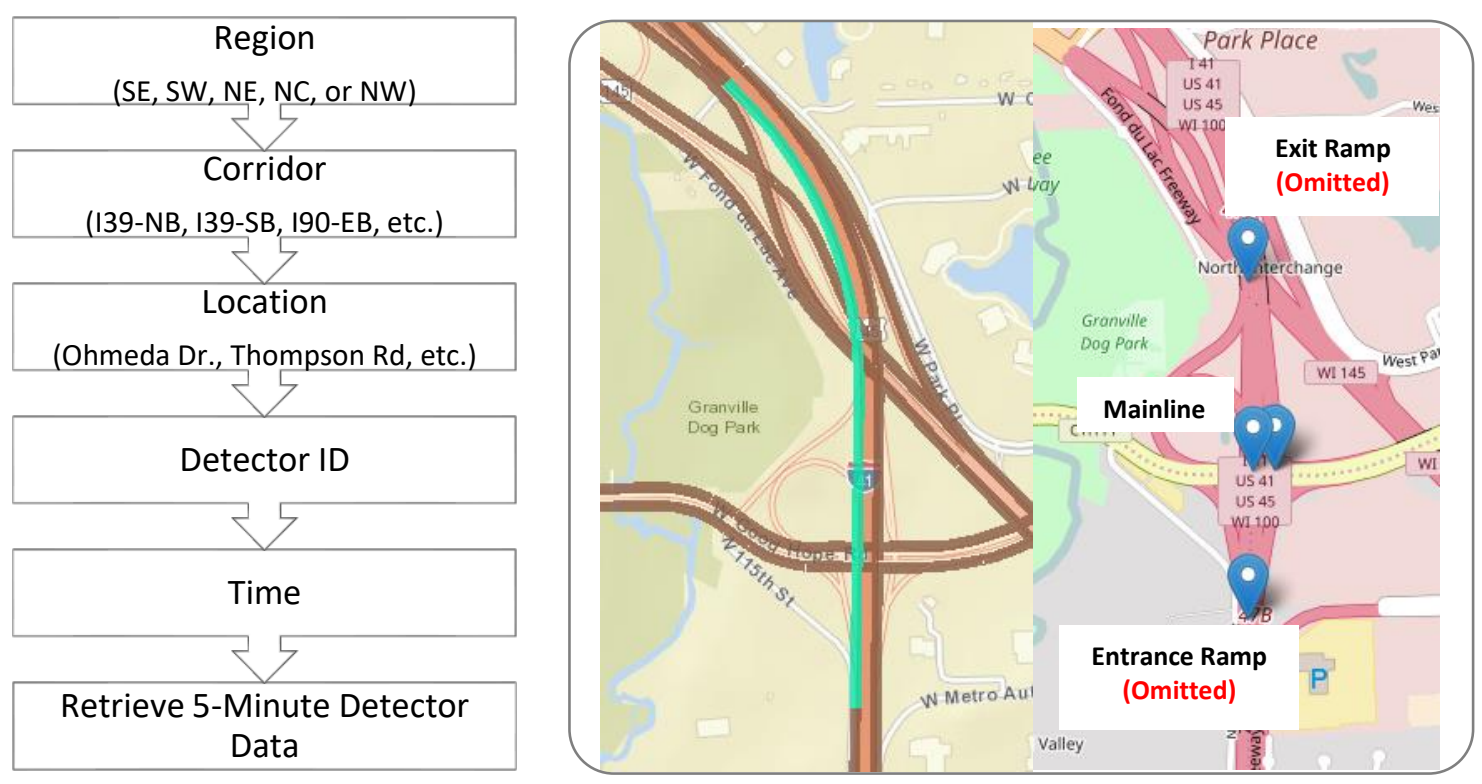

Figure 4: VSPOC Data Collection Process

Figure 5 shows an example of the selected VSPOC detectors that falls within the limits of the corresponding TMC. 

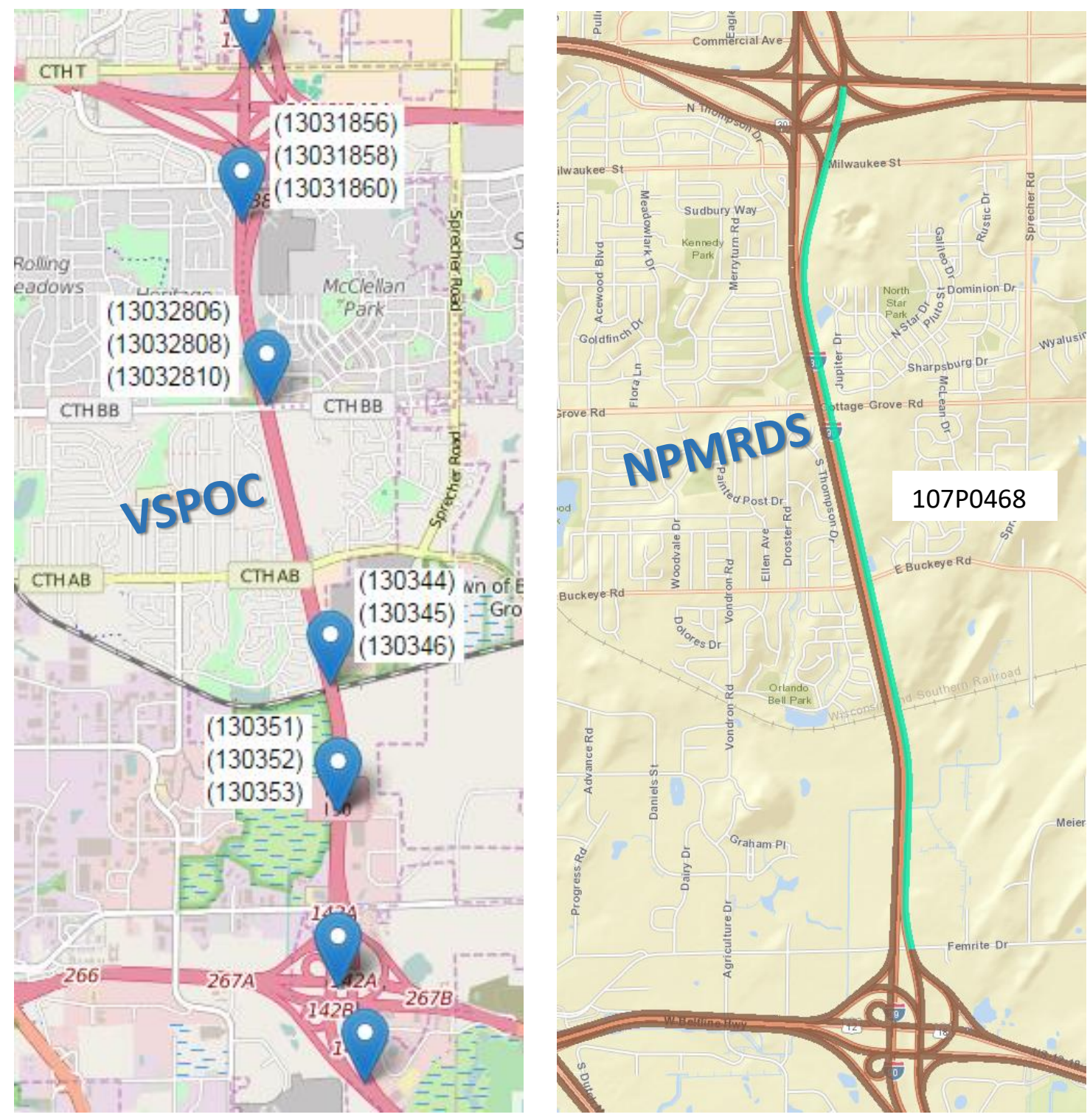

Figure 5: Example of VSPOC Detectors for the Corresponding TMC

\subsubsection{MV4000 Crash Data}

Wisconsin DOT's motor vehicle accident report is referred to as MV4000. WisTransPortal is the primary source for accessing the crash data archive of all reported crashes in Wisconsin from 1994 to the present. The crash data are available by accessing the 
Crash Data Retrieval Facility. Figure 6 shows the procedure a WisTransPortal user needs to go through to retrieve the crash data.

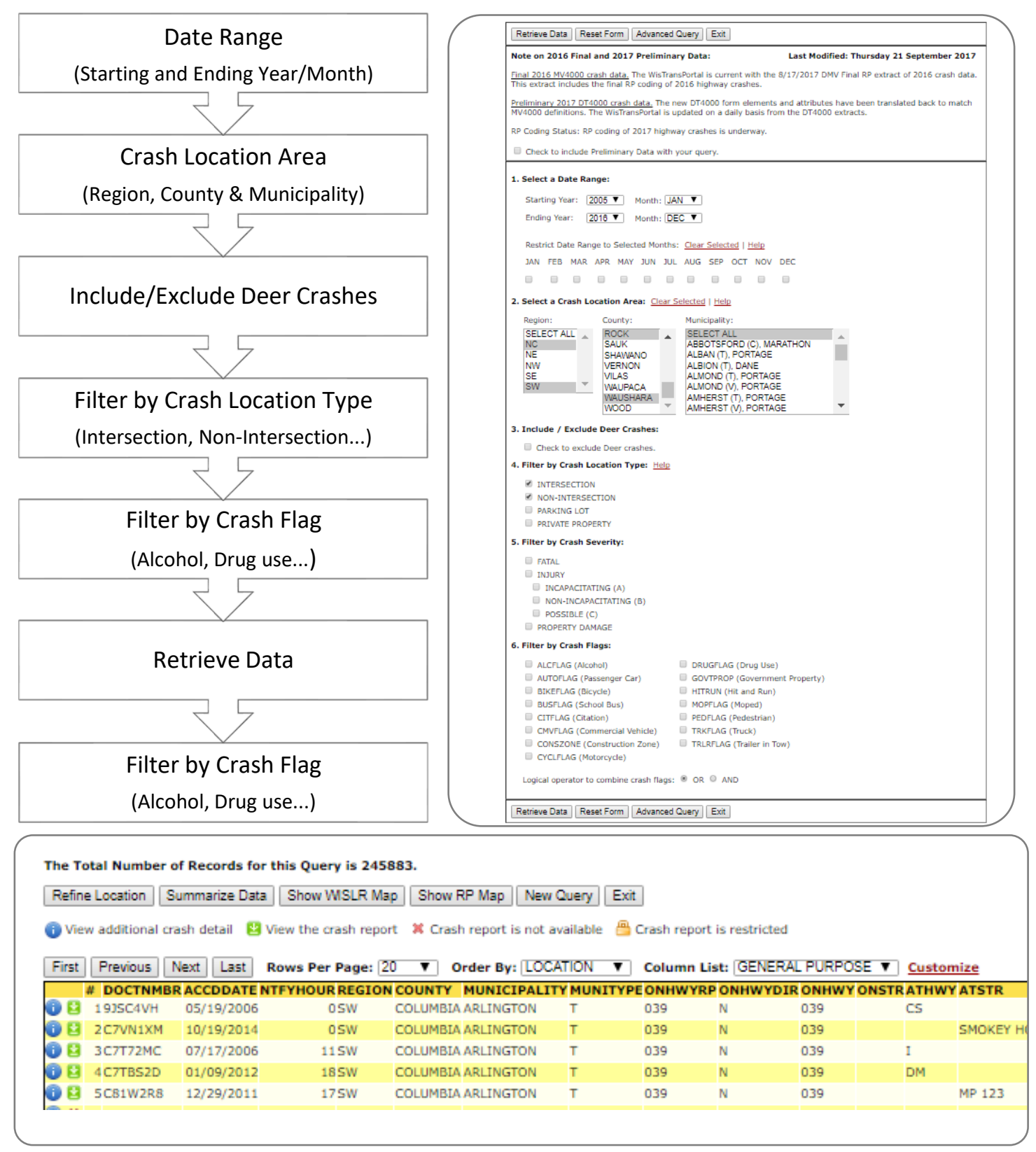

Figure 6: Procedure to Retrieve Crash data 
After following the procedure shown in Figure 6, an initial crash data table is generated. Clicking on the "Refine Location" box, allows the user to select a location of interest and reduce the number of crash reports to include only those in the investigated area.

Crash data were collected on the segments listed in Table 2. Figure 7 shows the location of the segments of interest on the map, while Table 3 summarizes them by Interstate and county. Data were collected from 2005 to 2017, covering periods of 10.5 years (Jan 2005 May 2015) prior to PSL increase and 2.25 years (July 2015 - Sep 2017) after the PSL increase. Since the data for 2017 are not official yet, the preliminary data were used instead. Because of that and due to some missing data, two different phases for the analysis were conducted. Phase 1 included data for 2016 only, while phase 2 also included data of 2017. 


\section{Highways picked for higher speed}

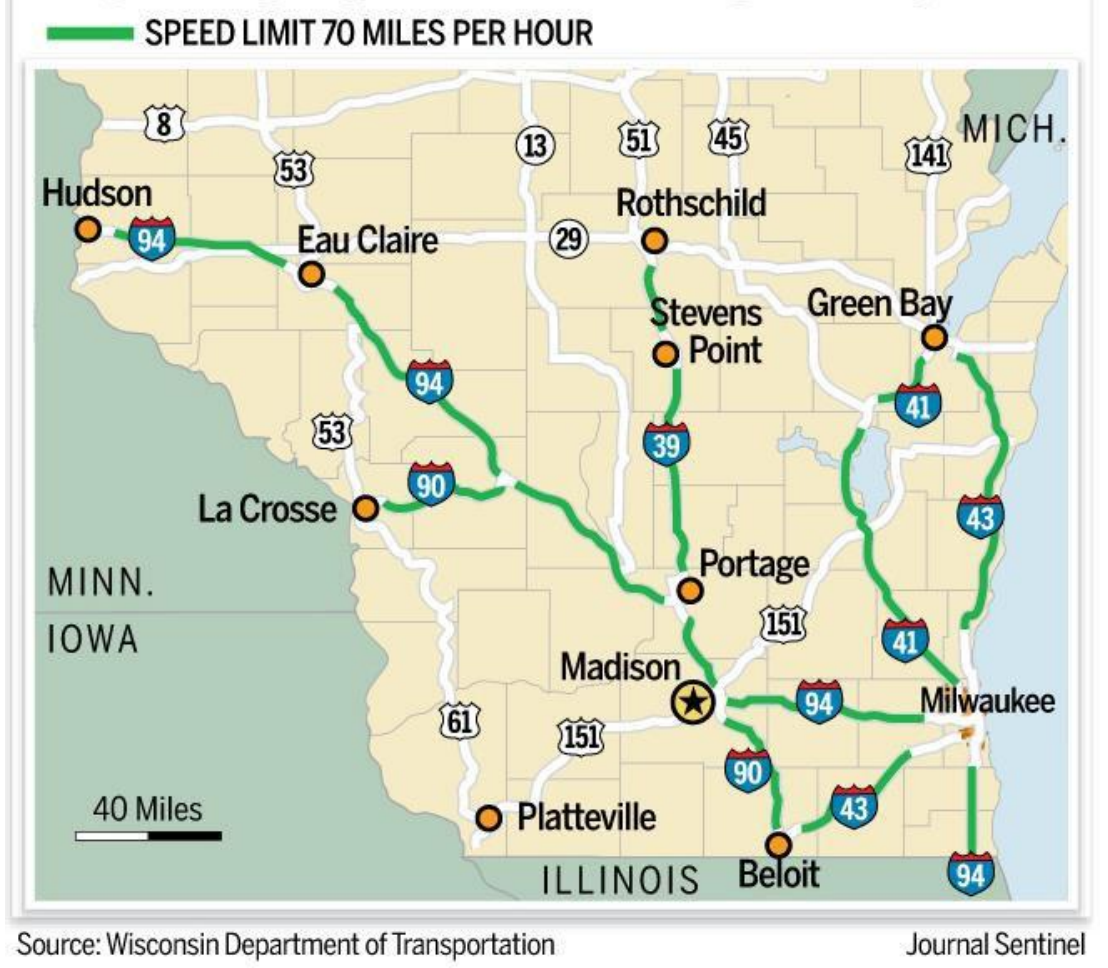

Figure 7: Highways with $70 \mathrm{mph}$ Speed limits

Table 3: Segments of interest by Interstate and County

\begin{tabular}{|c|c|c|c|c|c|c|c|c|}
\hline Interstate & $\begin{array}{c}1-94 \\
\text { (includes } \\
\text { I-39/90/94) }\end{array}$ & I-90 & $\begin{array}{c}\text { I-39 } \\
\text { (includes I- } \\
39 / 90 \text { ) } \\
\end{array}$ & |-41 & $\begin{array}{c}\mathrm{I}-43 \\
\text { (includes I- } \\
43 / 894) \\
\end{array}$ & I-535 & I-794 & $1-894$ \\
\hline \multirow{14}{*}{ County } & Columbia & La Cross & Columbia & Brown & Brown & Douglas & Milwaukee & Milwaukee \\
\hline & Dane & \multirow[t]{13}{*}{ Monroe } & Dane & Dodge & Manitowoc & & & \\
\hline & Dunn & & Marathon & Fond du Lac & Milwaukee & & & \\
\hline & Eau Claire & & Marquette & Milwaukee & Ozaukee & & & \\
\hline & Jackson & & Portage & Outagamie & Rock & & & \\
\hline & Jefferson & & Rock & Washington & Sheboygan & & & \\
\hline & Juneau & & Waushara & Waukesha & Walworth & & & \\
\hline & Kenosha & & & Winnebago & Waukesha & & & \\
\hline & Milwaukee & & & & & & & \\
\hline & Monroe & & & & & & & \\
\hline & Racine & & & & & & & \\
\hline & Sauk & & & & & & & \\
\hline & St. Croix & & & & & & & \\
\hline & Waukesha & & & & & & & \\
\hline
\end{tabular}




\subsubsection{Data Timeframe Period}

Maximum posted speed limit was increased on Wisconsin interstates the week of June 16, 2015. The before period data were collected for one-week time periods in every month from March 2014 to May 2015. The after period data were collected for one-week time periods in every month from July 2015 to June 2016. Figure 8 shows the calendar for the data collection

period, holidays and Sundays are indicated in red, and the weeks for which data were collected are highlighted in yellow. Weeks that had holidays were avoided when collecting data as these days do not depict a normal travel day. 


\begin{tabular}{|ccccccccc|}
\hline \multicolumn{8}{|c|}{ Mar 2014 } \\
Su Mo Tu We Th Fr Sa \\
\hline 2 & 3 & 4 & 5 & 6 & 7 & 8 \\
9 & 10 & 11 & 12 & 13 & 14 & 15 \\
16 & 17 & 18 & 19 & 20 & 21 & 22 \\
23 & 24 & 25 & 26 & 27 & 28 & 29 \\
30 & 31 & & & & & \\
\hline
\end{tabular}

Aug 2014

Su Mo Tu We Th Fr Sa

$\begin{array}{lllll} & & & 1 & 2\end{array}$

$\begin{array}{ccccccc}3 & 4 & 5 & 6 & 7 & 8 & 9 \\ 10 & 11 & 12 & 13 & 14 & 15 & 16\end{array}$

$\begin{array}{lllllll}17 & 18 & 19 & 20 & 21 & 22 & 23\end{array}$

$\begin{array}{lllllll}24 & 25 & 26 & 27 & 28 & 29 & 30\end{array}$ 31

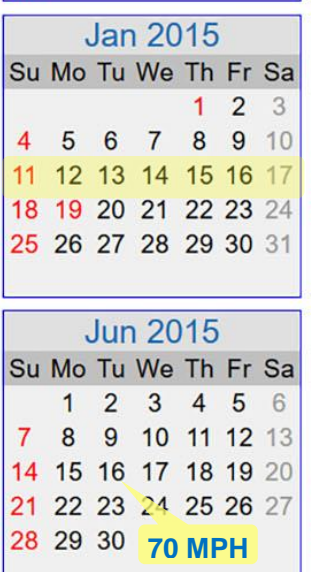

\begin{tabular}{|cccccccc}
\hline \multicolumn{1}{|c|}{ Nov 2015} \\
Su Mo & Tu We & Th & Fr Sa \\
1 & 2 & 3 & 4 & 5 & 6 & 7 \\
8 & 9 & 10 & 11 & 12 & 13 & 14 \\
15 & 16 & 17 & 18 & 19 & 20 & 21 \\
22 & 23 & 24 & 25 & 26 & 27 & 28 \\
29 & 30 & & & & & \\
\end{tabular}

Apr 2016

Su Mo Tu We Th Fr Sa

$\begin{array}{lllllll}3 & 4 & 5 & 6 & 7 & 8 & 9\end{array}$

$\begin{array}{lllllll}10 & 11 & 12 & 13 & 14 & 15 & 16\end{array}$

$\begin{array}{lllllll}17 & 18 & 19 & 20 & 21 & 22 & 23\end{array}$

$\begin{array}{lllllll}24 & 25 & 26 & 27 & 28 & 29 & 30\end{array}$
Apr 2014

Su Mo Tu We Th Fr Sa

$\begin{array}{ccccccc} & & 1 & 2 & 3 & 4 & 5 \\ 6 & 7 & 8 & 9 & 10 & 11 & 12\end{array}$

$\begin{array}{lllllll}13 & 14 & 15 & 16 & 17 & 18 & 19\end{array}$

$\begin{array}{lllllll}20 & 21 & 22 & 23 & 24 & 25 & 26\end{array}$

$\begin{array}{llll}27 & 28 & 29 & 30\end{array}$

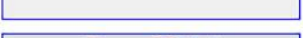

Sep 2014

Su Mo Tu We Th Fr Sa $\begin{array}{llllll}1 & 2 & 3 & 4 & 5 & 6\end{array}$

$\begin{array}{lllllll}7 & 8 & 9 & 10 & 11 & 12 & 13\end{array}$

$\begin{array}{lllllll}14 & 15 & 16 & 17 & 18 & 19 & 20\end{array}$

$\begin{array}{lllllll}21 & 22 & 23 & 24 & 25 & 26 & 27\end{array}$ $\begin{array}{lll}28 & 29 & 30\end{array}$

\begin{tabular}{|cccccccc|}
\hline \multicolumn{8}{|c|}{ Feb 2015} \\
Su Mo & Tu & We & Th & Fr & Sa \\
1 & 2 & 3 & 4 & 5 & 6 & 7 \\
8 & 9 & 10 & 11 & 12 & 13 & 14 \\
15 & 16 & 17 & 18 & 19 & 20 & 21 \\
22 & 23 & 24 & 25 & 26 & 27 & 28 \\
\hline 2 & & & & & & \\
\hline
\end{tabular}

Jul 2015

Su Mo Tu We Th Fr Sa

$\begin{array}{lllll} & 1 & 2 & 3 & 4\end{array}$

$\begin{array}{lllllll}5 & 6 & 7 & 8 & 9 & 10 & 11\end{array}$

$\begin{array}{lllllll}12 & 13 & 14 & 15 & 16 & 17 & 18\end{array}$

$\begin{array}{lllllll}19 & 20 & 21 & 22 & 23 & 24 & 25\end{array}$

$\begin{array}{llllll}26 & 27 & 28 & 29 & 30 & 31\end{array}$

Dec 2015

Su Mo Tu We Th Fr Sa $\begin{array}{lllll}1 & 2 & 3 & 4 & 5\end{array}$

$\begin{array}{lllllll}6 & 7 & 8 & 9 & 10 & 11 & 12\end{array}$

$\begin{array}{lllllll}13 & 14 & 15 & 16 & 17 & 18 & 19\end{array}$

$\begin{array}{lllllll}20 & 21 & 22 & 23 & 24 & 25 & 26\end{array}$

$\begin{array}{lllll}27 & 28 & 29 & 30 & 31\end{array}$

May 2016

Su Mo Tu We Th Fr Sa

$\begin{array}{lllllll}1 & 2 & 3 & 4 & 5 & 6 & 7\end{array}$

$\begin{array}{lllllll}8 & 9 & 10 & 11 & 12 & 13 & 14\end{array}$

$\begin{array}{lllllll}15 & 16 & 17 & 18 & 19 & 20 & 21\end{array}$

$\begin{array}{lllllll}22 & 23 & 24 & 25 & 26 & 27 & 28\end{array}$

$\begin{array}{lll}29 & 30 & 31\end{array}$

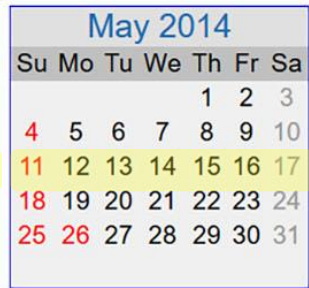

Oct 2014

Su Mo Tu We Th Fr Sa

$\begin{array}{lllll} & 1 & 2 & 3 & 4\end{array}$

$\begin{array}{lllllll}5 & 6 & 7 & 8 & 9 & 10 & 11\end{array}$

$\begin{array}{lllllll}12 & 13 & 14 & 15 & 16 & 17 & 18\end{array}$

$\begin{array}{lllllll}19 & 20 & 21 & 22 & 23 & 24 & 25\end{array}$

$\begin{array}{llllll}26 & 27 & 28 & 29 & 30 & 31\end{array}$

\begin{tabular}{|cccccccc|}
\hline \multicolumn{1}{|c|}{ Mar 2015} \\
Su & Mo & Tu We & Th & Fr & Sa \\
1 & 2 & 3 & 4 & 5 & 6 & 7 \\
8 & 9 & 10 & 11 & 12 & 13 & 14 \\
15 & 16 & 17 & 18 & 19 & 20 & 21 \\
22 & 23 & 24 & 25 & 26 & 27 & 28 \\
29 & 30 & 31 & & & & \\
\end{tabular}

Aug 2015

Su Mo Tu We Th Fr Sa

$\begin{array}{lllllll}2 & 3 & 4 & 5 & 6 & 7 & 8\end{array}$

$\begin{array}{lllllll}9 & 10 & 11 & 12 & 13 & 14 & 15\end{array}$

$\begin{array}{lllllll}16 & 17 & 18 & 19 & 20 & 21 & 22\end{array}$

$\begin{array}{lllllll}23 & 24 & 25 & 26 & 27 & 28 & 29\end{array}$ $\begin{array}{ll}30 & 31\end{array}$

Jan 2016

Su Mo Tu We Th Fr Sa

$\begin{array}{lllllll} & & & & 1 & 2 \\ 3 & 4 & 5 & 6 & 7 & 8 & 9\end{array}$

$\begin{array}{ccccccc}3 & 4 & 5 & 6 & 7 & 8 & 9 \\ 10 & 11 & 12 & 13 & 14 & 15 & 16\end{array}$

$\begin{array}{lllllll}17 & 18 & 19 & 20 & 21 & 22 & 23\end{array}$

$\begin{array}{lllllll}24 & 25 & 26 & 27 & 28 & 29 & 30\end{array}$ 31

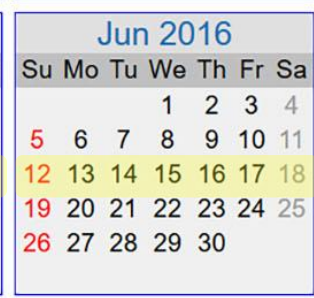

\begin{tabular}{|cccccccc|}
\hline \multicolumn{8}{|c|}{ Jun 2014} \\
Su Mo & Tu We & Th & Fr Sa \\
1 & 2 & 3 & 4 & 5 & 6 & 7 \\
8 & 9 & 10 & 11 & 12 & 13 & 14 \\
15 & 16 & 17 & 18 & 19 & 20 & 21 \\
22 & 23 & 24 & 25 & 26 & 27 & 28 \\
29 & 30 & & & & & \\
\end{tabular}

Nov 2014
Su Mo Tu We Th Fr Sa

Su Mo Tu We Th Fr Sa $\begin{array}{lllllll}2 & 3 & 4 & 5 & 6 & 7 & 8\end{array}$ $\begin{array}{lllllll}9 & 10 & 11 & 12 & 13 & 14 & 15\end{array}$ $\begin{array}{lllllll}16 & 17 & 18 & 19 & 20 & 21 & 22\end{array}$ $\begin{array}{lllllll}23 & 24 & 25 & 26 & 27 & 28 & 29\end{array}$ 30

\begin{tabular}{|cccccccc}
\hline \multicolumn{8}{|c|}{ Apr 2015} \\
Su Mo & Tu We & Th & Fr Sa \\
5 & 6 & 7 & 8 & 9 & 10 & 11 \\
12 & 13 & 14 & 15 & 16 & 17 & 18 \\
19 & 20 & 21 & 22 & 23 & 24 & 25 \\
26 & 27 & 28 & 29 & 30 & &
\end{tabular}

$$
\text { Sep } 2015
$$

Su Mo Tu We Th Fr Sa $\begin{array}{lllll}1 & 2 & 3 & 4 & 5\end{array}$ $\begin{array}{lllllll}6 & 7 & 8 & 9 & 10 & 11 & 12\end{array}$ $\begin{array}{lllllll}13 & 14 & 15 & 16 & 17 & 18 & 19\end{array}$ $\begin{array}{lllllll}20 & 21 & 22 & 23 & 24 & 25 & 26\end{array}$ $\begin{array}{llll}27 & 28 & 29 & 30\end{array}$

Feb 2016 Su Mo Tu We Th Fr Sa $\begin{array}{llllll}1 & 2 & 3 & 4 & 5 & 6\end{array}$ $\begin{array}{lllllll}7 & 8 & 9 & 10 & 11 & 12 & 13\end{array}$ $\begin{array}{lllllll}14 & 15 & 16 & 17 & 18 & 19 & 20\end{array}$ $\begin{array}{lllllll}21 & 22 & 23 & 24 & 25 & 26 & 27\end{array}$ 2829

\begin{tabular}{|ccccccccc|}
\hline \multicolumn{1}{|c|}{ Jul 2016} \\
Su Mo & Tu We & Th Fr & Sa \\
\hline & & & & 1 & 2 \\
3 & 4 & 5 & 6 & 7 & 8 & 9 \\
10 & 11 & 12 & 13 & 14 & 15 & 16 \\
17 & 18 & 19 & 20 & 21 & 22 & 23 \\
24 & 25 & 26 & 27 & 28 & 29 & 30 \\
31 & & & & & \\
\hline
\end{tabular}

Jul 2014

Su Mo Tu We Th Fr Sa

$\begin{array}{lllll}1 & 2 & 3 & 4 & 5\end{array}$

$\begin{array}{lllllll}6 & 7 & 8 & 9 & 10 & 11 & 12\end{array}$

$\begin{array}{lllllll}13 & 14 & 15 & 16 & 17 & 18 & 19\end{array}$

$\begin{array}{lllllll}20 & 21 & 22 & 23 & 24 & 25 & 26\end{array}$

$\begin{array}{lllll}27 & 28 & 29 & 30 & 31\end{array}$

Dec 2014

Su Mo Tu We Th Fr Sa $\begin{array}{llllll}1 & 2 & 3 & 4 & 5 & 6\end{array}$

$\begin{array}{lllllll}7 & 8 & 9 & 10 & 11 & 12 & 13\end{array}$

$\begin{array}{lllllll}14 & 15 & 16 & 17 & 18 & 19 & 20\end{array}$ $\begin{array}{lllllll}21 & 22 & 23 & 24 & 25 & 26 & 27\end{array}$ $\begin{array}{llll}28 & 29 & 30 & 31\end{array}$

\section{May 2015}

Su Mo Tu We Th Fr Sa

$\begin{array}{lllllll}3 & 4 & 5 & 6 & 7 & 8 & 9\end{array}$

$\begin{array}{lllllll}10 & 11 & 12 & 13 & 14 & 15 & 16\end{array}$

$\begin{array}{lllllll}17 & 18 & 19 & 20 & 21 & 22 & 23\end{array}$

$\begin{array}{lllllll}24 & 25 & 26 & 27 & 28 & 29 & 30\end{array}$ 31

Oct 2015

Su Mo Tu We Th Fr Sa

$\begin{array}{ccccccc}4 & 5 & 6 & 7 & 8 & 9 & 10\end{array}$

$\begin{array}{lllllll}11 & 12 & 13 & 14 & 15 & 16 & 17\end{array}$

$\begin{array}{lllllll}18 & 19 & 20 & 21 & 22 & 23 & 24\end{array}$

$\begin{array}{lllllll}25 & 26 & 27 & 28 & 29 & 30 & 31\end{array}$

Mar 2016

Su Mo Tu We Th Fr Sa $\begin{array}{lllll}1 & 2 & 3 & 4 & 5\end{array}$

$\begin{array}{lllllll}6 & 7 & 8 & 9 & 10 & 11 & 12\end{array}$

$\begin{array}{lllllll}13 & 14 & 15 & 16 & 17 & 18 & 19\end{array}$

$\begin{array}{lllllll}20 & 21 & 22 & 23 & 24 & 25 & 26\end{array}$

$\begin{array}{llllll}27 & 28 & 29 & 30 & 31\end{array}$

Aug 2016

Su Mo Tu We Th Fr Sa

$\begin{array}{llllll}1 & 2 & 3 & 4 & 5 & 6\end{array}$

$\begin{array}{lllllll}7 & 8 & 9 & 10 & 11 & 12 & 13\end{array}$

$\begin{array}{lllllll}14 & 15 & 16 & 17 & 18 & 19 & 20\end{array}$

$\begin{array}{lllllll}21 & 22 & 23 & 24 & 25 & 26 & 27\end{array}$

$\begin{array}{llll}28 & 29 & 30 & 31\end{array}$

Figure 8: Data Collection calendar 


\section{2 $\quad$ Statistical Tests}

\subsubsection{Statistical Approaches to Measuring Error}

Mean Absolute Error (MAE) [35]

The mean absolute error (MAE) gives a measure of the magnitude of error between two data sets without considering their direction. It's the average over the sample data set of the absolute differences between the observations of two data sets. However, the MAE does not indicate whether the estimates tend to be over-estimates or under-estimates. The MAE is defined as follows:

$$
M A E=\frac{1}{T} \sum_{i=1}^{t} \text { abs }\left(\text { Travel Speed }_{i}^{A}-\text { Travel Speed }_{i}^{B}\right)
$$

where $t$ is the number of observations.

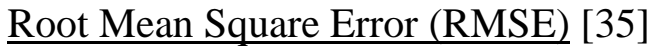

RMSE gives a measure of the average magnitude of error between two data sets. It is the square root of the average of the squared differences between two data set observations. Because squaring is a non-linear operation it weights outlier observations more heavily and gives a better indication of whether a data set contains outlier observations. RMSE is defined as:

$$
R M S E=\sqrt{\frac{1}{T} \sum_{i=1}^{t}\left(\text { Travel Speed }_{t}^{A}-\text { Travel Speed }_{t}^{B}\right)^{2}}
$$




\section{Correlation Coefficient, $\rho$}

The correlation coefficient, $\rho$, is the quantitative measure of correlation between datasets. $\rho=1$ is total positive correlation, 0 is no correlation, and -1 is total negative correlation.

$$
\begin{gathered}
\rho=\left(\frac{1}{\sigma_{A} * \sigma_{B} * T}\right) \sum\left(\text { Travel Speed }_{t}^{A}-\overline{\text { Travel Speed }_{t}^{A}}\right)\left(\text { Travel Speed }_{t}^{B}\right. \\
\left.-\overline{\text { Travel Speed }}{ }_{t}^{B}\right)
\end{gathered}
$$

where $\sigma_{A}$ and $\sigma_{B}$ are the standard deviations for each series.

\section{Theil's Inequality Coefficient, $U$ - Travel Time Difference [36]}

Theil's inequality coefficient is used to analyze the difference between two travel time sets. The value of $U$ will always fall between 0 and 1 . If $U=0$, all travel times are equal, a perfect match. If $U=1$, the differences are especially notable.

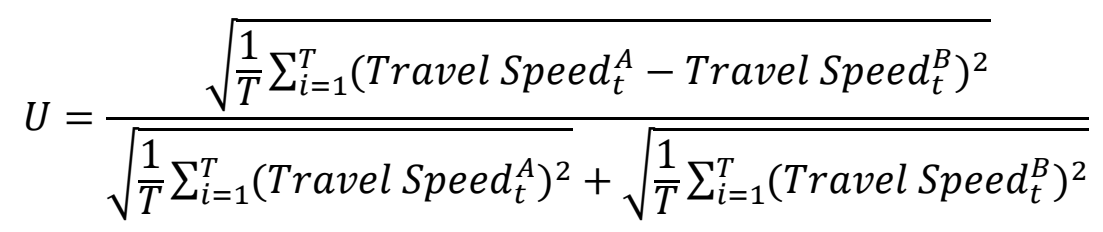

One useful property of the Theil inequality coefficient is that it can be decomposed into three components: bias, variance, and covariance proportions of $\mathrm{U}$.

\section{Bias Proportion, $U^{M}[36]$}

The bias proportion, $U^{M}$, is an indication of systematic error and it measures the extent to which the average values of the two travel time series deviate from each other. Whatever the value of the inequality coefficient $U$ is, it is best for $U^{M}$ to be close to zero. A large value of $U^{M}$ (above 0.2 ) would mean that a systematic bias is present. 


$$
U^{M}=\frac{\left(\overline{\text { Travel Speed }_{t}^{A}}-\overline{\text { Travel Speed }_{t}^{B}}\right)^{2}}{\left(\frac{1}{T}\right) \sum\left(\text { Travel Speed }_{t}^{A}-\text { Travel Speed }_{t}^{B}\right)^{2}}
$$

Variance Proportion, $U^{s}[36]$

The variance proportion, $\mathrm{U}^{\mathrm{S}}$, indicates the ability of the travel time estimation to replicate the degree of variability in the variable of interest. If $U^{s}$ is large, it means that one of the series has fluctuated considerably while the other series shows little fluctuation.

$$
U^{S}=\frac{\left(\sigma_{A}-\sigma_{B}\right)^{2}}{\left(\frac{1}{T}\right) \sum\left(\text { Travel Speed }_{t}^{A}-\text { Travel Speed }_{t}^{B}\right)^{2}}
$$

Covariance Proportion, $U^{c}[36]$

The covariance proportion, $U^{\mathbf{c}}$, measures unsystematic error. It represents the remaining error after deviations from average values have been accounted for. Since it is unreasonable to expect sources to be perfectly correlated with each other, this component of error is less worrisome than the previous two. The ideal distribution of inequality over the three sources is $U^{M}=U^{S}=0$ and $U^{c}=1$.

$$
U^{c}=\frac{2(1-\rho) \sigma_{A} \sigma_{B}}{\left(\frac{1}{T}\right) \sum\left(\text { Travel Speed }_{t}^{A}-\text { Travel Speed }_{t}^{B}\right)^{2}}
$$

\subsubsection{NPMRDS Speed Analysis}

Travel time data were collected for the 579 TMCs. Speed is then calculated as follows:

$$
\text { Speed }(m p h)=\frac{\text { TMC distance }(\text { miles })}{\text { travel time }(\text { seconds }) / 3600(\text { seconds } / \text { hour })}
$$


NPMRDS contains some irregular travel times corresponding to very low speeds and representing a very small fraction of the total number of observations. Hence, speeds less than $1 \mathrm{mph}$ were excluded.

Usually the $85^{\text {th }}$ percentile of speed is assumed to be the highest safe speed for a roadway section. This value is used in evaluating or recommending posted speed limits. It usually obtained from a spot speed study where a person in the field would collect speeds of free-flowing vehicles with a handheld radar. NPMRDS provides five-minute average travel times. Since this data is aggregated and there is no access to any other values such as a certain percentile, a measure of dispersion, or a vehicle count, the $85^{\text {th }}$ percentile speed is not identified and is replaced by the $80^{\text {th }}$ percentile speed. For each segment, the following statistics were calculated for all days from March 2014 to June 2016:

- $20^{\text {th }}$ percentile speed (speed value below which $20 \%$ of the observations may be found)

- $50^{\text {th }}$ percentile (median) speed

- $80^{\text {th }}$ percentile speed (speed value below which $80 \%$ of the observations may be found)

- Interquartile range (IQR, the difference between the third and first quartiles)

- Average speed

- Standard deviation

An additional parameter - the $20^{\text {th }}$ percentile speed - for speed distribution was calculated. The following two examples illustrate the usefulness of this parameter: first, if both the $80^{\text {th }}$ and $20^{\text {th }}$ percentile speed increase, which implies a systematic increase in speed; and 
second, if the $80^{\text {th }}$ increases, the median is unchanged, and the $20^{\text {th }}$ decreases, which implies increased dispersion.

\subsubsection{Non-Parametric Test: Mann-Whitney U Test}

A t-test is one of the most frequently used test in statistics. It is used to determine whether the mean of a population significantly differs from a specific value or from the mean of another population. In general, a t-test is ideal to use when each population in the dataset is normally distributed. If the data is not normally distributed, the Mann-Whitney-Wilcoxon $(\mathrm{MWW})$ - a non-parametric statistical hypothesis test - is used. In fact, when the data is normally distributed, the MWW test has an $86 \%$ of the power of the t-test. However, when the data is not normally distributed, the MWW test has a much larger power, sometimes up to infinity. Because normality assumption is not needed for the MWW test, it is more conservative to interpret its results, and, therefore, the test is less likely to draw the wrong conclusions. [37].

Mann-Whitney-Wilcoxon test is a nonparametric test of the null hypothesis that probability distributions are the same for two independent populations. In 1945, Wilcoxon proposed this test for two samples of equal sizes and in 1947, Mann and Whitney updated the test to handle unequal sample sizes as well as small samples. The MWW test is most useful for testing the equality of two population means and is an alternative to the two independent samples t-test when the assumption of normal population distributions is not satisfied [38]. The

null and alternative hypotheses for testing the differences between two mean speed measures, $\mu_{1}$ and $\mu_{2}$ for the Mann-Whitney $\mathrm{U}$ Test are: 
- Null Hypothesis $\left(\mathrm{H}_{0}\right)$ : The two sample distributions are drawn from the same population, or $\mathrm{H}_{0}: \mu_{1}-\mu_{2}=0$

- Alternative Hypothesis $\left(\mathrm{H}_{\mathrm{a}}\right)$ : The two sample distributions are drawn from two different populations, or $\mathrm{H}_{0}: \mu_{1}-\mu_{2} \neq 0$.

To obtain the test statistic, the two samples are combined, and all the observations are ranked from smallest to largest (ties are assigned the average rank of the tied observations). The smallest observation is indexed with 1 and the largest observation with $\mathrm{n}$. The $\mathrm{U}$ statistic is defined as follows:

$$
U=n_{1} n_{2}+\frac{n_{1}\left(n_{1}+1\right)}{2}-R_{1}
$$

where:

- $\quad R_{1}=$ sum of the ranks from sample 1 ;

- $\quad n_{1}=$ sample size of population 1

- $\quad n_{2}=$ sample size of population 2 .

The $\mathrm{U}$ statistic is a measure of the difference between the ranks of two samples. Based on the assumption that only mean differences exist between two populations, a large or small value of the test statistic provides evidence of a difference in the location of the two populations. For large samples, the distribution of the $U$ statistic is approximated by the normal distribution. The convergence to the normal distribution is rapid, such that for $n_{1} \geq 10$ and $n_{2} \geq 10$ there is a satisfactory normal approximation. The mean of $\mathrm{U}$ is given by:

$$
E(U)=\frac{n_{1} n_{2}}{2}
$$


The standard deviation of $\mathrm{U}$ is given by:

$$
\sigma_{U}=\sqrt{\frac{n_{1} n_{2}\left(n_{1}+n_{2}+1\right)}{12}}-R_{1}
$$

and the large sample test statistic is given by:

$$
Z^{*}=\frac{U-E(U)}{\sigma_{U}}
$$

The p-value associated with the Mann-Whitney U test is an indicator of the statistical significance of the posted speed limit increase in mean speed. A low p-value (i.e., less than or equal to 0.05) indicates a high probability that the difference in the posted speed limit influenced the mean speeds between two data collection periods. The $\mathrm{Z}^{*}$-statistic and p-value were computed for each TMC at the 95 percent confidence level [38].

\subsubsection{Statistical Hypothesis Test: F-test}

The two-sided F-test was used to determine if the differences in speed variance measures were statistically significant. Statistically significant changes in speed variance indicate that the observed speeds are different in the two-time periods being compared [38]. In this research, the null and alternative hypotheses for testing the differences in two variance speed measures, $\sigma_{1}^{2}$ and $\sigma_{2}^{2}$, are:

- Null Hypothesis $\left(\mathrm{H}_{0}\right)$ : No change in speed variance as a result of the 65 to $70 \mathrm{mph}$ posted speed limit increase, or $\mathrm{H}_{0}: \sigma_{1}^{2}-\sigma_{2}^{2}=0$

- Alternative Hypothesis $\left(\mathrm{H}_{\mathrm{a}}\right)$ : A change in speed variance as a result of the 65 to $70 \mathrm{mph}$ posted speed limit increase, or $\mathrm{H}_{\mathrm{a}}: \sigma_{1}^{2}-\sigma_{2}^{2} \neq 0$. 
For each TMC, an F-statistic was calculated between two data collection periods, before vs. after the increase in maximum PSL. The F-statistic is given by:

$$
F_{\left(n_{1}-1, n_{2}-1\right)}=\frac{s_{1}^{2}}{s_{2}^{2}}
$$

where:

- $\quad s_{1}, s_{2}=$ standard deviation of the samples for the before and after periods;

- $n_{1}, n_{2}=$ sample size of before and after periods.

The p-value associated with the F-statistic is an indicator of the statistical significance of the posted speed limit increase on mean speed. A low p-value (i.e., less than or equal to 0.05) indicates a high probability that the difference in the posted speed limit influenced the speed variance between two data collection periods. F-statistic and p-value were computed for each TMC at the 95 percent confidence level. 


\section{DATA ANALYSIS}

\subsection{Impact of Posted Speed Limit Increase on Traveling Speed}

\subsubsection{VSPOC and NPMRDS Comparisons}

First, VSPOC speeds are compared to NPMRDS for validity. Previous experience comparing travel times or speeds from various data collection methods indicate that probe sources are closely representative of ground truth given sufficient traffic volumes and sampling. Furthermore, GPS-probe sources are more internally consistent since they are not subject to differences in field hardware setup, poor calibration, or undocumented recalibration. Comparing the two data sets had a purpose of validating this understanding and checking for spatial discrepancies.

TMCs which had both NPMRDS data and VSPOC detectors available were used to compare NPMRDS and VSPOC data. Three trends were identified after calculating the error statistics and the Theil proportions:

\section{a. Good Match}

Figure 9 shows an example of a good match between VSPOC and NPMRDS speed data. In this specific example, slower speeds often relate to Sunday afternoon congestion. This fit can also be found by noting the low value of $U . U^{M}$ (bias) is also low indicating that both series do not deviate much from each other.

\begin{tabular}{ccccccc}
\hline MAE & RMSE & $\mathrm{U}$ & $\mathrm{U}^{\mathrm{M}}$ & $\mathrm{U}^{\mathrm{S}}$ & $\mathrm{UC}^{\mathrm{C}}$ & SUM \\
\hline 0.5260 & \multirow{2}{*}{3.9316} & 0.0306 & 0.0179 & 0.0138 & 0.9377 & 1.0000 \\
\hline
\end{tabular}




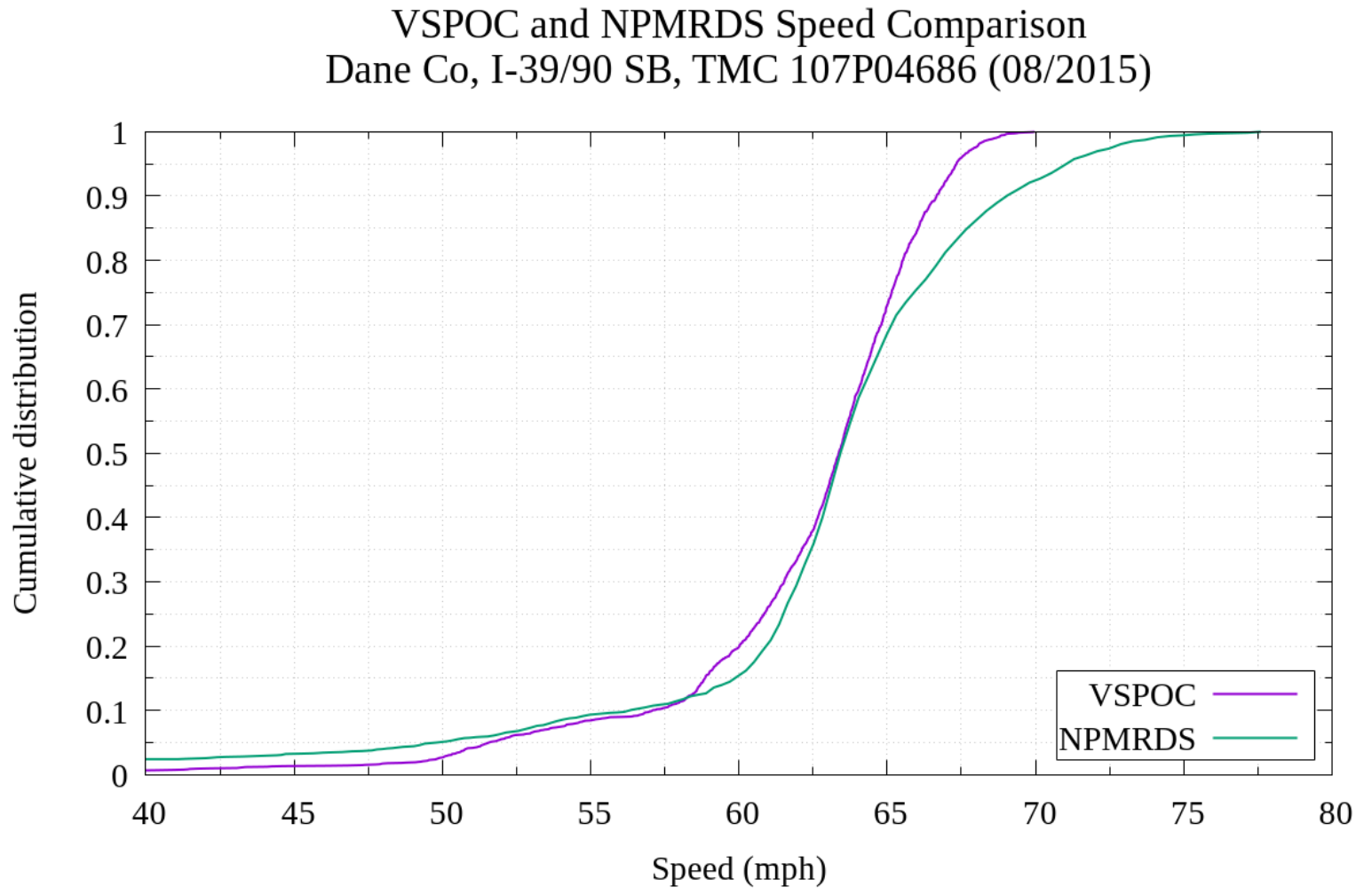

Figure 9: Good Match Between VSPOC and NPMRDS Speed

b. With Bias

Figure 10 shows an example of a clear bias in the distribution between VSPOC and NPMRDS speed data. Although $\mathrm{U}$ remains relatively low, MAE is higher, and $\mathrm{U}^{\mathrm{M}}$ is quite high, indicating that both series deviate from each other to a significant extent, hence a notable bias is present. This bias might be due to loop miscalibration, which is common and can have severe effects. In this case, observing the close agreement between data sources at the same location in the opposite direction suggests equipment calibration issues.

\begin{tabular}{ccccccc}
\hline MAE & RMSE & $\mathrm{U}$ & $\mathrm{U}^{\mathrm{M}}$ & $\mathrm{U}^{\mathrm{S}}$ & $\mathrm{U}^{\mathrm{C}}$ & SUM \\
\hline 7.3980 & 8.4424 & 0.0621 & 0.7679 & 0.0037 & 0.1664 & 1.0000 \\
\hline
\end{tabular}


VSPOC and NPMRDS Speed Comparison

Rock Co, I-39/90 NB, TMC 107P05602 (03/2015)

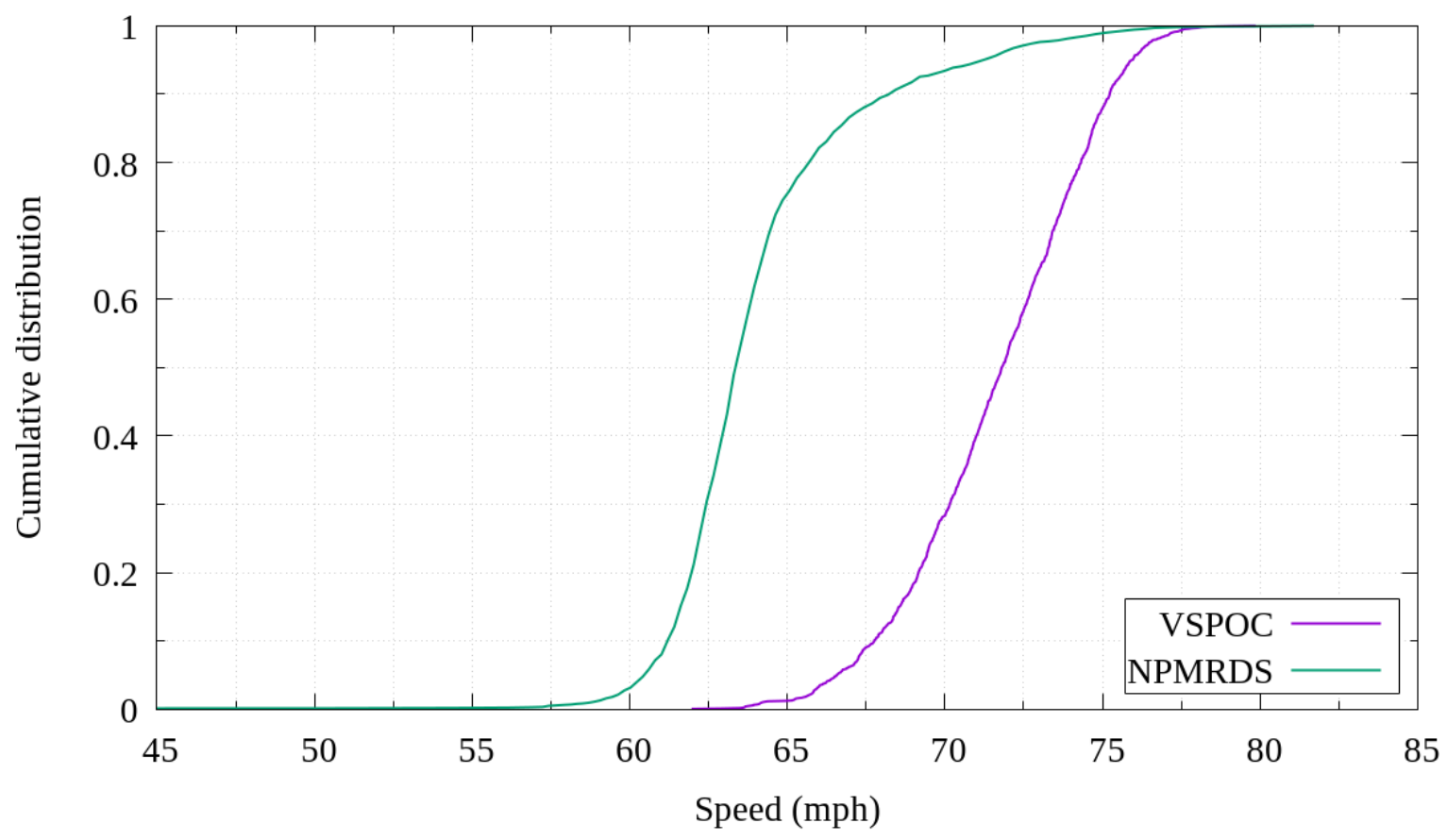

Figure 10: Bias Between VSPOPC and NPMRDS Speed

c. Moderate Match

Figure 11 shows an example of these data on a day with a major crash and lane closures, hence the slow speed values. It also shows some bias between VSPOC and NPMRDS speed data. VSPOC speeds trend slightly higher than those of NPMRDS, but the statistics indicate that they are in moderately close agreement.

\begin{tabular}{ccccccc}
\hline MAE & RMSE & U & $U^{M}$ & $U^{S}$ & $U^{C}$ & SUM \\
\hline 4.2622 & 10.6866 & 0.0850 & 0.1591 & 0.1294 & 0.6266 & 1.0000 \\
\hline
\end{tabular}




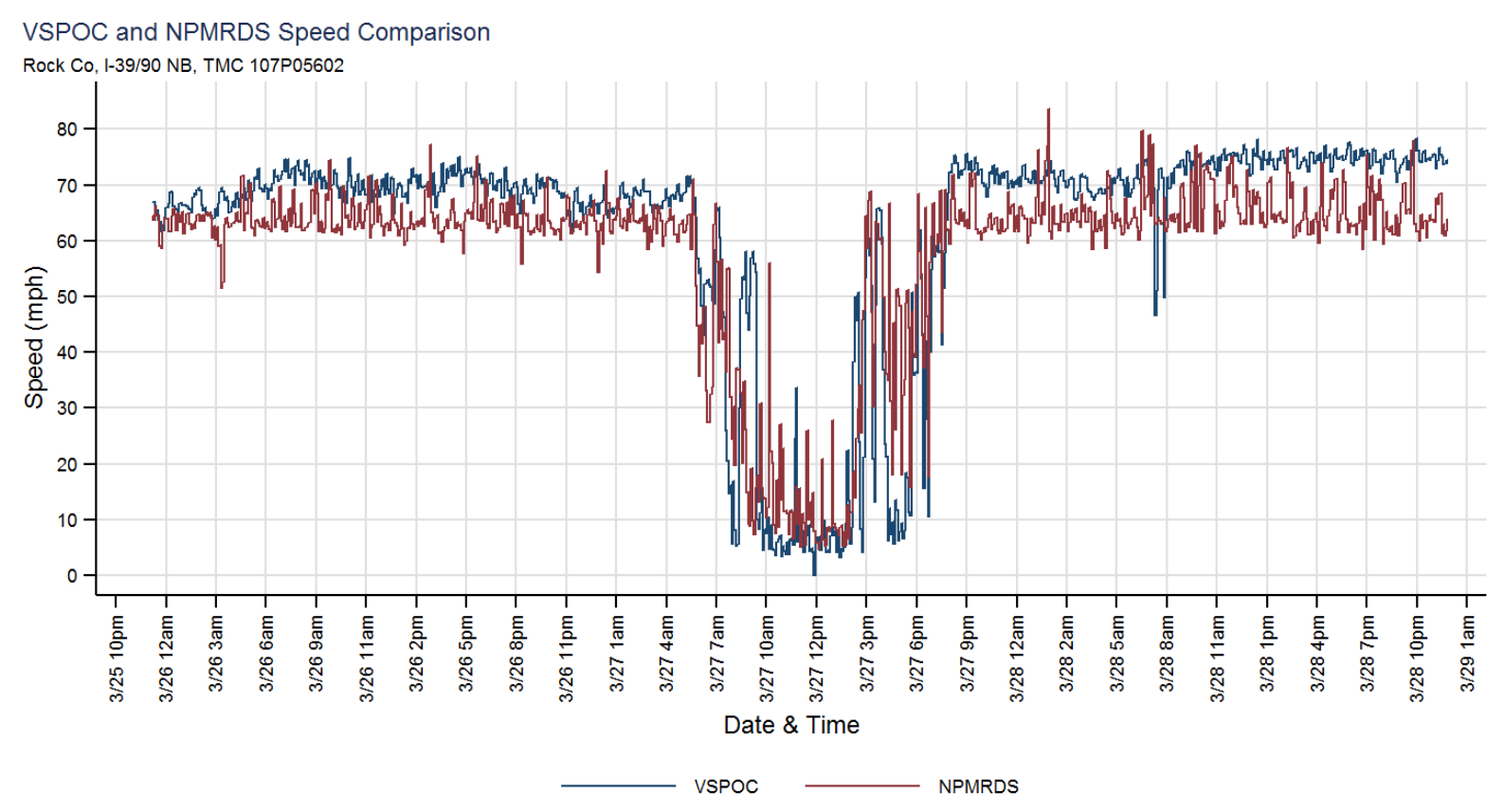

Figure 11: Moderate Match Between VSPOPC and NPMRDS Speed

Table 4 summarizes the range for each statistic conducted to compare VSPOC and NPMRDS data. $U$ and $\mathrm{U}^{\mathrm{M}}$ are the two most important statistics since they predict validity between both data sources.

Table 4: VSPOC and NPMRDS Comparison Statics

\begin{tabular}{lrrr}
\hline & Min & Median & Max \\
\hline MAE & 0.38 & 4.80 & 34.94 \\
\hline RMSE & 8.11 & 16.35 & 48.76 \\
\hline$U$ & 0.060 & 0.133 & 0.448 \\
\hline$U^{M}$ & $<0.001$ & 0.076 & 0.811 \\
\hline$U^{S}$ & $<0.001$ & 0.267 & 0.638 \\
\hline$U^{C}$ & 0.019 & 0.489 & 0.839 \\
\hline & & & $N=43$
\end{tabular}

A good match between VSPOC and NPMRDS data was found for 79.7\% of the segments with a bias proportion $\mathrm{U}^{\mathrm{M}}$ less than 0.2 , which was also noted with the low $\mathrm{U}$ (less than 0.2 ) for $72.1 \%$ of the segments. Since VSPOC coverage alone is much more limited, this research 
proceeds with utilizing the widespread NPMRDS data, but with the understanding of its differences and limitations.

\subsubsection{NPMRDS Speed Analysis}

For the 455 TMCs with increased PSL, a summary of statistics for the period of March 2014 to June 2016 is shown in Table 5.

Table 5: Summary Statistics

\begin{tabular}{lrrrr}
\hline Variable & Mean & Std. Dev. & Min & Max \\
\hline Distance (miles) & 3.27 & 2.53 & 0.10 & 13.66 \\
\hline $20^{\text {th }}$ Percentile Speed (mph) & 60.66 & 2.73 & 32.44 & 67.62 \\
\hline $50^{\text {th }}$ Percentile Speed (mph) & 63.60 & 2.17 & 45.06 & 77.52 \\
\hline $80^{\text {th }}$ Percentile Speed (mph) & 67.09 & 2.54 & 54.48 & 77.89 \\
\hline Interquartile Range (mph) & 4.99 & 1.73 & 0 & 24.96 \\
\hline Average Speed (mph) & 63.63 & 2.47 & 44.88 & 71.10 \\
\hline Standard Deviation (mph) & 5.20 & 1.38 & 2.14 & 15.81 \\
\hline
\end{tabular}

Figure 12 shows a scatterplot of the 579 TMCs under study. An increase of $5 \mathrm{mph}$ in the PSL did not lead to an increase of $5 \mathrm{mph}$ in the average traveling speed. The largest change in speed magnitudes is attributed to work zones effects rather than the increased PSL. Segments with increased PSL had a change in the of 1-3 mph range, while the remaining segments (Milwaukee area) had slight increase in the 0-1 mph range. 


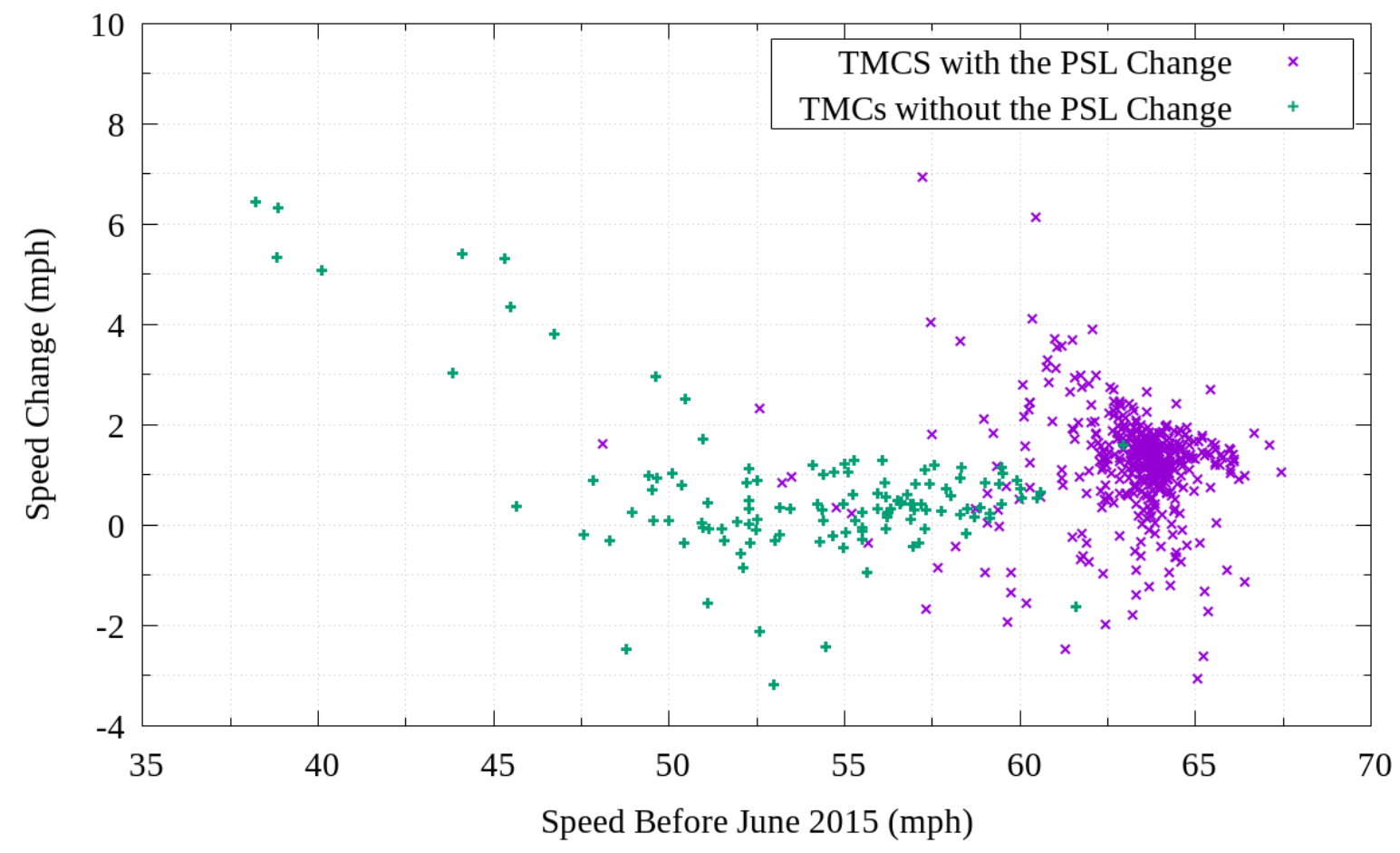

Figure 12: Before/After Speed Plot of All Segments

For segments with PSL change, the mean speed increased between 0.8 and $2.8 \mathrm{mph}$ for all vehicles in the study sample, while that of TMCs without a PSL change (Milwaukee area) increased on average by $0.8 \mathrm{mph}$. For segments with PSL change, the average standard deviation was $5.25 \mathrm{mph}$, while that of TMCs without a PSL change was $5.82 \mathrm{mph}$. The Metrics for a typical segment are shown month by month in Figure 13. A small increase in most metrics is evident after the increase of PSL, indicated by the gray vertical bar. 


\section{Effect of Change in Posted Speed Limit} Jefferson Co, I-94 WB, TMC 107P05407

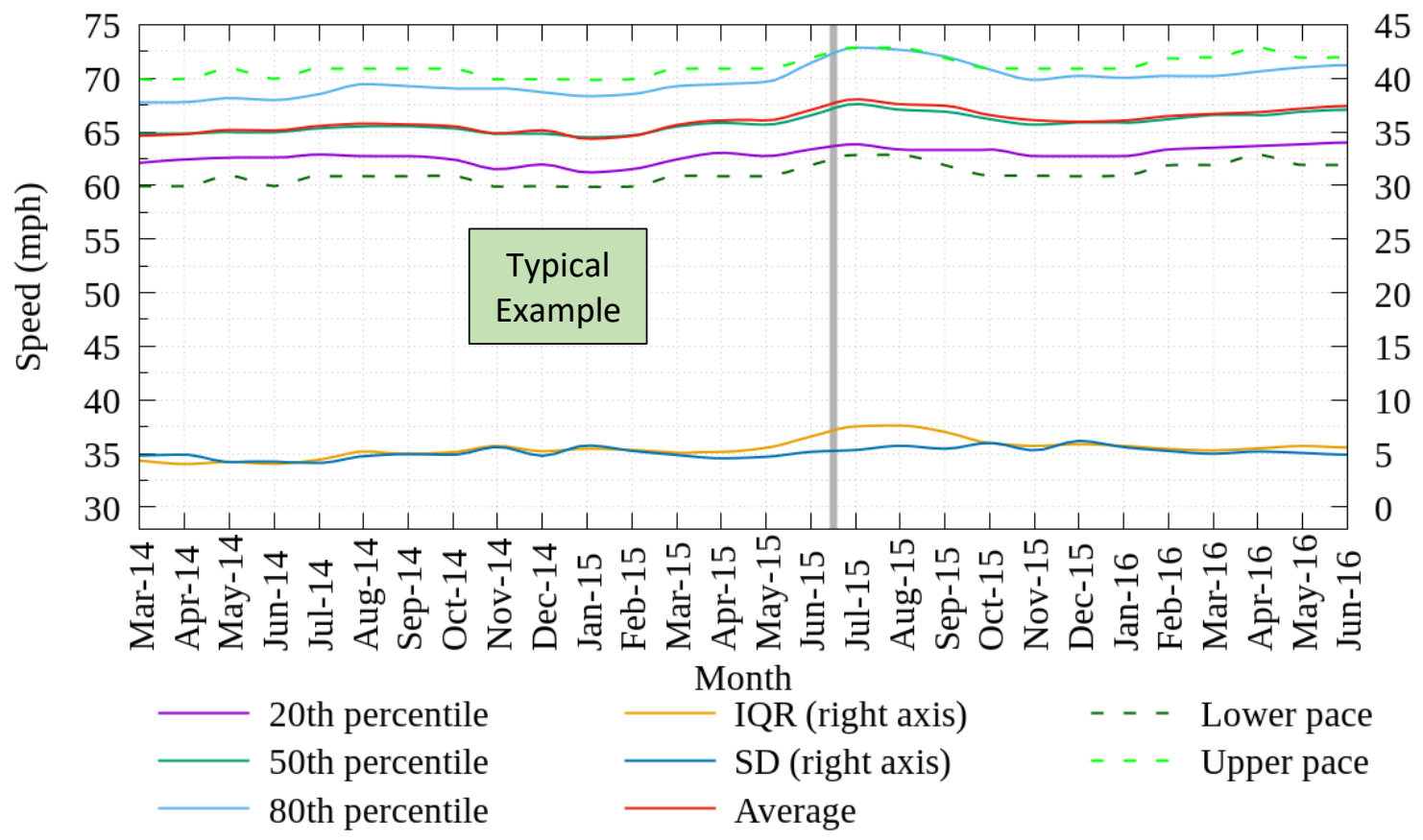

Figure 13: Typical Example of Metrics for a Segment

Some segments showed a seasonal cyclical pattern in speed distributions. A cumulative distribution function (CDF) was plotted to depict this variation. Figure 14 shows an example of seasonal variation which shows slower speeds in winter and higher speeds in summer. To control for the seasonal effects (along with weather effect), the analysis was conducted for the same 11-month period before (July 2014 - May 2015) and after (July 2015 - May 2016) the increase of the PSL. 
Speed Distribution

Columbia County, TMC 107N053093 (Jan-Dec/2015)

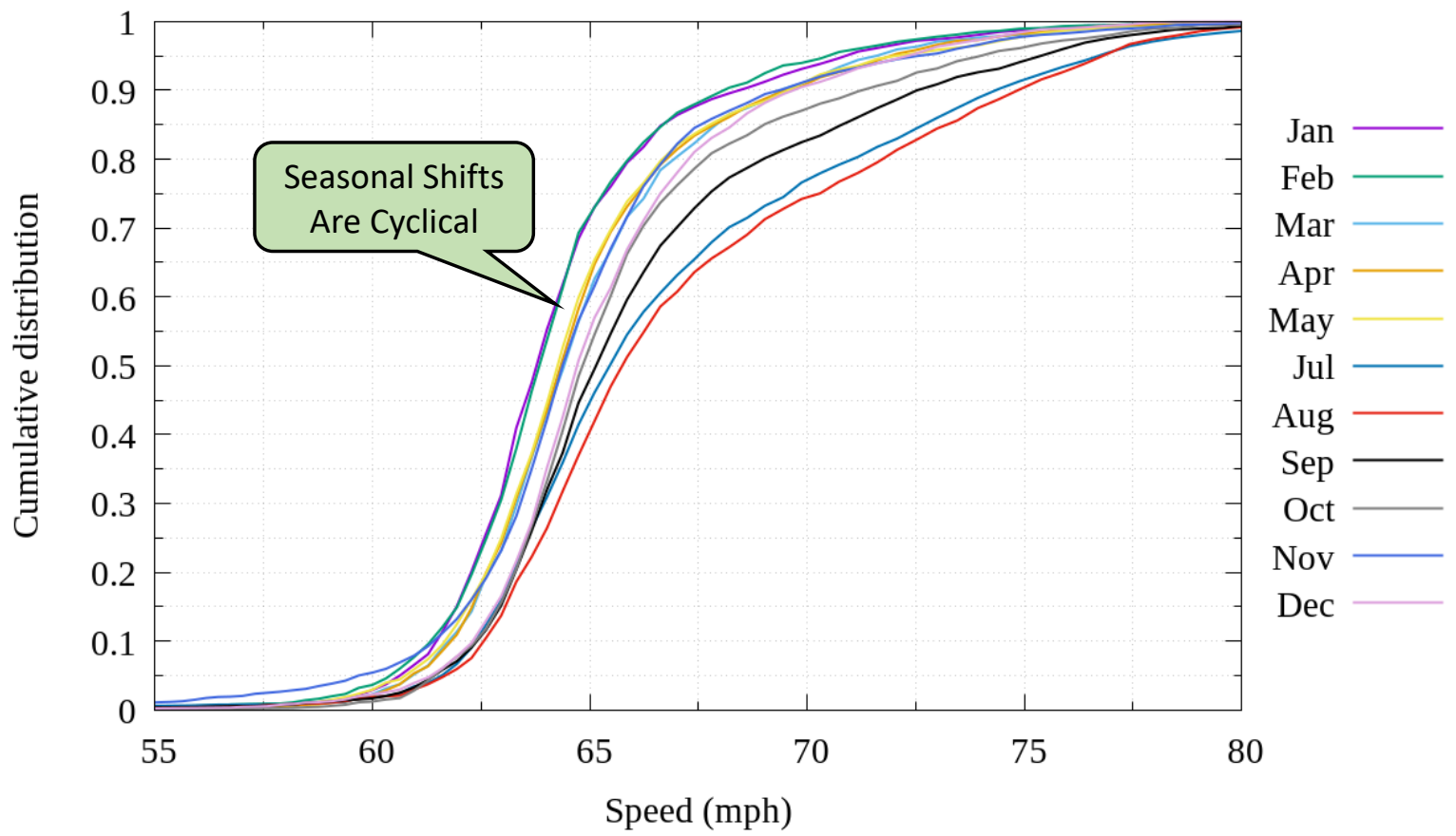

Figure 14: Example of Seasonal Variation in Passenger Vehicle Speeds

In addition to seasonal variation, the effects of work zones were identified for some segments. Figure 15 shows an example of a segment with work zone effects. 


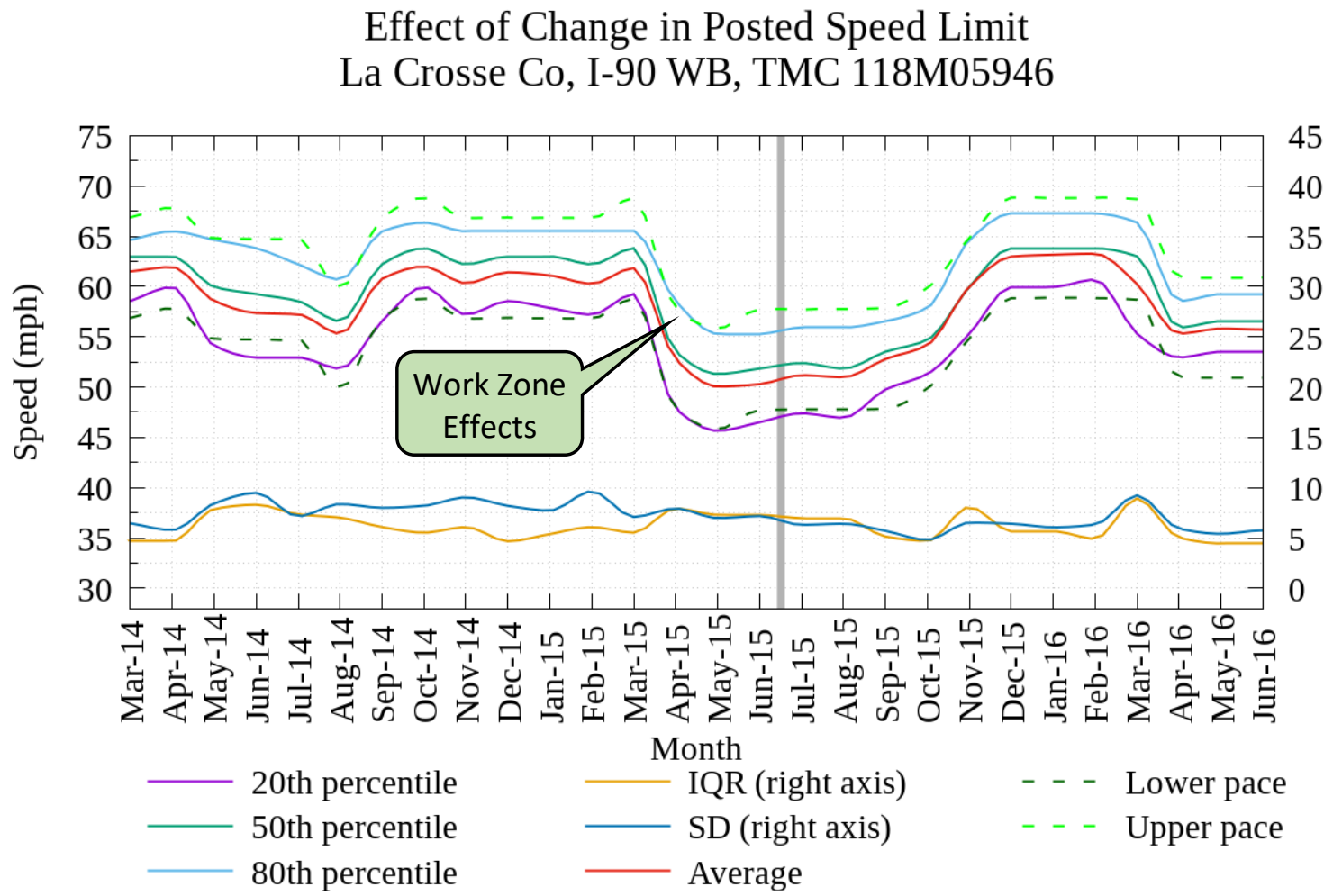

Figure 15: Example Segment with Work Zone Effects

Some segments were clearly affected by work zones while others were not. This research did not verify locations of work zones through the lane closure records, and hence did not look at their effect on operating speed. Instead, an additional parameter was calculated: the shift from the monthly median speed observations. For each segment, the maximum shift in median speed over the months of data observed is identified. Figure 16 shows the maximum shift of speed for all 579 TMCs, of which $22.8 \%$ had a shift greater than $2.5 \mathrm{mph}$. For the comparison TMCs, $25.8 \%$ had a shift greater than $2.5 \mathrm{mph}$, while $22.0 \%$ of the TMCs with increased PSL had a shift greater than $2.5 \mathrm{mph}$. This $2.5 \mathrm{mph}$ threshold is carried forward in subsequent plots. 


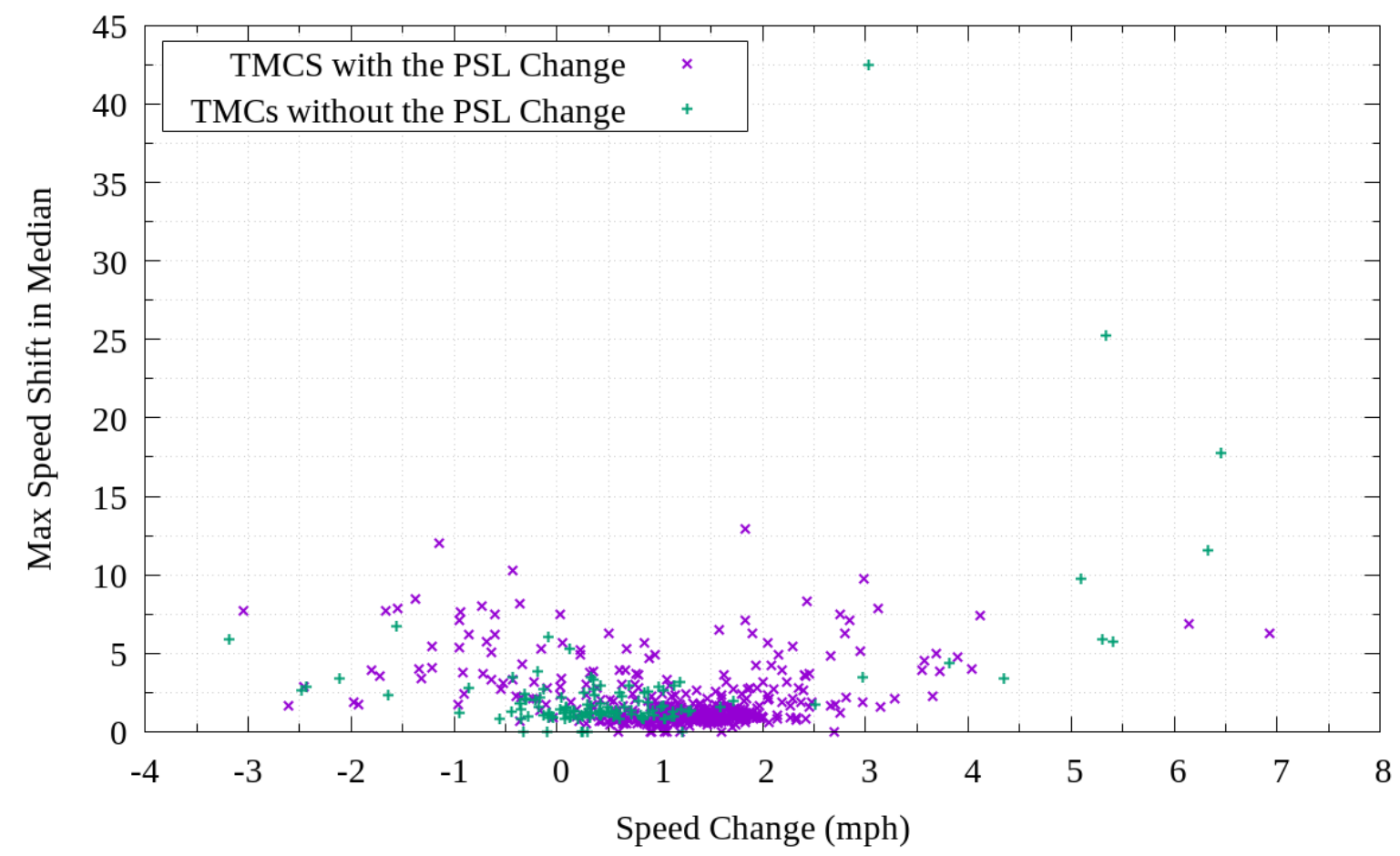

Figure 16: Maximum Speed Shift for Each TMC

\subsubsection{Non-Parametric Test: Mann-Whitney U Test (MWW test)}

Figure 17 shows the p-values obtained from the MWW test conducted for each TMC at the two periods: before and after increasing the PSL. 


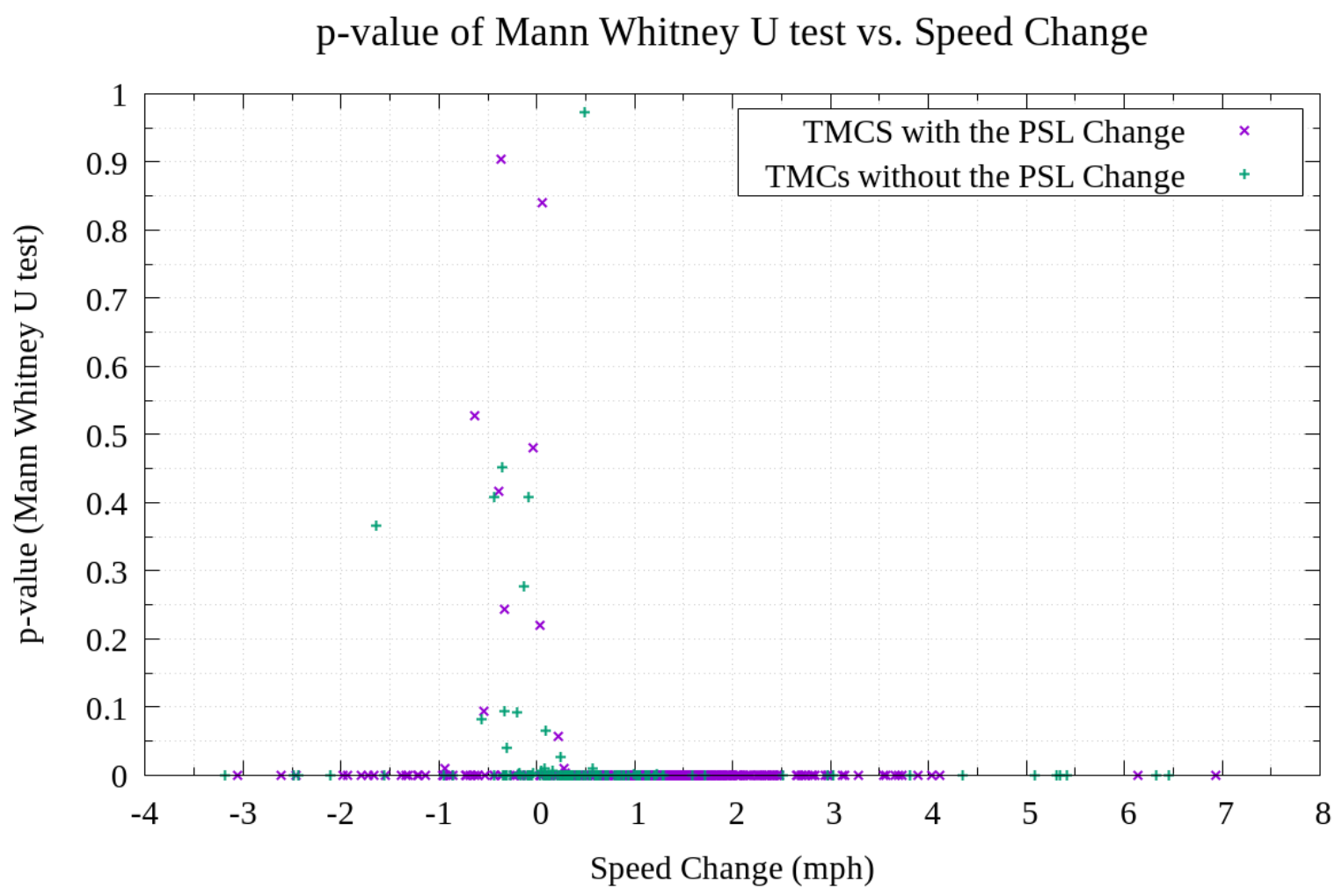

Figure 17: P-value (of Mann-Whitney U Test) for Each TMC's Speed Change

Figure 18 shows the p-values obtained from the MWW test conducted for the comparison TMCs at the two periods: before and after increasing the PSL. For a very small number of TMCs (10 of the 124 TMCs), the null hypothesis is retained (p-value > 0.05), which means there is not enough evidence from the current sample of speeds to indicate that the mean speed differs between the before and after periods. For the rest of the TMCs, the null hypothesis is rejected (p-value $<0.05)$. Segments with greater values of shift are the more likely work zone effects, particularly the large negative changes in speed. 


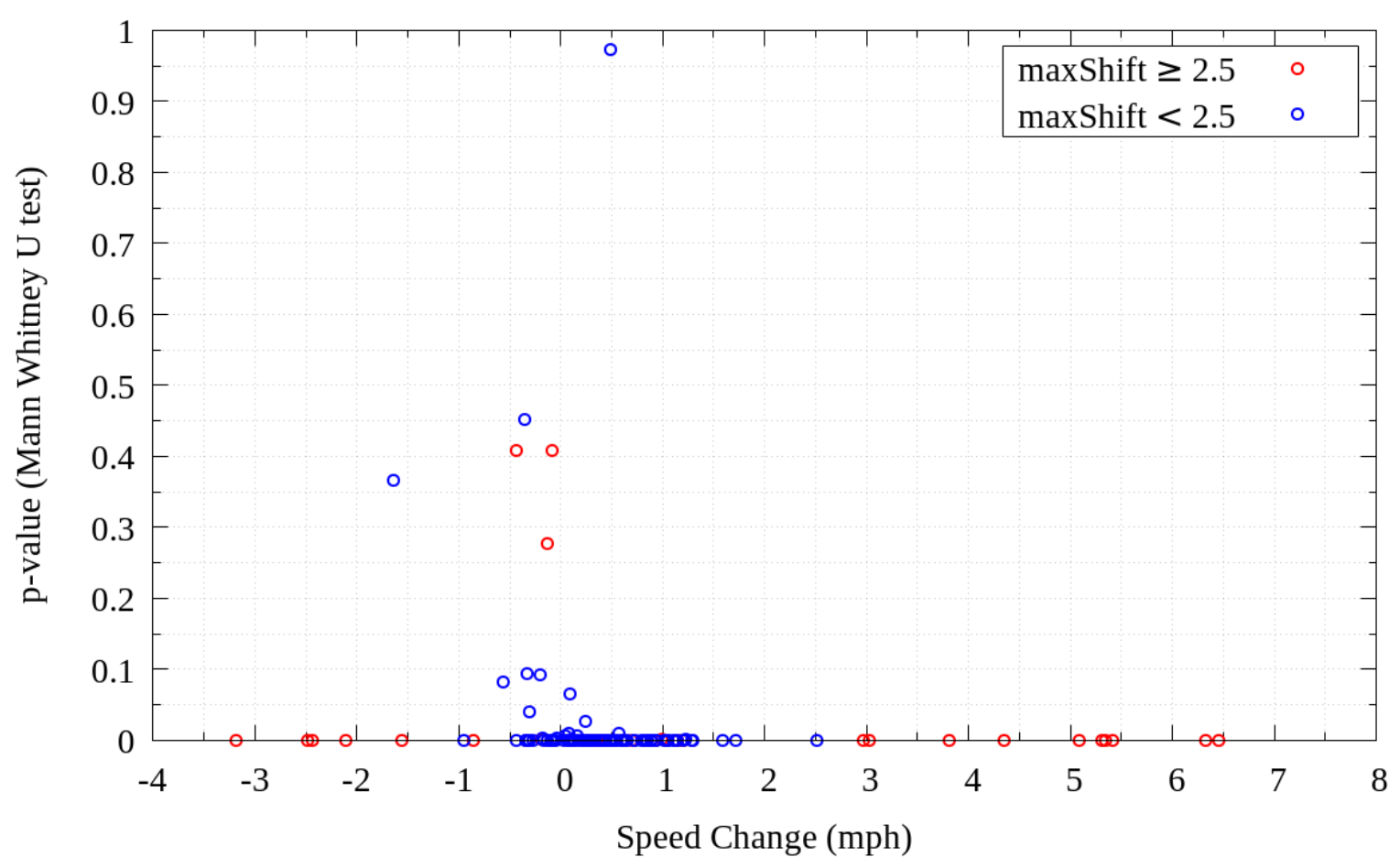

Figure 18: Comparison TMCs MWW test Results

Figure 19 shows the p-values obtained from the MWW test conducted for the 455 TMCs with an increase in the PSL between the two 11-month periods. For a very small number of TMCs ( 9 of the 455 TMCs), the null hypothesis is retained (p-value > 0.05), which means there is insufficient evidence from the current sample of speeds to indicate that the speed mean differs between the before and after periods. For the rest of the TMCs, the null hypothesis is rejected ( $\mathrm{p}$-value $<0.05$ ), which means there is sufficient evidence from the sample to indicate that the speeds differ, and that a speed comparison is statistically significant at the 95 percent confidence level. This difference is reasonably attributed to the increase in posted speed limit from 65 to $70 \mathrm{mph}$ when comparing the before and after periods, which could mean that drivers are adapting to the new posted speed. For segments with increased posted speed limit from 65 to $70 \mathrm{mph}$, the mean speed increased between 0.8 and $2.8 \mathrm{mph}$ for all vehicles in the study 
sample. For the comparison area (Milwaukee area), the mean speed increased on average by $0.8 \mathrm{mph}$.

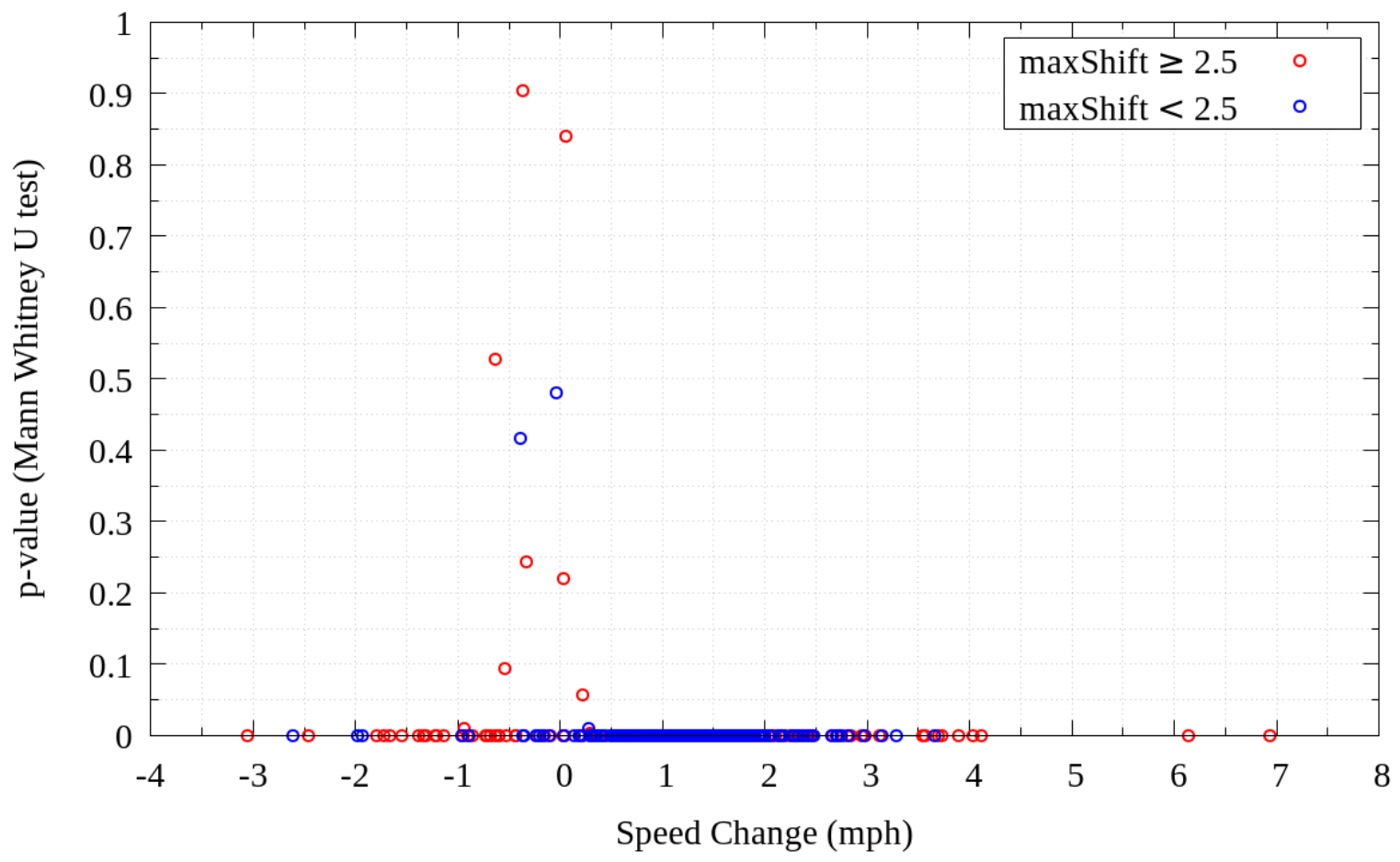

Figure 19: P-value (of t-test) for each TMC's Speed Change

$21 \%$ of TMCs with statistically significant mean difference had a maximum shift greater than $2.5 \mathrm{mph}$. Most TMCs with maximum shift greater than $2.5 \mathrm{mph}$ had a noticeable work zone effect. Hence, the statistically significant mean difference may either be attributed to the work zone effects or to the increase in the posted speed limit.

\subsubsection{Statistical Hypothesis Test: F-test}

Figure 20 shows the p-values obtained from the F-test conducted for each TMC at the two periods: before and after increasing the PSL. For a very small number of TMCs, the null hypothesis is retained ( $\mathrm{p}$-value $>0.05$ ), which means there is not enough evidence from the current sample of speeds to indicate that the variance speed differs between the before and 
after periods. for the rest of the TMCs, the null hypothesis is rejected (p-value $<0.05$ ), which means there is enough evidence from the sample to indicate that the variance speed differs, and a speed comparison is statistically significant at the $95 \%$ confidence level.

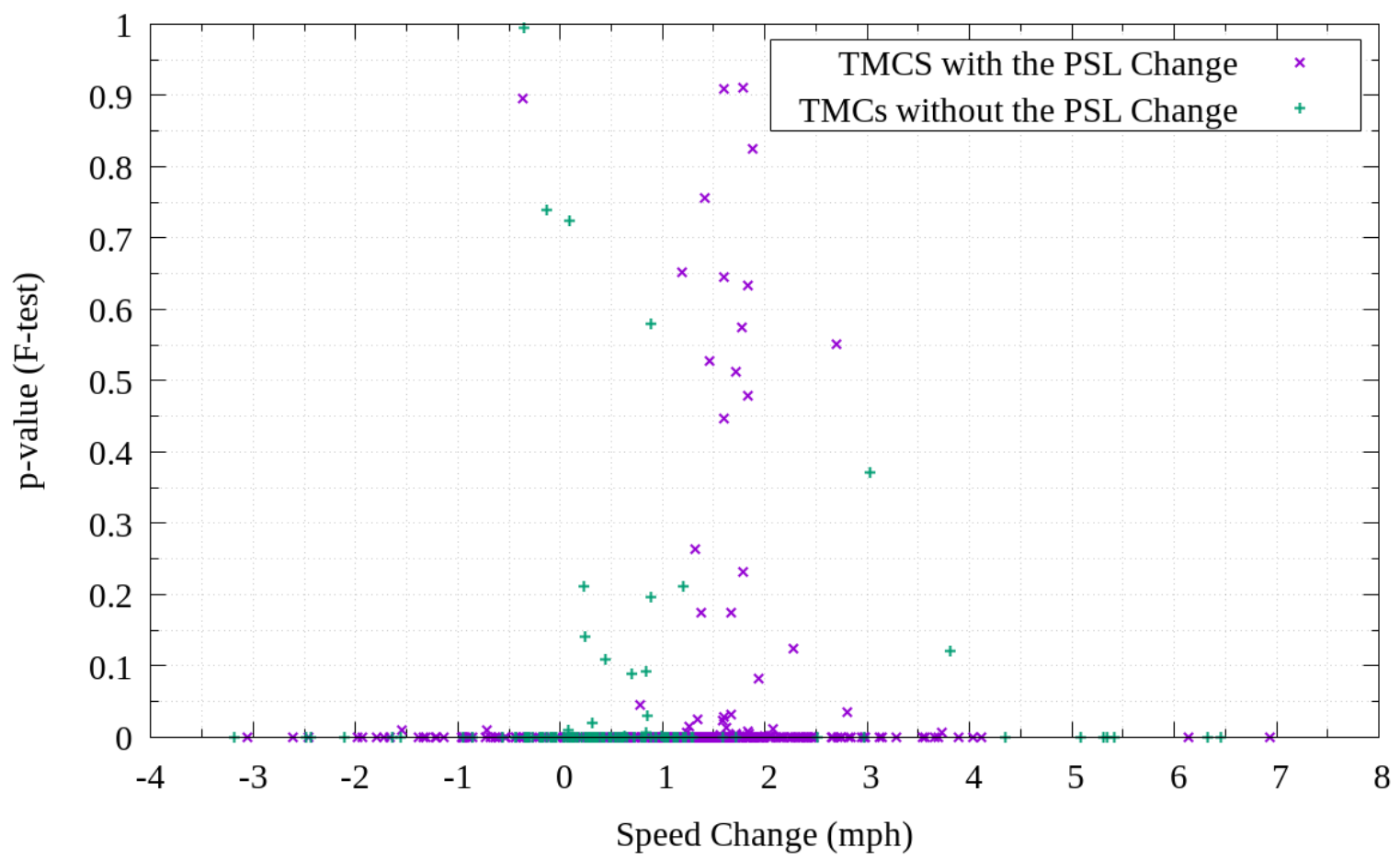

Figure 20: P-value (of F-test) for Each TMC's Speed Change

\subsection{Impact of Posted Speed Limit Increase on Safety}

One method to investigate the effects of increasing speed on safety impacts is a before and after study using crash rates (the combination of crash frequency and traffic volumes). Several segments had missing volume data in VSPOC or no data at all, which did not allow the computation of crash rates. For this reason, safety impact of raising the speed limit was investigated with a before and after study using crash frequency. Appendix 7.1 to 7.8 show the data used to analyze the crash data for the before and after period. 
Each section in the appendix also shows a box plot that summarizes the data for each segment. For each segment identified in Table 3, a summary of statistics for the before and after periods is shown in Table 6.

Table 6: Summary Statistics for Crash Data

\begin{tabular}{|c|c|c|c|c|c|c|c|}
\hline $\begin{array}{c}\text { Segment (year } \\
\text { included) }\end{array}$ & $\begin{array}{c}\text { Sample size } \\
\text { (Before) }\end{array}$ & $\begin{array}{c}\text { Monthly } \\
\text { Average } \\
\text { Crashes } \\
\text { (Before) }\end{array}$ & $\begin{array}{c}\text { Sampl } \\
\text { e Size } \\
\text { (After) }\end{array}$ & $\begin{array}{c}\text { Monthly } \\
\text { Average } \\
\text { Crashes } \\
\text { (After) }\end{array}$ & $\begin{array}{c}\text { Mann } \\
\text { Whitney } \\
\text { U test }\end{array}$ & p-value & $\begin{array}{c}\text { Statisticall } \\
\mathbf{y} \\
\text { Significan } \\
\text { t } \\
\text { Differenc } \\
\text { e? }\end{array}$ \\
\hline I-39/90 (2016) & 125 & 86.032 & 18 & 116.7222 & 423 & $1.95 E-05$ & yes \\
\hline I-39-90 (2017) & 125 & 86.032 & 27 & 112.6667 & 704 & $2.14 \mathrm{E}-06$ & yes \\
\hline I-41 (2016) & 125 & 105.944 & 18 & 94.55556 & 1093 & 0.84794026 & no \\
\hline I-41 (2017) & 125 & 105.944 & 27 & 100.037 & 1492 & 0.347103098 & no \\
\hline I-43 (2016) & 125 & 51.624 & 18 & 58.11111 & 729.5 & 0.016176986 & yes \\
\hline I-43 (2017) & 125 & 51.624 & 27 & 56 & 1150 & 0.009606415 & yes \\
\hline I-43M (2016) & 125 & 58.424 & 18 & 60.72222 & 866 & 0.115546903 & no \\
\hline I-43M (2017) & 125 & 58.424 & 27 & 58.14815 & 1479 & 0.315836515 & no \\
\hline I-535 (2016) & 125 & 1.568 & 18 & 1.833333 & 1001 & 0.435899086 & no \\
\hline I-535 (2017) & 125 & 1.568 & 27 & 1.814815 & 1426 & 0.192794446 & no \\
\hline I-794 (2016) & 125 & 0.448 & 18 & 0.833333 & 819 & 0.028648972 & yes \\
\hline I-794 (2017) & 125 & 0.448 & 27 & 0.851852 & 1148.5 & 0.002630548 & yes \\
\hline I-894 (2016) & 125 & 22.312 & 18 & 0.222222 & 2239 & $1.16 \mathrm{E}-11$ & yes \\
\hline I-90 (2016) & 125 & 15.136 & 18 & 10.77778 & 1313 & 0.25311944 & no \\
\hline I-90 (2017) & 125 & 15.136 & 27 & 11.07407 & 1870 & 0.379539648 & no \\
\hline I-94 (2016) & 125 & 105.168 & 18 & 107.1667 & 854 & 0.099661318 & no \\
\hline I-94 (2017) & 125 & 105.168 & 27 & 101.9259 & 1395 & 0.159172482 & no \\
\hline I-94M (2016) & 125 & 7.592 & 7 & 1.571429 & 819 & 0.000101565 & yes \\
\hline
\end{tabular}

Figure 21 shows the difference in the average crashes for the before and after periods. Segments with small differences in the number of monthly average crashes are those that have no statistically significant difference between the before and after periods. 


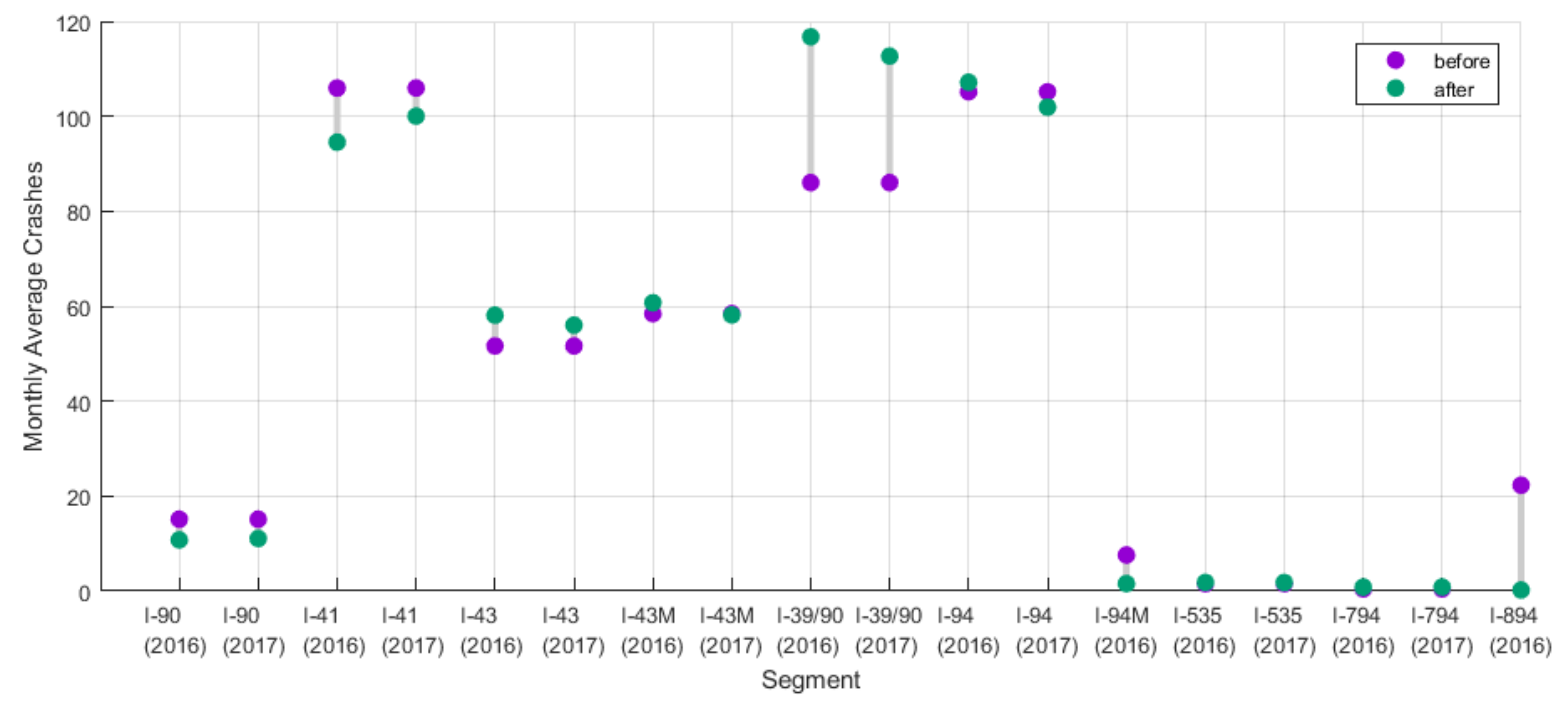

Figure 21: Monthly average Crashes for the Before and After Speed Limit Increase periods

Figure 22 shows the p-values obtained from the MWW test conducted for the monthly crash data at the two periods: before and after increasing the PSL, using 2016 data for the after period. For $50 \%$ of the segments, the null hypothesis is retained (p-value $>0.05)$, which means there is not enough evidence from the current sample of crash data to indicate that the number of crashes differ between the before and after periods. For the other half of the segments, the null hypothesis is rejected ( $\mathrm{p}$-value $<0.05$ ). 


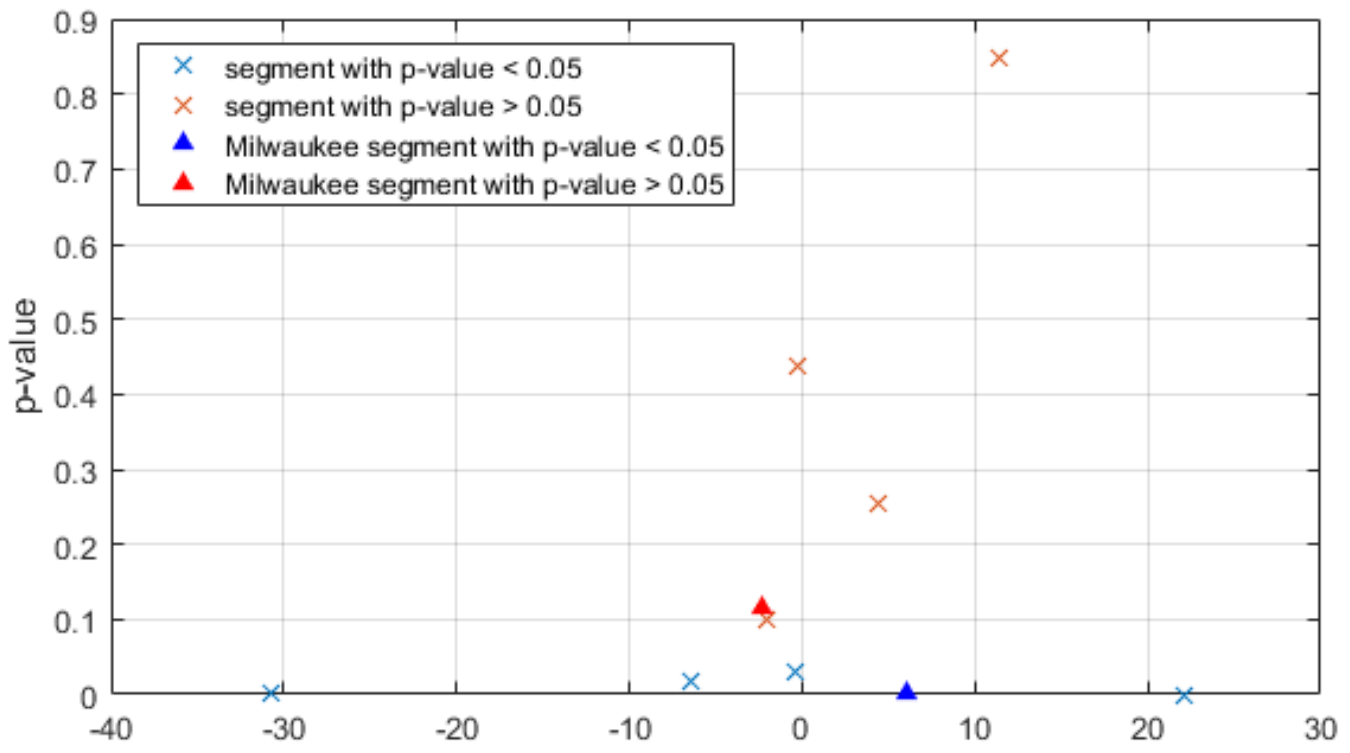

Figure 22: Monthly average Crashes Difference Between Before and After Speed Limit Increase using 2016 Data

Figure 23 shows the p-values obtained from the MWW test conducted for the monthly crash data at the two periods: before and after increasing the PSL, using the preliminary 2017 data in addition to 2016 data. For $62.5 \%$ of the segments, the null hypothesis is retained (pvalue $>0.05$ ), which means there is not enough evidence from the current sample of crash data to indicate that the number of crashes differ between the before and after periods. for the remaining $37.5 \%$ of segments, the null hypothesis is rejected (p-value < 0.05 ). 


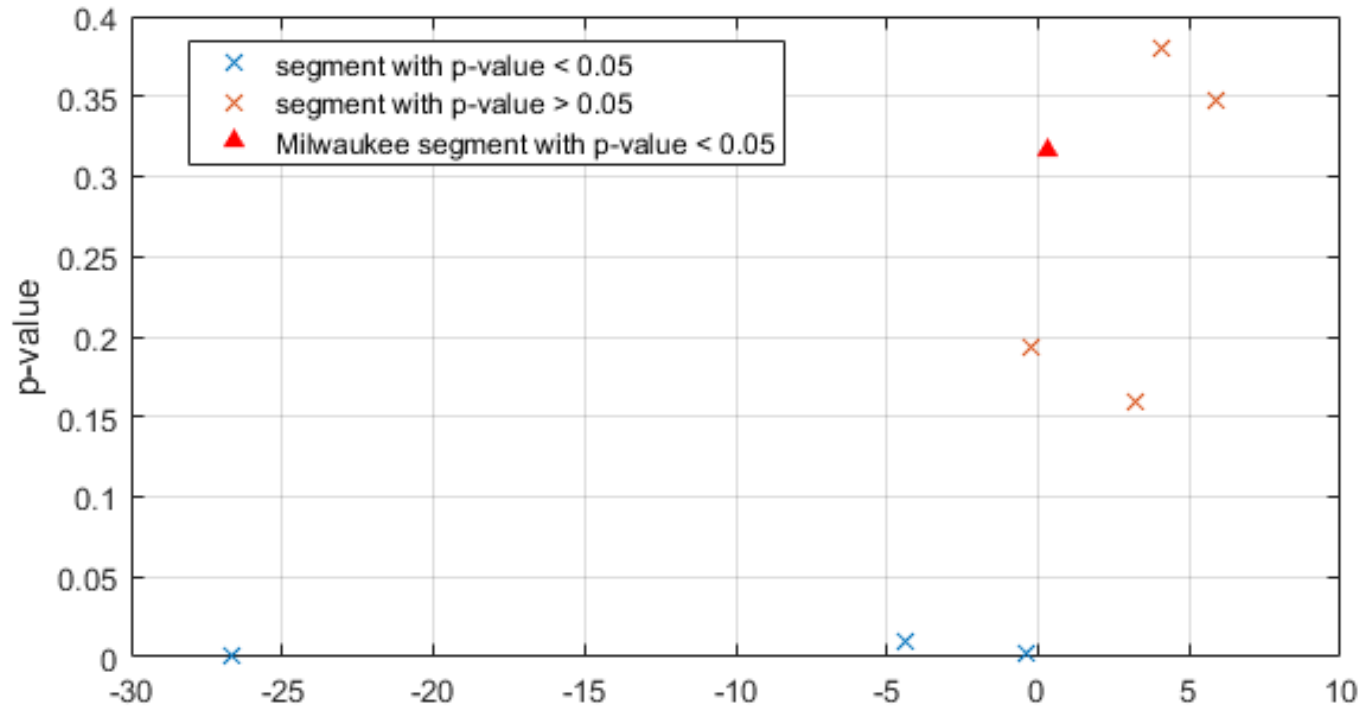

Figure 23: Monthly average Crashes Difference Between Before and After Speed Limit Increase using 2017 Data 


\section{CONCLUSION}

During the week of June 16, 2015, the posted speed limit on most of the Interstate system in Wisconsin was increased from 65 to $70 \mathrm{mph}$. Segments in the Milwaukee area (I-794, I-984, I-94 and I-43) as well as I-535 were excluded from this increase.

For segments with PSL change, the mean speed of all vehicles in the study sample increased between 0.8 and $2.8 \mathrm{mph}$, while that of TMCs without a PSL change (Milwaukee area) increased on average by $0.8 \mathrm{mph}$. These values are consistent with the literature review in chapter 2 .

Generally, the NPMRDS were valid compared to the VSPOC data. They were more consistent along interstates. Where a bias was present, it could likely be attributable to detector calibration. Seasonal effects were present in many segments. Seasonal trends were mitigated by using isochronal 11-month periods before and after the PSL. More pronounced work zone effects existed in several segments. Probable work zones were flagged by using a 2.5 or 5.0 mph threshold in the month to month median speed shift observed in the data, and indicated on graphics as such.

For TMCs with and without a PSL change, the Mann-Whitney U Test was conducted. Most TMCs for both cases had a p-value less than 0.05, meaning that enough evidence exists from the sample to indicate that the speeds differ, and that a speed comparison is statistically significant at the 95 percent confidence level. $21 \%$ of TMCs with statistically significant mean difference had a maximum median shift greater than $2.5 \mathrm{mph}$. These TMCs had a noticeable 
work zone effect. Hence, the statistically significant mean difference may be attributed to the work zone effect or to the increase in the posted speed limit.

For most TMCs, the F-test results showed a p-value less than 0.05, which means that there is enough evidence from the sample to indicate that the variance speed differs, and that a speed comparison is statistically significant at the 95 percent confidence level.

Using data up until 2016 resulted in a small sample size for the after period (12 data points). For segments with and without a PSL change (Milwaukee area), the Mann-Whitney U Test was conducted. For both cases, $50 \%$ of the segments had a p-value less than 0.05 , meaning that enough evidence exists from the sample to indicate that the average number of monthly crashes differs between the before and after periods, and that a crash comparison is statistically significant at the 95 percent confidence level.

Using data up until 2017 also resulted in a relatively small sample size for the after period (27 data points). Conducting the Mann-Whitney U Test for segments with and without a PSL change indicated that $43 \%$ of the segments had a p-value less than 0.05 , meaning that enough evidence exists from the sample to indicate that the average number of monthly crashes differs between the before and after periods, and that a crash comparison is statistically significant at the 95 percent confidence level. As for the remaining $57 \%$ of the segments, the Mann-Whitney U Test did not show any difference in the average number of monthly crashes. Only one segment in the Milwaukee area had data for 2017, and it showed no statistically significant difference between the before and after periods. Using the before and after analysis does not establish a cause and effect relationship between increasing the PSL and the increase in the average number of crashes. Hence, it is not clear whether the increase in the average 
monthly crashes was due to increasing the PSL or due to other factors such as weather, alcohol, distraction or others.

\subsection{Future Research/Work}

To isolate trends seen in NPMRDS, such as general shifts over time, or annual or seasonal cyclical patterns, a subset of locations with additional data collection should be used. Moreover, additional characteristic trends in the speed data should be identified to isolate any confounding effects.

As discussed previously, several segments had work zones effects. Connecting speed data to work zone data from the Wisconsin Lane Closure System (WisLCS) will greatly increase the control for work zone effects, while establishing effects of work zones and their posted speeds.

Geographic transition areas around PSL changes should be further investigated, which may require more spatially granular data than what is available in NPMRDS.

Increasing the sample size for the after period resulted in increasing the percentage of segments that showed no statistically significant difference in the average number of monthly crashes between the before and after periods. This result emphasizes the fact that increasing the sample size results in increasing the power of the statistical test. Hence, to have a better depth in the analysis, further investigation should be carried out for the crash analysis in time. Analysis can also be done using other methodologies such as the negative binomial model, Bayesian approach, or other. Segments that showed a statistically significant difference in the average number of monthly crashes should be further investigated to better attribute the difference to the increase in posted speed limit or to other factors such as weather, alcohol or 
others. Crash severity analysis should also be carried out to check whether there was a statistically significant increase in fatalities or crash severities. 


\section{REFERENCE}

[1] National Research Council (U.S.), Ed., Managing speed: review of current practice for setting and enforcing speed limits. Washington, D.C: Transportation Research Board, National Research Council, National Academy Press, 1998.

[2] National Research Council (U.S.), Ed., Managing speed: review of current practice for setting and enforcing speed limits. Washington, D.C: Transportation Research Board, National Research Council, National Academy Press, 1998.

[3] A. Dutta and D. A. Noyce, "Impacts of Raising Speed Limits on Traffic Safety." [Online]. Available:

http://www.topslab.wisc.edu/workgroups/TSC/Speed_Limit_Lit_ReviewUpdated_071405.pdf. [Accessed: 24-Aug-2017].

[4] "Speed Concepts: Informational Guide - Safety | Federal Highway Administration." [Online]. Available: https://safety.fhwa.dot.gov/speedmgt/ref_mats/fhwasa10001/. [Accessed: 05-Dec-2017].

[5] W. C. Taylor, "THE IMPACT OF RAISING THE SPEED LIMIT ON FREEWAYS IN MICHIGAN.," 2000.

[6] "Wisconsin Legislature: AB27: Bill Text." [Online]. Available: http://docs.legis.wisconsin.gov/2015/related/proposals/ab27/_19. [Accessed: 24-Aug2017].

[7] "Wisconsin Legislature: 2015 Wisconsin Act 19." [Online]. Available: https://docs.legis.wisconsin.gov/2015/related/acts/19. [Accessed: 24-Aug-2017].

[8] N. V. Malyshkina and F. L. Mannering, "Analysis of the Effect of Speed Limit Increases on Accident-Injury Severities," arXiv preprint arXiv:0806.1354, 2008.

[9] M. DETROIT, W. TRIM, and O. AKRON, "Evaluating the Impacts of Speed Limit Policy Alternatives," 2014.

[10] K. Kockelman, J. Bottom, Y. Kweon, J. Ma, and X. Wang, Safety impacts and other implications of raised speed limits on high-speed roads. Transportation Research Board, 2006.

[11] Y. M. Najjar, R. W. Stokes, E. R. Russell, H. E. Ali, and X. C. Zhang, "Impact of new speed limits on Kansas highways," Kansas Department of Transportation Topeka, KS, 2000.

[12] Insurance Institute for Highway Safety, "Map of maximum posted speed limits on rural interstates." [Online]. Available:

http://www.iihs.org/iihs/topics/laws/speedlimits/mapmaxspeedonruralinterstates?topicNa me=Speed\#map. [Accessed: 07-Sep-2017].

[13] J. Upchurch, “Arizona's experience with the 65-mph speed limit," Transportation Research Record, vol. 1244, pp. 1-6, 1989.

[14] J. D. Jernigan, Impact of the 65 Mph Speed Limit on Virginia's Rural Interstate Highways, 1989-1992. Virginia Transportation Research Council, 1994.

[15] D. B. Brown, S. Maghsoodloo, and M. E. McArdle, "The safety impact of the $65 \mathrm{mph}$ speed limit: a case study using Alabama accident records," Journal of Safety Research, vol. 21, no. 4, pp. 125-139, 1990.

[16] D. J. Mace and R. Heckard, "Effect of the 65 MPH Speed Limit on Travel Speeds and Related Crashes. Final Report," 1991. 
[17] Wisconsin Department of Transportation (WisDOT), "Speed limits in Wisconsin after repeal of the national maximum speed limit," Jan. 1996.

[18] Wisconsin Department of Transportation (WisDOT), "Report on raising speed limits in wisconsin from $55 \mathrm{mpf}$ to $65 \mathrm{mph}$."

[19] P. McCarthy, "Effect of speed limits on speed distributions and highway safety: a survey of recent literature," Transport Reviews, vol. 21, no. 1, pp. 31-50, 2001.

[20] E. M. Ossiander and P. Cummings, "Freeway speed limits and traffic fatalities in Washington State," Accident Analysis \& Prevention, vol. 34, no. 1, pp. 13-18, 2002.

[21] N. Alemazkoor and H. Hawkins, "Examining Impacts of Increasing Speed Limit on Speed Distribution: Case Study," in Transportation Research Board 93rd Annual Meeting, 2014.

[22] W. Hu and A. T. McCartt, "Raising the Speed Limit from 75 to $80 \mathrm{mph}$ on Utah Rural Interstate: Effects on Vehicle Speeds," in Transportation Research Board 93rd Annual Meeting, 2014.

[23] E. T. Donnell and B. Hamadeh, "70 mph Study," Pennsylvania Transportation Institute.

[24] T. Epperlein, "The impact of the $65 \mathrm{mph}$ speed limit in Arizona," Arizona: Arizona Statistical Analysis Center, 1989.

[25] M. M. Gallaher et al., "Effects of the 65-mph speed limit on rural interstate fatalities in New Mexico," Jama, vol. 262, no. 16, pp. 2243-2245, 1989.

[26] L. S. Friedman, D. Hedeker, and E. D. Richter, "Long-term effects of repealing the national maximum speed limit in the United States," American Journal of Public Health, vol. 99, no. 9, pp. 1626-1631, 2009.

[27] C. M. Farmer, "Relationship of traffic fatality rates to maximum state speed limits," Traffic injury prevention, vol. 18, no. 4, pp. 375-380, 2017.

[28] C. Lave and P. Elias, "Did the 65 mph speed limit save lives?," Accident Analysis \& Prevention, vol. 26, no. 1, pp. 49-62, 1994.

[29] S. Binkowski, T. Maleck, W. Taylor, and T. Czewski, "Evaluation of Michigan 70mph speed limit," Transportation Research Record: Journal of the Transportation Research Board, no. 1640, pp. 37-46, 1998.

[30] R. R. Souleyrette, T. B. Stout, and A. Carriquiry, "Evaluation of Iowa's 70 Mph Speed Limit: 2.5 Year Update," Center for Transportation Research and Education, Iowa State University, 2009.

[31] P. Quinn and A. L. Schneider, "New Law: See Which Highways Will Have a 70 MPH Speed Limit on Jan. 1," 30-Dec-2013. [Online]. Available: https://patch.com/illinois/stcharles-il/new-law-see-which-highways-will-have-a-70-mphspeed-limit-stcharles-il. [Accessed: 07-Sep-2017].

[32] K. Harder and J. Bloomfield, "Evaluating the Effectiveness of the Minnesota Speed Management Program," 2007.

[33] G. Manning and C. Grossman, "Joint Legislative Task Force on Department of Transportation Issues,” Dec. 2015.

[34] "Traffic Operations and Safety Laboratory - ITS." [Online]. Available: http://www.topslab.wisc.edu/its/topms/data/. [Accessed: 25-Aug-2017].

[35] "MAE and RMSE - Which Metric is Better?," Human in a Machine World, 23-Mar2016. . 
[36] J. D. Sterman, "Appropriate summary statistics for evaluating the historical fit of system dynamics models," Dynamica, vol. 10, no. 2, pp. 51-66, 1984.

[37] E. L. Lehmann and H. D'abrera, Nonparametrics: statistical methods based on ranks. Holden-Day, 1975.

[38] S. P. Washington, M. G. Karlaftis, and F. Mannering, Statistical and econometric methods for transportation data analysis. CRC press, 2010. 


\section{APPENDICES}

\section{Appendix A I-90}

Crash data for I-90 collected by month:

\begin{tabular}{|c|cccccccccccccc|}
\hline I-90 & 2005 & 2006 & 2007 & 2008 & 2009 & 2010 & 2011 & 2012 & 2013 & 2014 & 2015 & 2016 & 2017 \\
\hline Jan & 24 & 17 & 23 & 63 & 30 & 36 & 59 & 30 & 20 & 32 & 37 & 11 & 24 \\
Feb & 22 & 35 & 22 & 44 & 8 & 29 & 14 & 12 & 23 & 27 & 15 & 13 & 7 \\
Mar & 22 & 27 & 16 & 17 & 27 & 7 & 14 & 5 & 12 & 18 & 11 & 15 & 11 \\
Apr & 3 & 11 & 10 & 7 & 5 & 10 & 17 & 9 & 14 & 6 & 6 & 7 & 15 \\
May & 9 & 12 & 10 & 9 & 4 & 0 & 7 & 4 & 2 & 9 & 2 & 7 & 9 \\
Jun & 10 & 6 & 4 & 5 & 9 & 8 & 8 & 8 & 17 & 9 & & 6 & 11 \\
Jul & 18 & 8 & 7 & 9 & 3 & 18 & 13 & 12 & 7 & 17 & 5 & 10 & 13 \\
Aug & 11 & 8 & 7 & 2 & 9 & 9 & 9 & 3 & 13 & 8 & 3 & 6 & 8 \\
Sep & 8 & 6 & 11 & 9 & 3 & 9 & 6 & 8 & 5 & 12 & 4 & 12 & 7 \\
Oct & 9 & 5 & 3 & 3 & 6 & 5 & 6 & 3 & 12 & 6 & 4 & 5 & \\
Nov & 44 & 8 & 6 & 27 & 7 & 7 & 12 & 11 & 24 & 26 & 17 & 18 & \\
Dec & 18 & 7 & 71 & 68 & 41 & 32 & 27 & 30 & 45 & 7 & 25 & 26 & \\
\hline
\end{tabular}


Box plot for I-90 data:

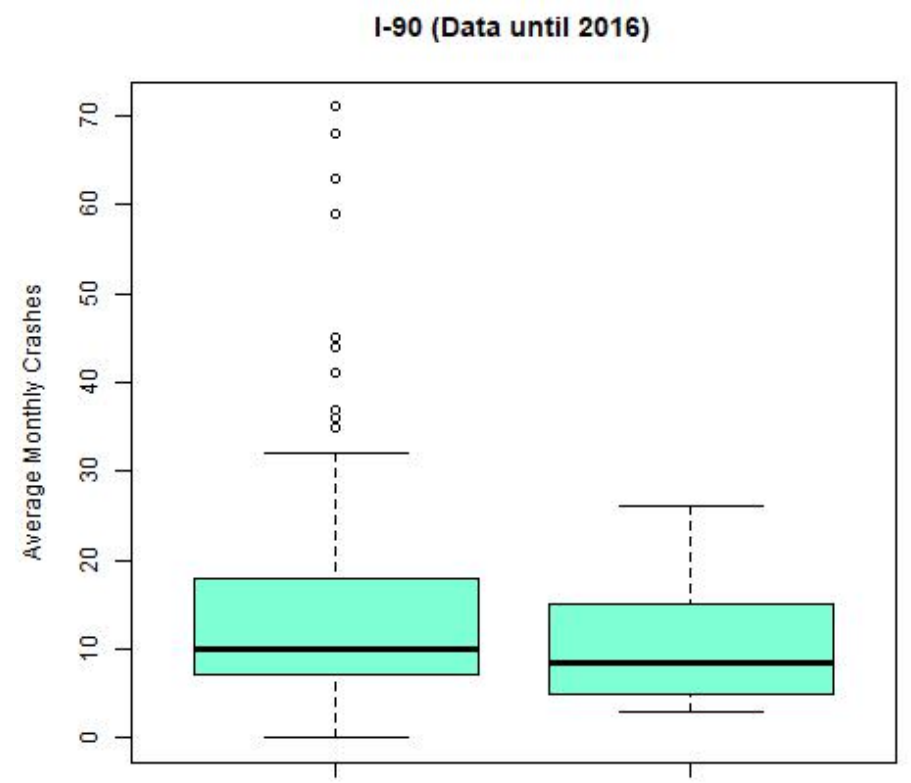

Before (left) and After (right) Speed Increase Crashes

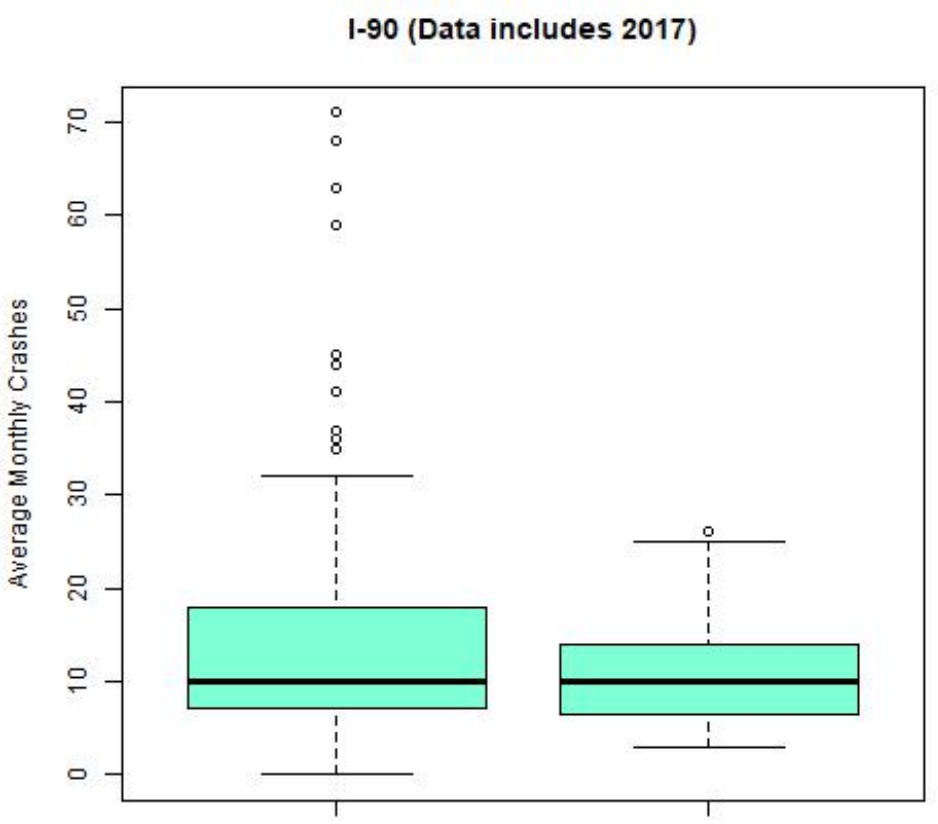

Before (left) and After (right) Speed Increase Crashes 


\section{Appendix B I-41}

Crash data for I-41 collected by month:

\begin{tabular}{|c|ccccccccccccc|}
\hline I-41 & 2005 & 2006 & 2007 & 2008 & 2009 & 2010 & 2011 & 2012 & 2013 & 2014 & 2015 & 2016 & 2017 \\
\hline Jan & 203 & 94 & 163 & 326 & 198 & 88 & 218 & 144 & 158 & 255 & 213 & 101 & 162 \\
Feb & 165 & 125 & 128 & 305 & 160 & 153 & 213 & 110 & 158 & 162 & 101 & 89 & 117 \\
Mar & 121 & 96 & 103 & 98 & 113 & 49 & 122 & 56 & 116 & 137 & 79 & 137 & 155 \\
Apr & 43 & 64 & 110 & 79 & 63 & 71 & 99 & 49 & 77 & 83 & 67 & 64 & 69 \\
May & 73 & 74 & 80 & 76 & 69 & 49 & 58 & 48 & 60 & 73 & 59 & 92 & 78 \\
Jun & 104 & 63 & 70 & 61 & 62 & 73 & 74 & 62 & 63 & 64 & & 91 & 115 \\
Jul & 89 & 79 & 77 & 73 & 86 & 98 & 66 & 53 & 69 & 77 & 40 & 93 & 103 \\
Aug & 84 & 73 & 84 & 94 & 72 & 64 & 60 & 64 & 69 & 81 & 52 & 105 & 119 \\
Sep & 76 & 72 & 63 & 61 & 66 & 71 & 59 & 64 & 73 & 72 & 74 & 80 & 81 \\
Oct & 92 & 52 & 81 & 64 & 91 & 83 & 66 & 84 & 73 & 82 & 64 & 97 \\
Nov & 178 & 88 & 105 & 116 & 75 & 72 & 84 & 56 & 107 & 167 & 75 & 92 \\
Dec & 156 & 126 & 278 & 414 & 224 & 228 & 103 & 159 & 286 & 114 & 128 & 228 \\
\hline
\end{tabular}


Box plot for I-41 data:

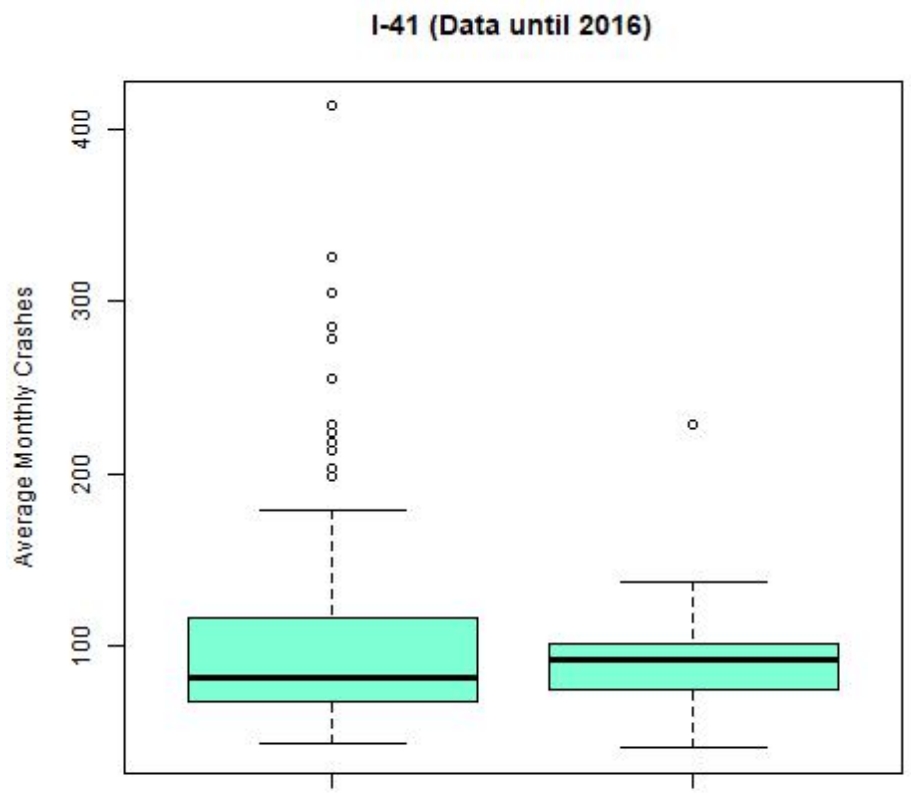

Before (left) and After (right) Speed Increase Crashes

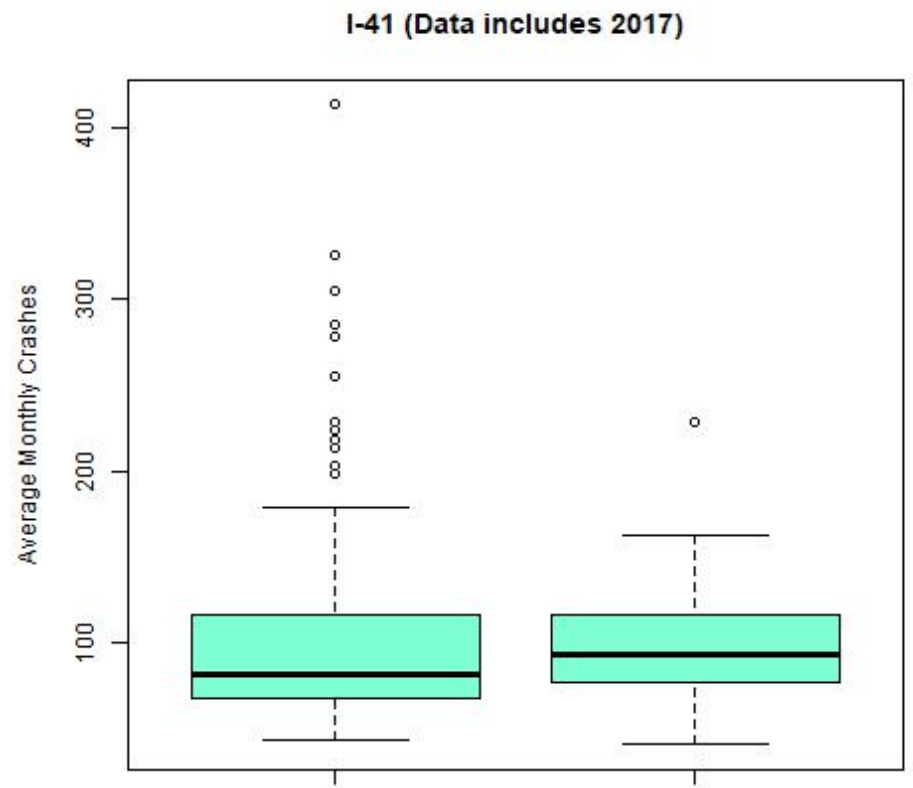

Before (left) and After (right) Speed Increase Crashes 


\section{Appendix C I-43}

Crash data for I-43 collected by month:

\begin{tabular}{|c|cccccccccccccc|}
\hline I-43 & 2005 & 2006 & 2007 & 2008 & 2009 & 2010 & 2011 & 2012 & 2013 & 2014 & 2015 & 2016 & 2017 \\
\hline Jan & 83 & 52 & 83 & 136 & 113 & 32 & 115 & 71 & 64 & 168 & 75 & 81 & 69 \\
Feb & 66 & 51 & 82 & 192 & 94 & 79 & 114 & 47 & 95 & 115 & 51 & 60 & 49 \\
Mar & 72 & 48 & 67 & 57 & 59 & 12 & 64 & 54 & 62 & 53 & 44 & 75 & 76 \\
Apr & 22 & 35 & 51 & 30 & 29 & 26 & 35 & 23 & 37 & 52 & 26 & 47 & 29 \\
May & 32 & 38 & 38 & 33 & 27 & 20 & 35 & 29 & 33 & 34 & 31 & 46 & 44 \\
Jun & 42 & 39 & 33 & 34 & 31 & 26 & 25 & 26 & 23 & 34 & & 35 & 50 \\
Jul & 43 & 43 & 32 & 32 & 37 & 54 & 25 & 24 & 33 & 26 & 50 & 54 & 49 \\
Aug & 37 & 37 & 35 & 23 & 28 & 43 & 34 & 36 & 33 & 33 & 56 & 57 & 54 \\
Sep & 45 & 41 & 48 & 26 & 30 & 35 & 48 & 22 & 33 & 33 & 33 & 53 & 46 \\
Oct & 38 & 35 & 40 & 44 & 37 & 37 & 28 & 31 & 24 & 36 & 46 & 43 & \\
Nov & 87 & 54 & 51 & 59 & 31 & 36 & 40 & 26 & 64 & 65 & 54 & 53 & \\
Dec & 94 & 49 & 159 & 184 & 114 & 64 & 48 & 69 & 107 & 54 & 71 & 132 & \\
\hline
\end{tabular}

Milwaukee Area:

\begin{tabular}{|c|ccccccccccccc|}
\hline I-43 M & 2005 & 2006 & 2007 & 2008 & 2009 & 2010 & 2011 & 2012 & 2013 & 2014 & 2015 & 2016 & 2017 \\
\hline Jan & 96 & 48 & 116 & 110 & 110 & 26 & 128 & 57 & 88 & 81 & 122 & 56 & 39 \\
Feb & 64 & 64 & 81 & 80 & 84 & 48 & 80 & 17 & 75 & 76 & 101 & 63 & 40 \\
Mar & 35 & 28 & 55 & 84 & 39 & 43 & 23 & 15 & 45 & 50 & 52 & 58 & 68 \\
Apr & 38 & 39 & 58 & 33 & 35 & 62 & 65 & 35 & 44 & 50 & 34 & 53 & 48 \\
May & 53 & 54 & 43 & 41 & 43 & 54 & 42 & 36 & 48 & 44 & 53 & 63 & 68 \\
Jun & 58 & 46 & 44 & 48 & 31 & 66 & 49 & 33 & 45 & 53 & & 63 & 66 \\
Jul & 49 & 51 & 43 & 45 & 31 & 57 & 48 & 48 & 45 & 45 & 52 & 52 & 52 \\
Aug & 47 & 36 & 71 & 59 & 46 & 38 & 44 & 72 & 50 & 51 & 54 & 50 & 55 \\
Sep & 69 & 63 & 52 & 49 & 56 & 51 & 50 & 56 & 39 & 53 & 67 & 59 & 41 \\
Oct & 54 & 56 & 68 & 50 & 64 & 63 & 54 & 77 & 49 & 68 & 63 & 56 & \\
Nov & 61 & 57 & 70 & 80 & 55 & 61 & 56 & 44 & 67 & 61 & 64 & 48 \\
Dec & 87 & 82 & 105 & 156 & 66 & 95 & 43 & 78 & 100 & 64 & 80 & 92 & \\
\hline
\end{tabular}


Box plot for I-43 data:

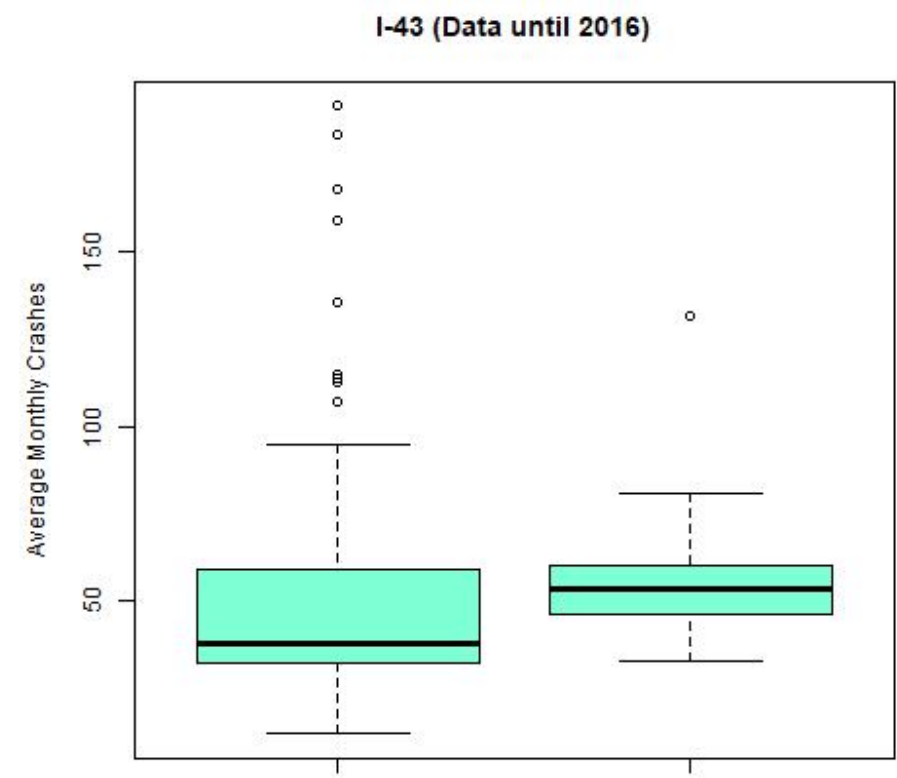

Before (left) and After (right) Speed Increase Crashes

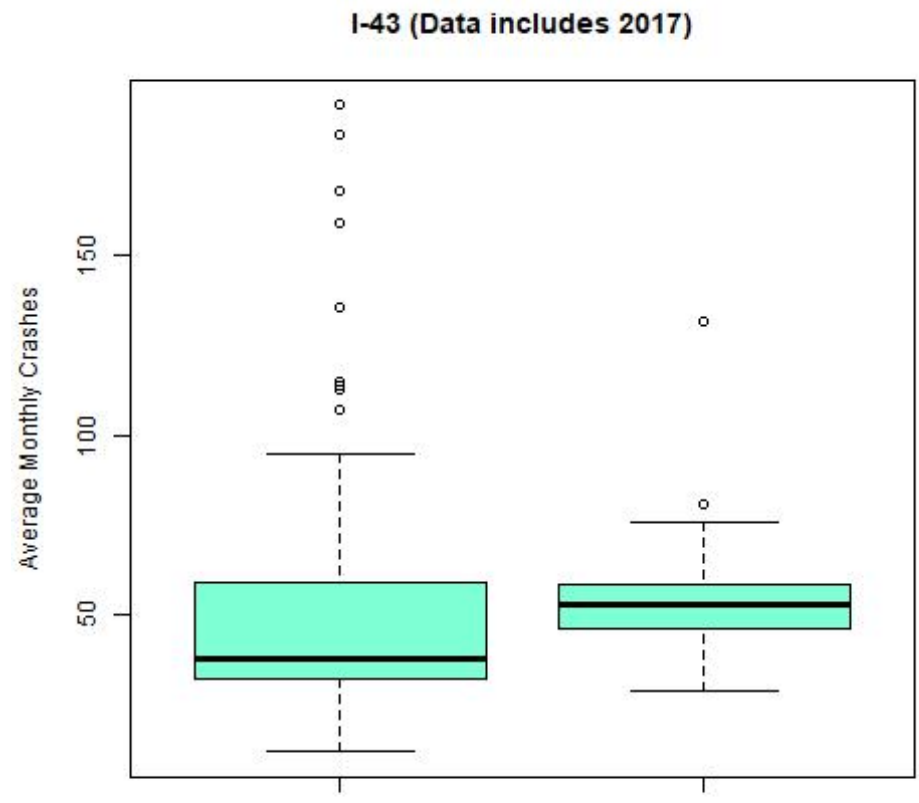

Before (left) and After (right) Speed Increase Crashes 
I-43 Milwaukee Area (Data until 2016)

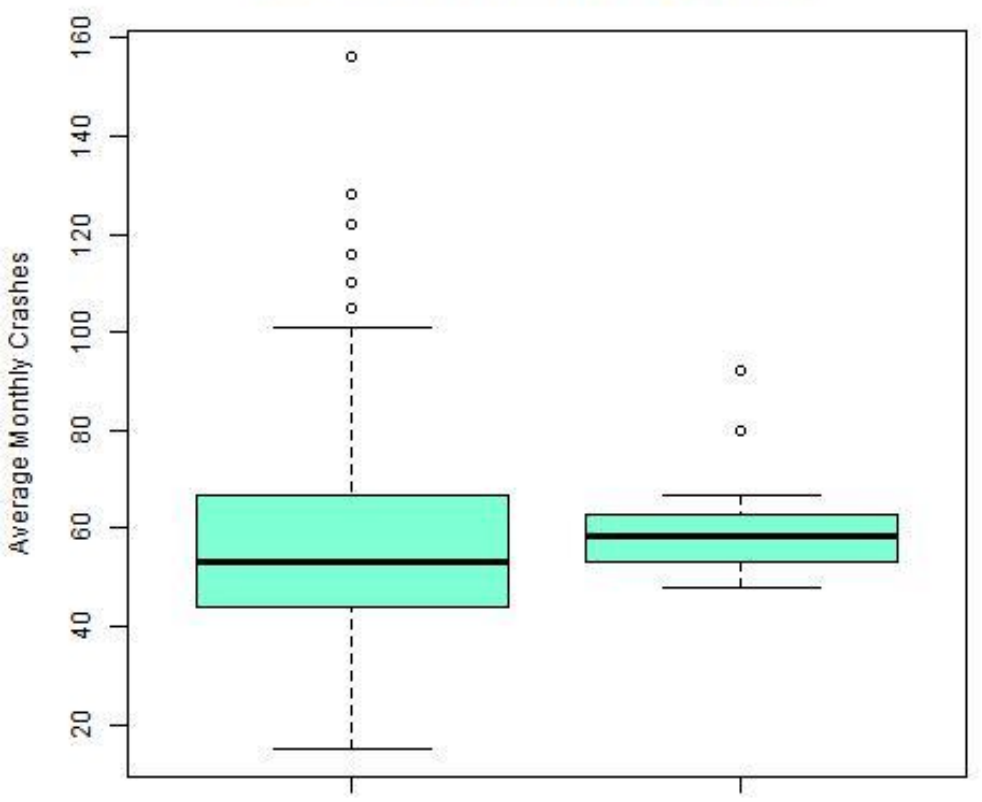

Before (left) and After (right) Speed Increase Crashes

I-43 Milwaukee Area (Data includes 2017)

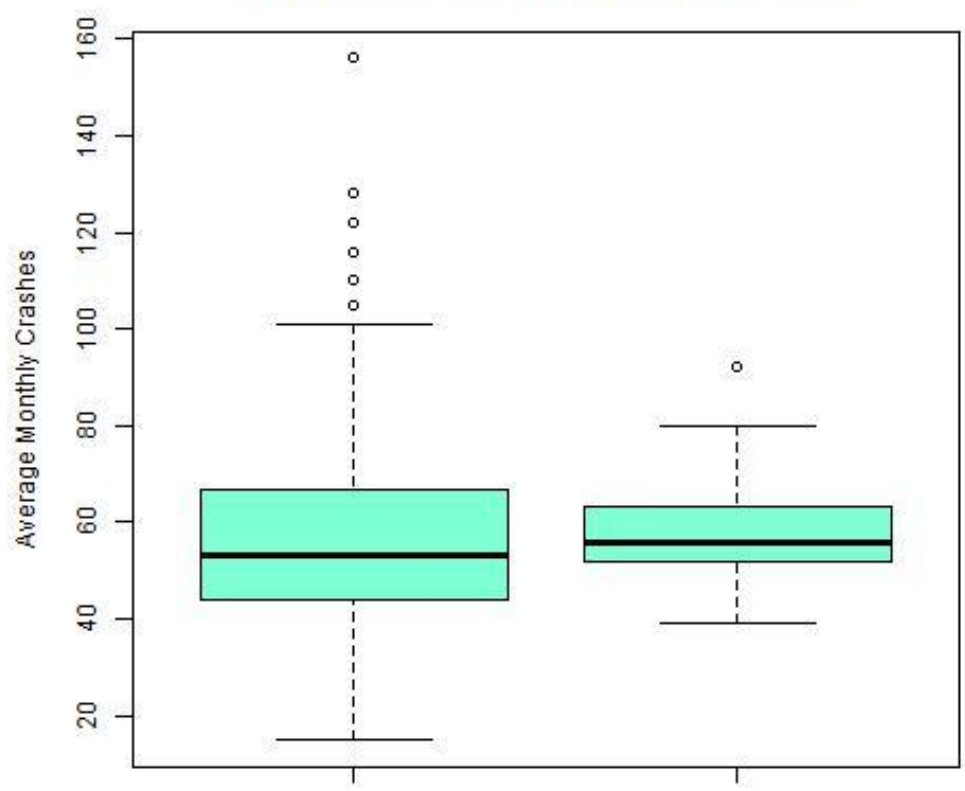

Before (left) and After (right) Speed Increase Crashes 


\section{Appendix D I-39/90}

Crash data for I-39/90 collected by month:

\begin{tabular}{|c|c|c|c|c|c|c|c|c|c|c|c|c|c|}
\hline I-39/90 & 2005 & 2006 & 2007 & 2008 & 2009 & 2010 & 2011 & 2012 & 2013 & 2014 & 2015 & 2016 & 2017 \\
\hline Jan & 224 & 63 & 127 & 309 & 162 & 72 & 179 & 132 & 114 & 209 & 192 & 96 & 115 \\
\hline Feb & 112 & 93 & 162 & 329 & 83 & 96 & 141 & 72 & 107 & 149 & 112 & 102 & 70 \\
\hline Mar & 85 & 87 & 119 & 80 & 82 & 42 & 67 & 42 & 84 & 87 & 81 & 159 & 86 \\
\hline Apr & 36 & 55 & 59 & 43 & 33 & 41 & 74 & 49 & 61 & 38 & 52 & 105 & 73 \\
\hline May & 51 & 72 & 52 & 47 & 42 & 60 & 47 & 52 & 54 & 65 & 85 & 85 & 112 \\
\hline Jun & 57 & 51 & 63 & 57 & 53 & 51 & 57 & 69 & 55 & 65 & & 97 & 131 \\
\hline Jul & 88 & 79 & 73 & 69 & 70 & 85 & 80 & 71 & 88 & 82 & 110 & 131 & 150 \\
\hline Aug & 67 & 61 & 85 & 54 & 64 & 62 & 68 & 69 & 93 & 85 & 107 & 146 & 122 \\
\hline Sep & 54 & 62 & 68 & 42 & 54 & 48 & 62 & 61 & 60 & 80 & 88 & 126 & 82 \\
\hline Oct & 66 & 69 & 56 & 51 & 50 & 40 & 40 & 62 & 57 & 50 & 84 & 115 & \\
\hline Nov & 132 & 62 & 68 & 67 & 42 & 67 & 66 & 50 & 72 & 112 & 92 & 109 & \\
\hline Dec & 154 & 79 & 272 & 219 & 164 & 145 & 86 & 134 & 223 & 74 & 136 & 213 & \\
\hline
\end{tabular}


Box plot for I-39/90 data:

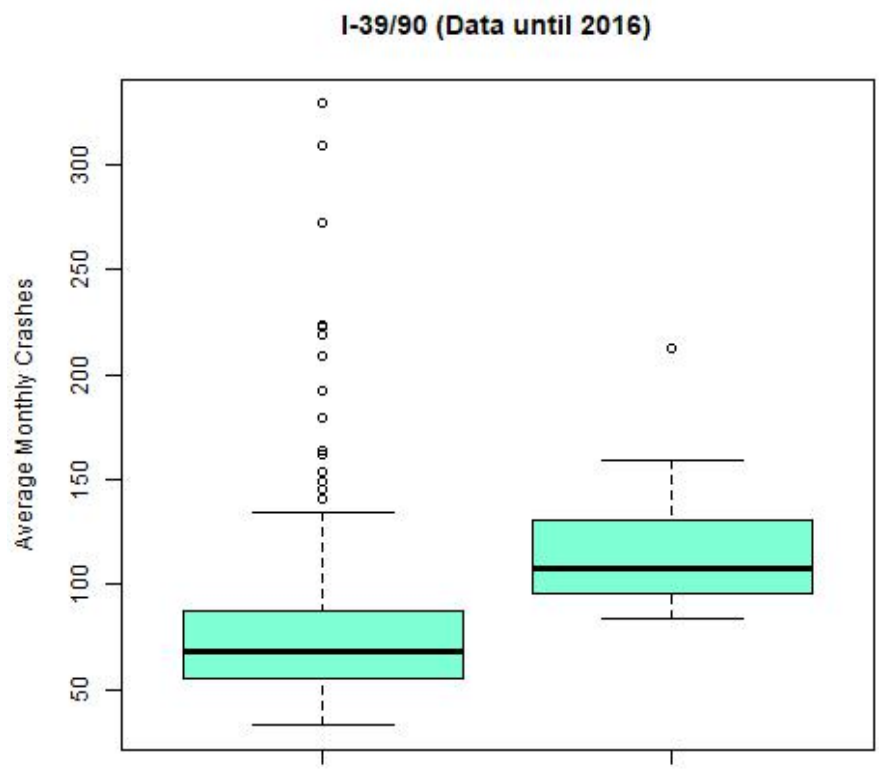

Before (left) and After (right) Speed Increase Crashes

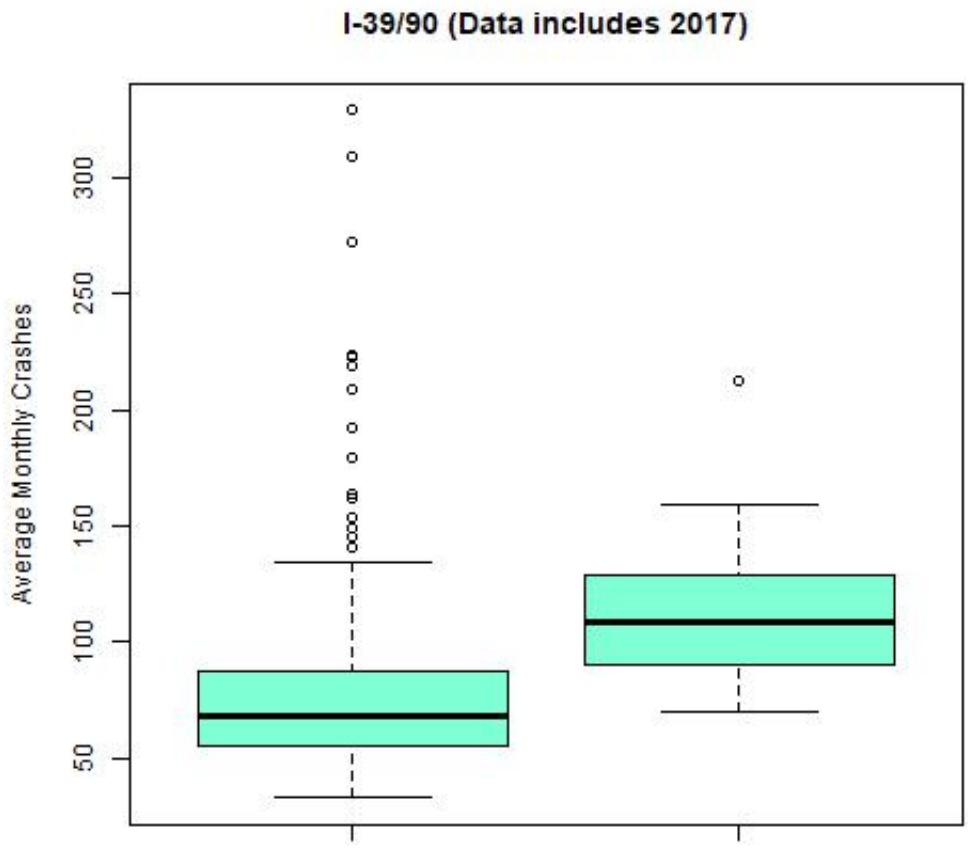

Before (left) and After (right) Speed Increase Crashes 


\section{Appendix E I-94}

Crash data for I-94 collected by month:

\begin{tabular}{|c|ccccccccccccc|}
\hline I-94 & 2005 & 2006 & 2007 & 2008 & 2009 & 2010 & 2011 & 2012 & 2013 & 2014 & 2015 & 2016 & 2017 \\
\hline Jan & 216 & 110 & 162 & 211 & 163 & 115 & 246 & 132 & 128 & 182 & 201 & 97 & 104 \\
Feb & 141 & 125 & 179 & 278 & 90 & 127 & 175 & 92 & 142 & 195 & 87 & 119 & 63 \\
Mar & 171 & 137 & 116 & 135 & 78 & 63 & 96 & 54 & 121 & 84 & 59 & 118 & 101 \\
Apr & 61 & 61 & 97 & 78 & 56 & 53 & 68 & 39 & 96 & 84 & 57 & 91 & 87 \\
May & 65 & 78 & 75 & 71 & 77 & 30 & 45 & 80 & 85 & 68 & 96 & 70 & 101 \\
Jun & 88 & 80 & 102 & 73 & 80 & 85 & 49 & 72 & 90 & 78 & & 104 & 83 \\
Jul & 104 & 110 & 117 & 92 & 69 & 111 & 89 & 74 & 79 & 116 & 92 & 98 & 98 \\
Aug & 90 & 105 & 101 & 68 & 70 & 75 & 78 & 74 & 66 & 96 & 121 & 93 & 110 \\
Sep & 99 & 79 & 84 & 59 & 68 & 72 & 79 & 73 & 68 & 62 & 73 & 90 & 76 \\
Oct & 79 & 87 & 84 & 79 & 84 & 77 & 58 & 89 & 71 & 64 & 94 & 89 & \\
Nov & 157 & 81 & 82 & 128 & 54 & 97 & 73 & 73 & 120 & 162 & 113 & 109 \\
Dec & 197 & 103 & 309 & 327 & 157 & 198 & 118 & 154 & 256 & 73 & 130 & 228 & \\
\hline
\end{tabular}

Milwaukee Area:

\begin{tabular}{|c|c|c|c|c|c|c|c|c|c|c|c|c|c|}
\hline I-94 M & 2005 & 2006 & 2007 & 2008 & 2009 & 2010 & 2011 & 2012 & 2013 & 2014 & 2015 & 2016 & 2017 \\
\hline Jan & 12 & 6 & 10 & 6 & 22 & 4 & 13 & 13 & 11 & 14 & 17 & & \\
\hline Feb & 13 & 11 & 9 & 14 & 6 & 19 & 16 & 1 & 6 & 11 & 15 & & \\
\hline Mar & 6 & 12 & 7 & 8 & 10 & 5 & 3 & 5 & 10 & 8 & 4 & & \\
\hline Apr & 10 & 10 & 4 & 5 & 7 & 6 & 7 & 1 & 4 & 3 & 2 & & \\
\hline May & 5 & 8 & 5 & 4 & 6 & 7 & 5 & 4 & 6 & 8 & 0 & & \\
\hline Jun & 8 & 12 & 6 & 12 & 5 & 5 & 4 & 8 & 5 & 4 & & & \\
\hline Jul & 12 & 7 & 5 & 4 & 6 & 8 & 10 & 4 & 9 & 2 & 0 & 1 & \\
\hline Aug & 7 & 4 & 12 & 2 & 8 & 4 & 7 & 8 & 6 & 4 & 4 & & \\
\hline Sep & 5 & 11 & 9 & 3 & 5 & 9 & 7 & 1 & 3 & 4 & 1 & & \\
\hline Oct & 5 & 4 & 6 & 10 & 5 & 5 & 6 & 4 & 4 & 6 & 1 & & \\
\hline Nov & 11 & 3 & 10 & 12 & 6 & 6 & 3 & 1 & 5 & 5 & 0 & & \\
\hline Dec & 12 & 20 & 27 & 16 & 13 & 9 & 6 & 8 & 18 & 4 & 4 & & \\
\hline
\end{tabular}


Box plot for I-94 data:

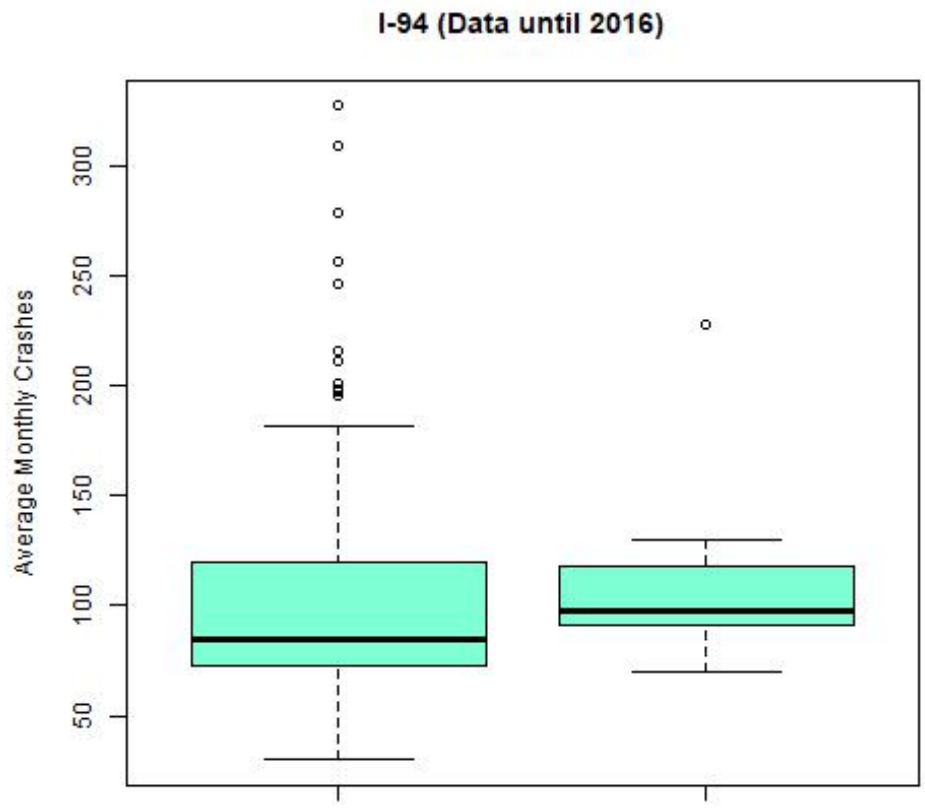

Before (left) and After (right) Speed Increase Crashes

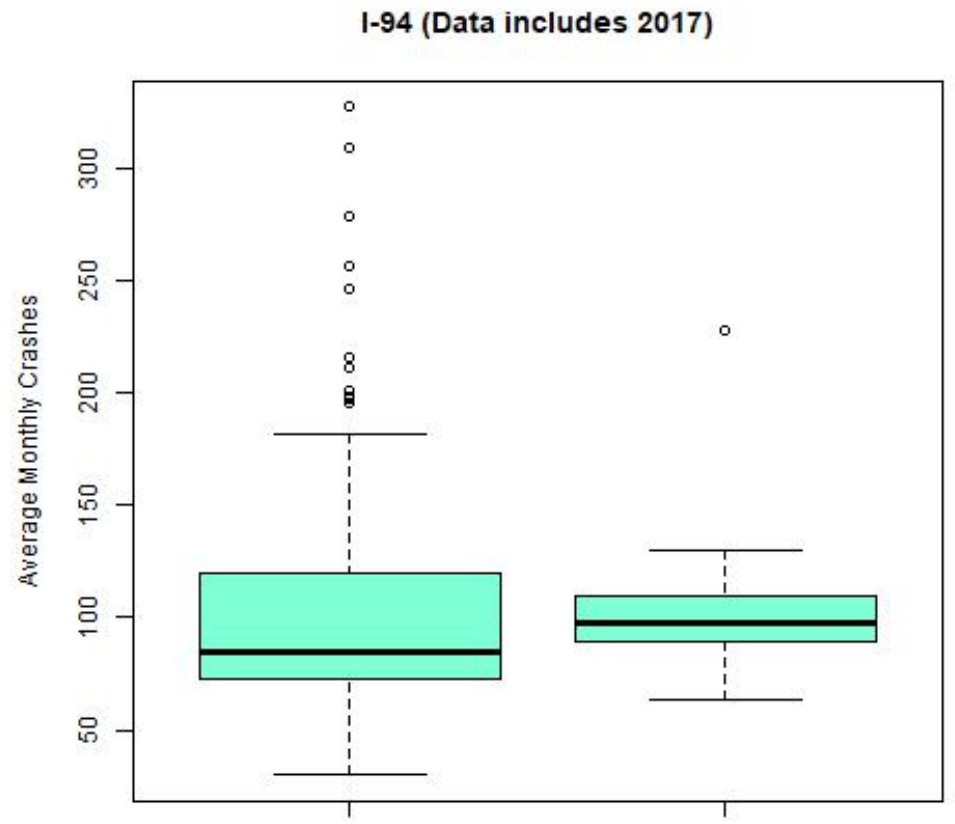

Before (left) and After (right) Speed Increase Crashes 
I-94 Milwaukee Area (Data until 2016)

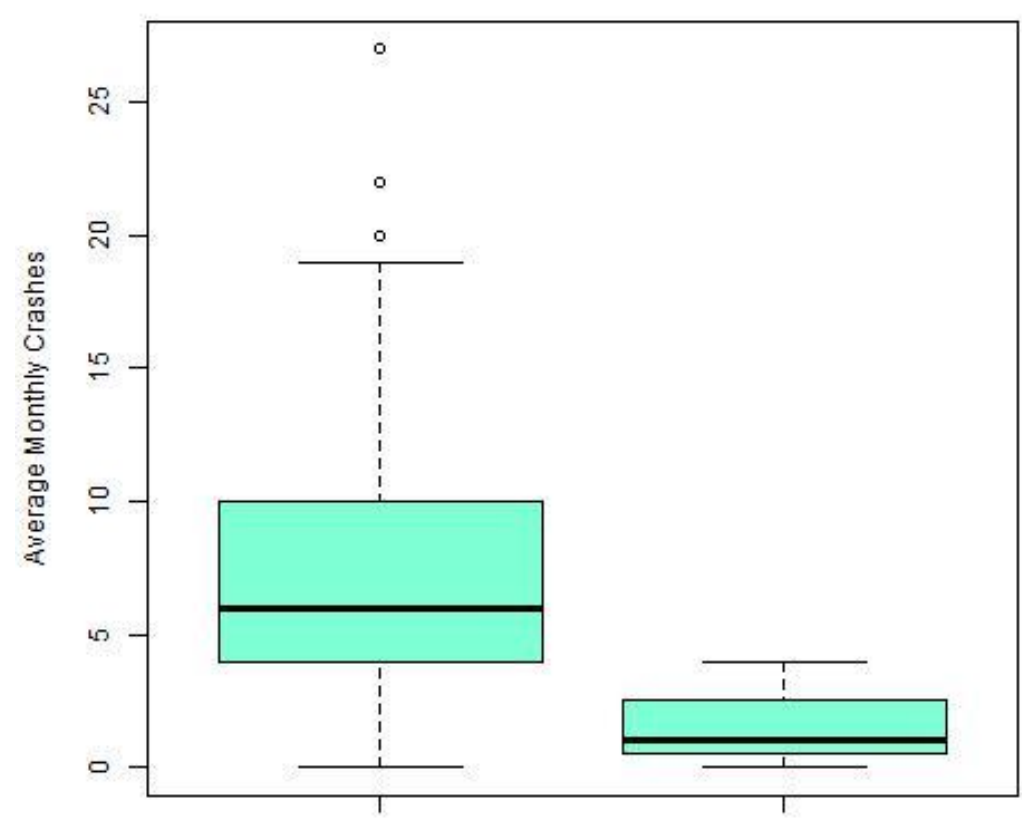

Before (left) and After (right) Speed Increase Crashes 


\section{Appendix F I-535}

Crash data for I-535 collected by month:

\begin{tabular}{|c|cccccccccccccc|}
\hline I-535 & 2005 & 2006 & 2007 & 2008 & 2009 & 2010 & 2011 & 2012 & 2013 & 2014 & 2015 & 2016 & 2017 \\
\hline Jan & 9 & 0 & 2 & 0 & 5 & 2 & 5 & 5 & 8 & 12 & 8 & 3 & 4 \\
Feb & 0 & 3 & 2 & 2 & 0 & 2 & 0 & 1 & 0 & 2 & 1 & 0 & 1 \\
Mar & 1 & 1 & 3 & 1 & 2 & 2 & 1 & 1 & 0 & 3 & 2 & 0 & 2 \\
Apr & 0 & 0 & 0 & 1 & 1 & 0 & 0 & 1 & 1 & 2 & 2 & 0 & 1 \\
May & 0 & 0 & 1 & 3 & 1 & 0 & 0 & 1 & 0 & 1 & 1 & 1 & 0 \\
Jun & 0 & 2 & 0 & 0 & 0 & 0 & 0 & 0 & 0 & 0 & & 2 & 2 \\
Jul & 3 & 0 & 1 & 1 & 3 & 0 & 3 & 0 & 1 & 1 & 1 & 1 & 3 \\
Aug & 1 & 0 & 3 & 0 & 4 & 0 & 2 & 0 & 1 & 3 & 2 & 2 & 1 \\
Sep & 1 & 0 & 1 & 1 & 0 & 1 & 1 & 0 & 2 & 1 & 3 & 0 & 2 \\
Oct & 0 & 1 & 0 & 0 & 1 & 1 & 1 & 0 & 3 & 2 & 1 & 0 & \\
Nov & 1 & 0 & 2 & 0 & 2 & 1 & 3 & 2 & 1 & 5 & 6 & 1 & \\
Dec & 0 & 2 & 9 & 7 & 1 & 2 & 1 & 2 & 5 & 2 & 3 & 7 & \\
\hline
\end{tabular}


Box plot for I-535 data:

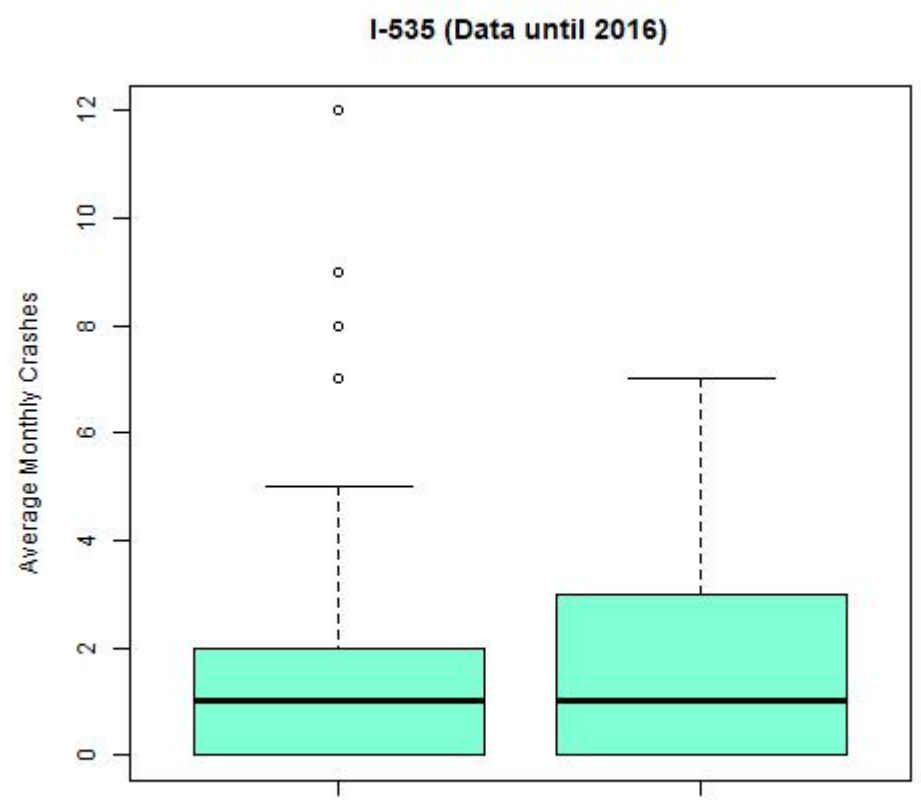

Before (left) and After (right) Speed Increase Crashes

I-535 (Data includes 2017)

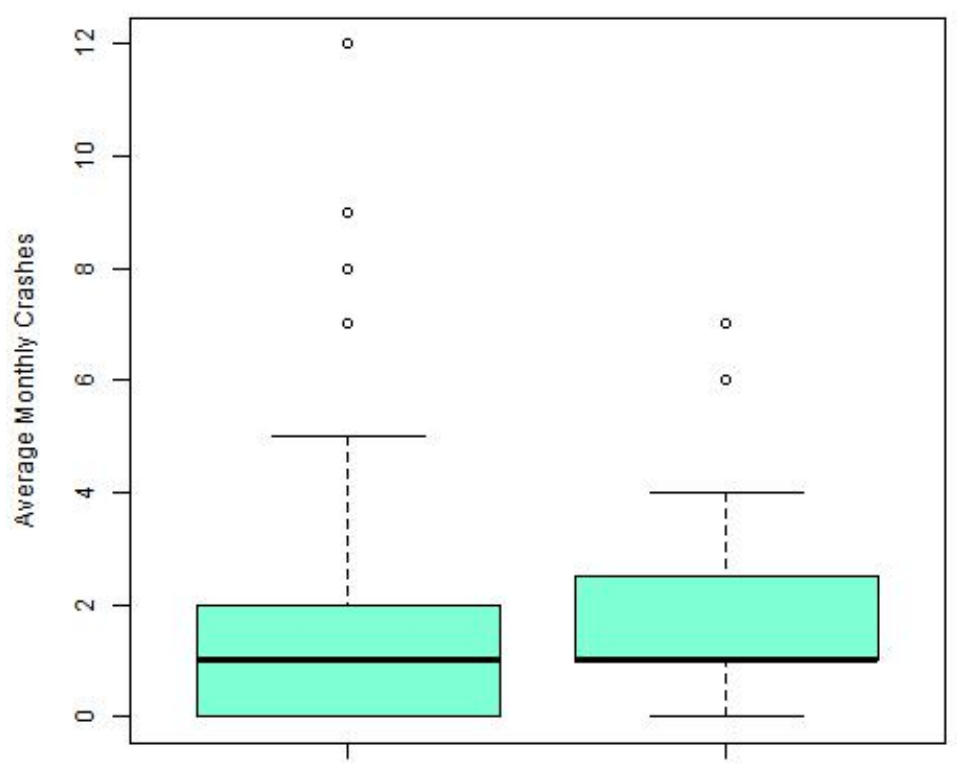

Before (left) and After (right) Speed Increase Crashes 


\section{Appendix G I-794}

Crash data for I-794 collected by month:

\begin{tabular}{|c|cccccccccccccc|}
\hline I-794 & 2005 & 2006 & 2007 & 2008 & 2009 & 2010 & 2011 & 2012 & 2013 & 2014 & 2015 & 2016 & 2017 \\
\hline Jan & 3 & 1 & 0 & 0 & 2 & 0 & 0 & 0 & 0 & 1 & 0 & 1 & 1 \\
Feb & 1 & 0 & 1 & 0 & 0 & 0 & 1 & 0 & 0 & 0 & 1 & 1 & 0 \\
Mar & 2 & 1 & 0 & 1 & 0 & 0 & 2 & 0 & 0 & 0 & 1 & 1 & 1 \\
Apr & 0 & 0 & 0 & 0 & 0 & 0 & 0 & 0 & 0 & 2 & 0 & 1 & 1 \\
May & 1 & 1 & 1 & 0 & 0 & 0 & 0 & 0 & 0 & 1 & 0 & 0 & 1 \\
Jun & 0 & 1 & 0 & 0 & 0 & 0 & 0 & 3 & 0 & 0 & & 1 & 1 \\
Jul & 1 & 1 & 0 & 0 & 0 & 3 & 0 & 0 & 1 & 0 & 0 & 1 & 2 \\
Aug & 0 & 1 & 0 & 0 & 0 & 2 & 0 & 1 & 0 & 0 & 1 & 0 & 1 \\
Sep & 1 & 2 & 0 & 0 & 0 & 0 & 0 & 3 & 0 & 0 & 0 & 0 & 0 \\
Oct & 1 & 0 & 0 & 0 & 0 & 0 & 1 & 0 & 0 & 0 & 0 & 1 & \\
Nov & 1 & 1 & 0 & 0 & 0 & 0 & 0 & 1 & 1 & 0 & 0 & 3 \\
Dec & 1 & 0 & 2 & 0 & 0 & 1 & 1 & 0 & 0 & 1 & 1 & 3 & \\
\hline
\end{tabular}


Box plot for I-794 data:

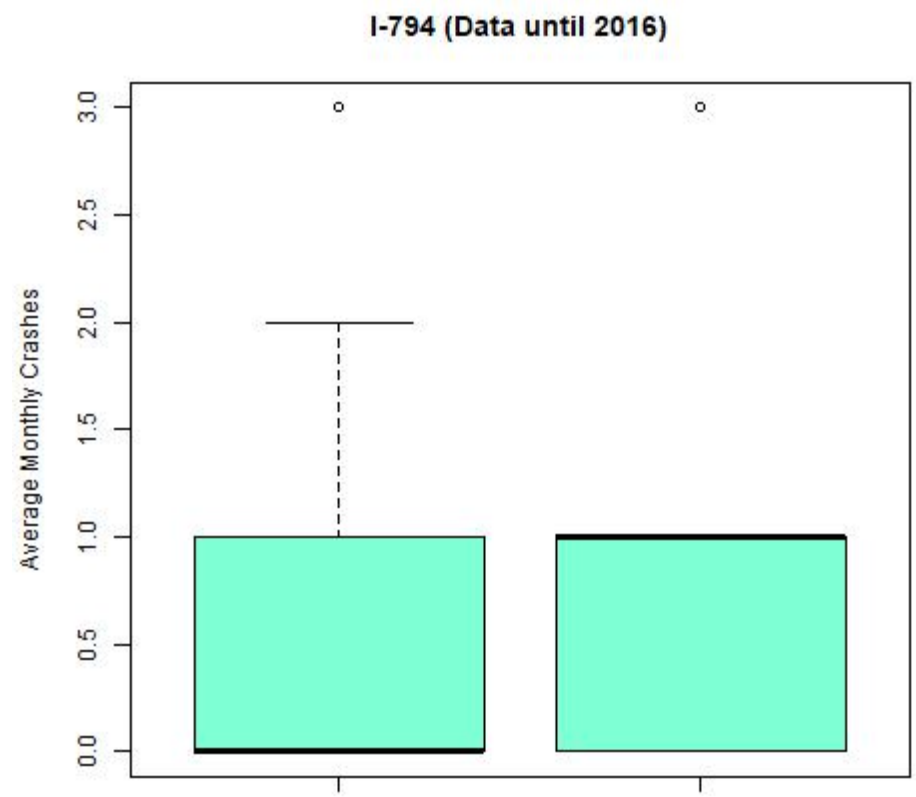

Before (left) and After (right) Speed Increase Crashes

I-794 (Data includes 2017)

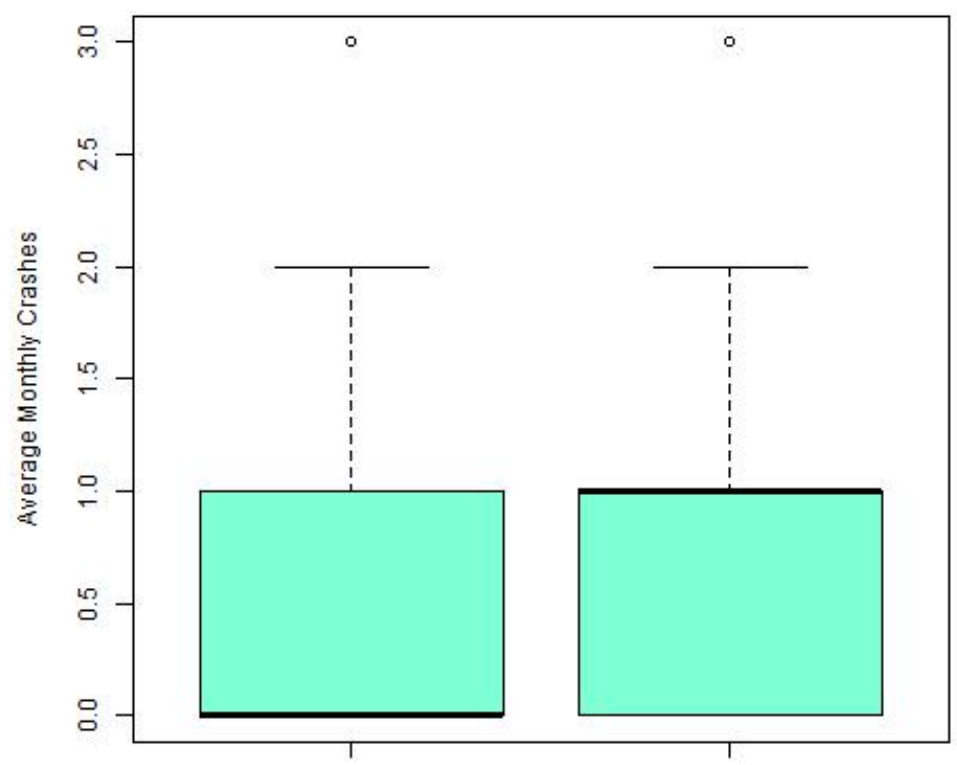

Before (left) and After (right) Speed Increase Crashes 


\section{Appendix H I-894}

Crash data for I-894 collected by month:

\begin{tabular}{|c|cccccccccccc|c|}
\hline I-894 & 2005 & 2006 & 2007 & 2008 & 2009 & 2010 & 2011 & 2012 & 2013 & 2014 & 2015 & 2016 & 2017 \\
\hline Jan & 37 & 26 & 36 & 40 & 39 & 15 & 26 & 16 & 18 & 55 & 15 & \\
Feb & 25 & 23 & 26 & 27 & 26 & 26 & 30 & 5 & 23 & 29 & 14 & \\
Mar & 18 & 20 & 25 & 25 & 13 & 19 & 17 & 11 & 10 & 14 & 10 & 1 & \\
Apr & 14 & 35 & 29 & 21 & 16 & 16 & 16 & 10 & 17 & 17 & 4 & & \\
May & 19 & 20 & 12 & 12 & 15 & 24 & 16 & 16 & 24 & 21 & & \\
Jun & 30 & 22 & 18 & 19 & 10 & 17 & 18 & 31 & 23 & 20 & & \\
Jul & 28 & 18 & 28 & 22 & 14 & 25 & 17 & 20 & 15 & 19 & & \\
Aug & 27 & 27 & 23 & 26 & 24 & 24 & 28 & 21 & 19 & 26 & & \\
Sep & 27 & 18 & 25 & 16 & 12 & 27 & 16 & 18 & 30 & 20 & & \\
Oct & 21 & 36 & 31 & 18 & 24 & 36 & 21 & 19 & 24 & 22 & 1 & \\
Nov & 32 & 32 & 28 & 17 & 23 & 23 & 26 & 25 & 32 & 20 & & 1 \\
Dec & 31 & 39 & 35 & 21 & 26 & 35 & 21 & 25 & 24 & 21 & 1 & \\
\hline
\end{tabular}

Box plot for I-894 data:

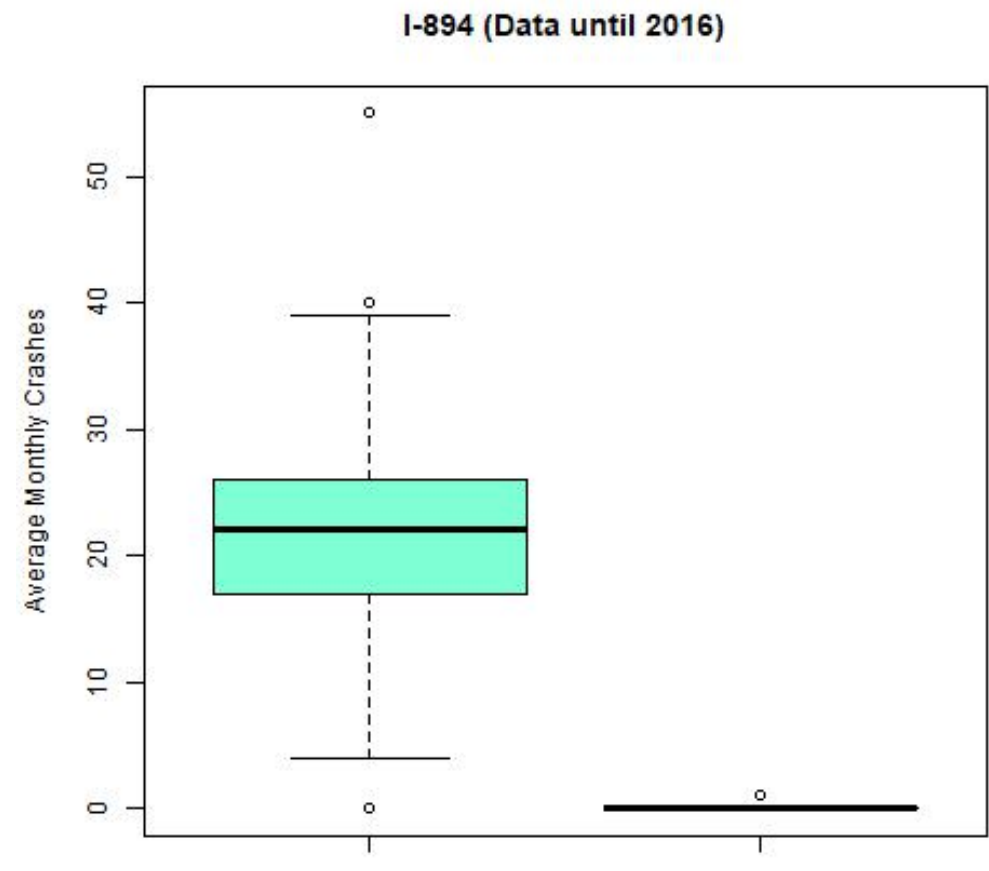

Before (left) and After (right) Speed Increase Crashes 